San Jose State University

SJSU ScholarWorks

Master's Theses

Master's Theses and Graduate Research

1991

\title{
The Reproductive biology and natural history of the black phoebe (Sayornis nigricans Swainson) in central California
}

Blair O. (Blair Oliver) Wolf

San Jose State University

Follow this and additional works at: https://scholarworks.sjsu.edu/etd_theses

\section{Recommended Citation}

Wolf, Blair O. (Blair Oliver), "The Reproductive biology and natural history of the black phoebe (Sayornis nigricans Swainson) in central California" (1991). Master's Theses. 275.

DOI: https://doi.org/10.31979/etd.45tx-qb6h

https://scholarworks.sjsu.edu/etd_theses/275

This Thesis is brought to you for free and open access by the Master's Theses and Graduate Research at SJSU ScholarWorks. It has been accepted for inclusion in Master's Theses by an authorized administrator of SJSU ScholarWorks. For more information, please contact scholarworks@sjsu.edu. 


\section{INFORMATION TO ÚSERS}

This manuscript has been reproduced from the microfilm master. UMI films the text directly from the original or copy submitted. Thus, some thesis and dissertation copies are in typewriter face, while others may be from any type of computer printer.

The quality of this reproduction is dependent upon the quality of the copy submitted. Broken or indistinct print, colored or poor quality illustrations and photographs, print bleedthrough, substandard margins, and improper alignment can adversely affect reproduction.

In the unlikely event that the author did not send UMI a complete manuscript and there are missing pages, these will be noted. Also, if unauthorized copyright material had to be removed, a note will indicate the deietion.

Oversize materials (e.g., maps, drawings, charts) are reproduced by sectioning the original, beginning at the upper left-hand corner and continuing from left to right in equal sections with small overiaps. Each original is also photographed in one exposure and is included in reduced form at the back of the book.

Photographs included in the original manuscript have been reproduced xerographically in this copy. Higher quality 6 " $x$ 9" black and white photographic prints are available for any photographs or illustrations appearing in this copy for an additional charge. Contact UMI directly to order.

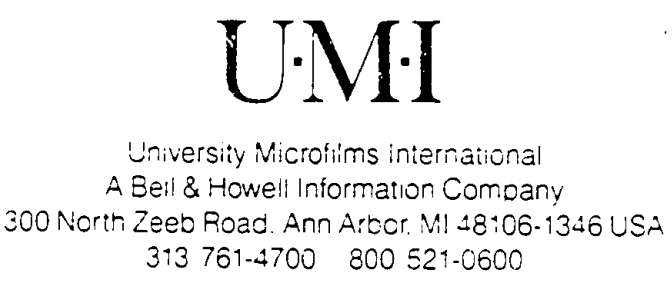


Order Number 1947190

The reproductive biology and natural history of the black phoebe (Sayornis nigricans Swainson) in central California

Wolf, Blair Oliver, M.A.

San Jose State University, 1991 


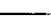




\title{
THE REPRODUCTIVE BIOLOGY AND NATURAL HISTORY OF THE BLACK
} PHOEBE (Sayornis nigricans Swainson) IN CENTRAL CALIFORNIA

\author{
A Thesis \\ Presented to \\ The Faculty of the Department of Biological Sciences \\ San Jose State University
}

\author{
In Partial Fulfillment \\ of the Requirements for the Degree \\ Master of Arts
}

\author{
By \\ Blair Oliver Wolf \\ December, 1991
}


APPROVED FOR THE DEPARTMENT OF BIOLOGICAL SCIENCES

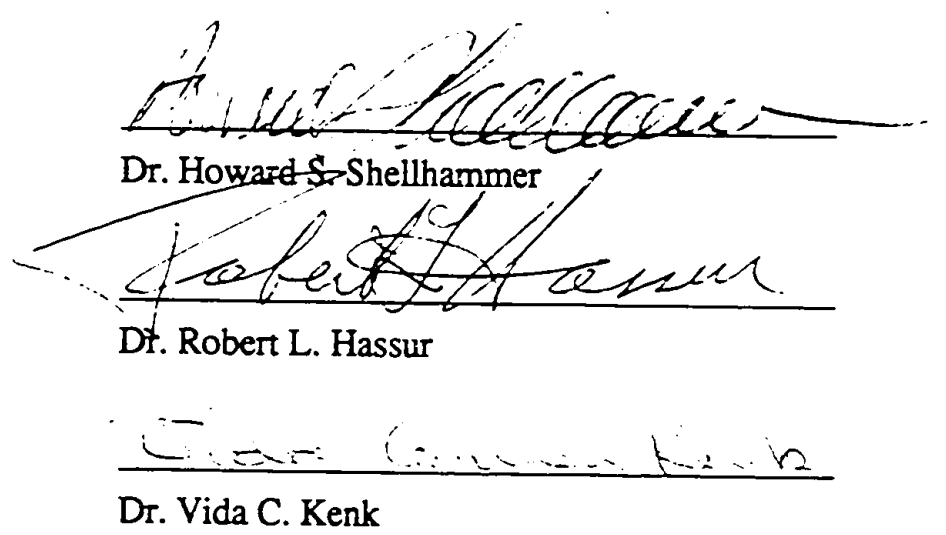

APPROVED FOR THE UNIVERSITY

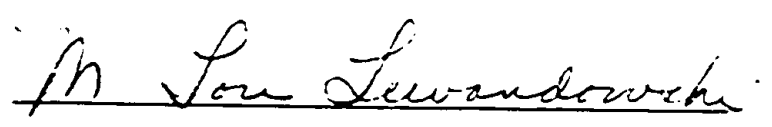




\title{
ABSTRACT \\ THE REPRODUCTTVE BIOLOGY AND NATURAL HISTORY OF THE BLACK PHOEBE (Sayornis nigricans Swainson) IN CENTRAL CALIFORNIA
}

\author{
by Blair $\mathrm{O}$. Wolf
}

The reproductive biology of the Black Phoebe was studied at Coyote Creek Riparian Station at the south end of the San Francisco Bay, Califormia. A total of 24 breeding pairs were observed during 1988, 1989, and 1990. Breeding commenced in mid to late February with Nest Site Showing displays and frequent chasing by paired birds, and ended in early June with the fledging of the last brood. Typically two broods were raised by each pair in any one year. Old nests were reused from year to year and most pairs chose to rebuild an old nest rather than consuruct a completely new nest. First egg dates ranged from March 18 to May 6 for first clutches and from April 13 to May 31 for second clutches. Eggs were laid at a rate of one per day approximately 1.5 hours after civil sunrise with the last egg being laid later. Eggs from second clutches were significantly larger than eggs from first clutches. Clutch size did not vary between years or clutches, and averaged 4.55 eggs (range 3-5) per clutch. Incubation was carried out by the female and the mean length of the incubation period was 16.2 days. Young birds fledged from the nest approximately 18 to 20 days after hatching. Nesting success and mortality were also examined. 


\section{ACKNOWLEDGMENTS}

I thank Dr. Howard Shellhammer, Dr. Rober Hassur and Dr. Vida Kenk, the members of my committee, for their endurance, patience, advice and expediency in the face of approaching deadlines. Their contributions to this project and my education are gratefully acknowledged.

Dr. L. Richard Mewaldt, my mentor, Micheal Rigney and the volunteer members of Coyote Creek Riparian Station deserve my gratiude for their assistance in colorbanding Black Phoebes and assisting me with the project. I especially thank Dr. John Delevoryas and David Johnson for their photographic skills and contributions of many attractive phoebe slides. Mike Crawford, Stephanie Jones, Elizabeth Johnson, Brigitte Fergeson, Bruce Katano, Chris Otahal, and others were especially helpful with other aspects of the field work and made the experience much more enjoyable.

John Hammond, of SJSU, provided computer support from time to time during the project. Dr. Charles Bell provided assistance in writing a colorband combination computer program.

The Western Foundation of Vertebrate Zoology kindly provided copies of egg record cards for sets of Black Phoebe eggs in their collection.

Chris Thompson, of ASU, gratefully provided statistical advice and ran the statistical analyses. Dr. Glenn Walsberg, of ASU, showed great patience and understanding while I completed this thesis during my first year at ASU. His suppori is greatly appreciated.

Gerald Balistreri sparked my professional interest in birds and his friendship and encouragement gave me inspiraiion to persue this project. 
My family, especially my father provided unflagging moral and oftentimes monetary support and I am very grateful. My Wife, Deanna, I thank for her patience, constant support and for Cole, my son the helper.

This thesis is dedicated to the late Dr. L. Richard Mewaldt, who served as my major advisor until his death on August 19, 1991. Dick's motivation, endless support and advice helped me to direct my energy towards my personal and academic goals. He was a great mentor and a kind friend. 


\section{TABLE OF CONTENTS}

INTRODUCTION AND LITERATURE REVIEW ....................................

General Background ..................................................

Description .......................................................... I

Distribution........................................................... 4

Taxonomy ............................................................. 5

Literature Review....................................................... 5

Scope of this Investigation ............................................... 11

THE STUDY AREA .......................................................... 12

General Characteristics ................................................. 12

Study Area Habitats................................................... 13

General Overview................................................ 13

The Foothill/Valley Riparian Community. ............................ 13

The Valley Grassland Community. .................................... 15

The Levee System, Adjacent Culver, and Sludge Lagoons. .............. 15

MATERIALS AND METHODS ............................................... 19

Chronology ............................................................. 19

Measurements and Banding................................................ 19

Nest Measurements ................................................ 19

Nest Placement. ................................................... 19

Egg Measurements................................................... 19

Adult and Nestling Measurements........................................ 20

Banding........................................................ 21

Observational Data .................................................... 22

Statistical Analysis ..................................................... 23

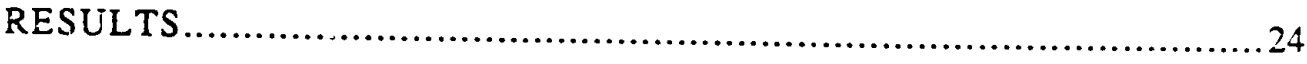

Reproductive Chronology ...............................................24

Prenesting Courtship Behavior ............................................24

Nest Site Showing. ............................................. 24

Supplanting and Chasing........................................... 27

Nest Site Selection .................................................... 28

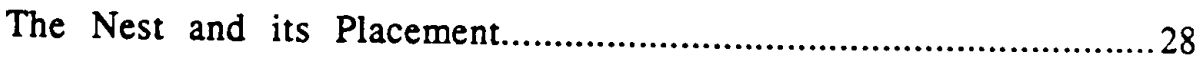

General Description. ............................................ 28 
Nest Base and Outer Shell.............................................. 28

Nest Lining........................................................ 30

Nest Dimensions ............................................... 30

Nest Placement ................................................. 30

Re-use of Old Nests................................................. 30

Nest Building Behavior......................................................... 34

Gathering Behavior. ............................................ 34

Nest Construction.................................................. 36

Temporal Aspects of Nest Construction............................... 36

Laying ............................................................. 38

Laying Behavior................................................ 38

Temporal Aspects of Laying. ....................................... 38

The Egg: Description, Measurements and Variation.................................41

General description..................................................4 41

Dimensions....................................................... 41

Variation in Egg Size.....................................................44

Variation in Egg Coloration......................................... 47

Clutch Size ......................................................... 52

Variation in Clutch Size................................................. 52

Incubation ........................................................... 52

General Aspects ................................................ 52

Rhythm of Incubation................................................ 52

Incubation Behavior....................................................5

Length of the incubation period.............................................5

Loss of Weight by Eggs............................................60 60

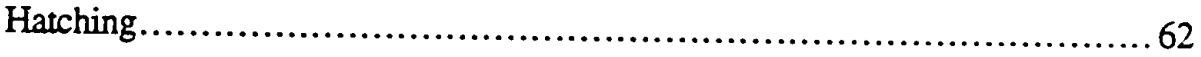

Hatching Sequence.............................................62 62

Hatching Intervai. .............................................. 62

Eggshell Disposal. .............................................6 62

Nestling Development ................................................6 63

Weigint.........................................................6 63

Growth of remiges and rectrices............................................6 63

Description of nestling on the day of hatching..........................6 63

Day four of the nestling period. .....................................6 68 
Day six of the nestling period....................................... 69

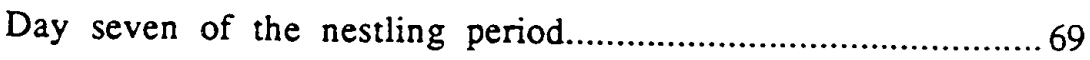

Day eight of the nestling period................................................69

Day nine of the nestling period. ..................................... 70

Day ten of the nestling period......................................... 70

Day twelve of the nestling period............................................ 70

Day fourteen of the nestling period......................................... 72

Day sixteen of the nestling period.................................... 72

Day eighteen of the nestling period.......................................... 72

Fledging ............................................................. 72

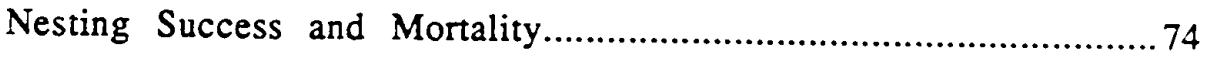

DISCUSSION.............................................................. 78

Prenesting Courtship Behavior ......................................... 78

Nest Site Showing ............................................ 78

Chasing ...................................................... 78

Nest Site Selection ................................................... 78

Nest Site Characteristics............................................ 78

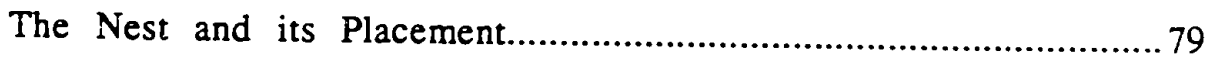

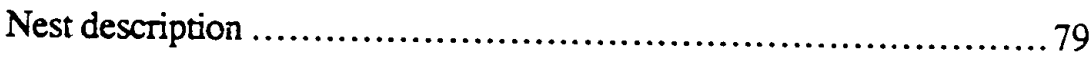

Nest Placement ................................................. 80

Nest Building Behavior....................................................... 81

Construction of New Nests and Reuse of Old Nests ................. 81

Laying ............................................................... 83

Dates and Time of Laying ......................................... 83

Laying Rate .................................................... 84

The Egg: Description, Measurements and Variation................................ 84

General Description and Measurements .............................. 84

Variation in Egg Size.................................................. 84

Variation in Egg Coloration ........................................ 85

Clutch Size ......................................................... 86

Variation in Clutch Size................................................. 86

Incubation .......................................................... 87

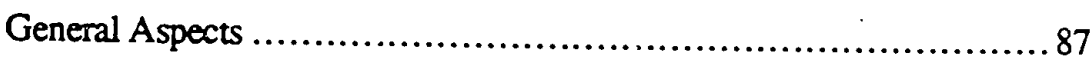

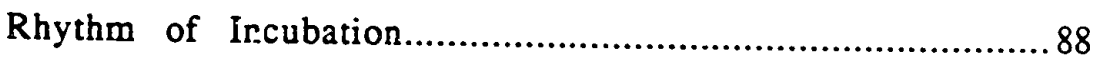


Length of the Incubation Period ...................................... 89

Loss of Weight by Eggs.......................................... 90

Hatching.............................................................. 90

Hatching Sequence and Interval ................................... 90

Eggshell Disposal ................................................ 91

Nestling Development ................................................. 91

Weight ......................................................... 91

Feather Growth.............................................. 92

Fledging ............................................................. 92

General aspects ............................................... 92

Nesting Success and Mortality................................................. 93

Nest Success and Mortality ....................................... 93

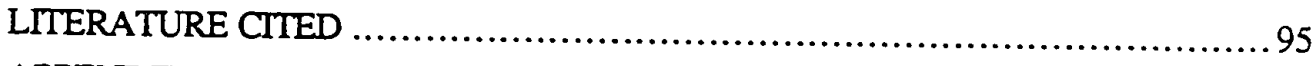

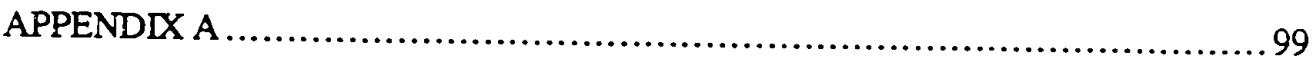




\section{LIST OF TABLES}

Table

page

1. Nest dimensions of selected nests prior to laying for 1989 and $1990 \ldots \ldots .31$

2. Mean number of days required to construct or reconstruct a nest............ 37

3. Observations of laying behavior of a female at NS 14 on April 4, 1990.... 39

4. Observations of laying behavior of a female at NS 14 on April 5, 1990.... 39

5. Ranges of first egg dates for all clutches laid in 1989 and 1990

6. Mean number of days after nest completion, fledging, and nest destruction before first egg is laid for 1989 and 1990.

7. Mean time of laying after civil sunrise.

8. Measurable characteristics of all eggs laid in 1989.

9. Measurable characteristics of all eggs laid in 1990.

10. Variation in egg volume with egg number and laying sequence for eggs laid in 1989

11. Variation in egg volume with egg number and laying sequence for eggs laid in 1990

12. Variation in egg volume with egg number and laying sequence for eggs laid in 1989 and 1990 combined.

13. The frequency and amount of spotting on five egg clutches for 1989 and 1990 combined

14. The frequency and amount of spotting on four egg clutches for 1989 and 1990 combined

15. Clutch sizes of $1 \mathrm{st}$ and 2 nd clutches laid in 1988, 1989, 1990

16. Temporal aspects of incubation at three nests over a period of three days in 1990

17. Mean length of the incubation period for clutches in 1989 and 1990. 59

18. Egg weight loss (\%) for clutches monitored in 1990 .61 
19. Weights of nestling Black Phoebes according to age in days..................64 64

20. Age of nestlings at the time of fledging in days since hatching................ 75

21. Nesting success and mortality for complete clutches in 1989 and 1990 ..... 76 


\section{LIST OF FIGURES}

Figure

page

1. Photo of adult Black Phoebe

2. Map showing Coyote Creek Riparian Station (CCRS) in relation to the San Francisco Bay and a diagram of the immediate study area.

3. Photograph of one of 16 Black Phoebe nest sites. Poison Hemlock (Conium maculatum) dominates the areas adjacent to the culvert 14

4. Cross-sectional diagram of a typical Black Phoebe nest site 17

5. Diagram depicting reproductive chronology for 1989. .25

6. Diagram depicting reproductive chronology for 1990. 26

7. Photo of a newly constructed Black Phoebe nest .29

8. Dimensional diagram of typical Black Phoebe nest....................... 32

9. Graph showing nest placement within the concrete crossovers 33

10. Photo of freshly laid Black Phoebe eggs. 42

11. Graph of egg volume as a function of laying sequence for all complete clutches laid in 1989

12. Graph of egg volume as a function of laying sequence for all complete clutches laid in 1990.

13. Graph of egg volume as a function of laying sequence for all complete clutches laid in 1989 and 1990 combined.

14. Diagram showing attentive/inattentive thythms of three incubating female Black Phoebes in 1990 .54

15. Graph of mean nestling mass versus age in days 65

16. Graph of mean wing and tail lengths versus nestling age in days. 66

17. Photo of nestling Black Phoebe on the day of hatching. 67

18. Photo of nestling Black Phoebe at twelve days of age 71

19. Photo of nestling Black Phoebe at eighteen days of age 73 


\section{INTRODUCTION AND LITERATURE REVIEW}

\section{General Background}

The Black Phoebe (Sayornis nigricans Swainson) is a common resident flycatcher (Figure 1) of the riparian, lacustrine, and emergent wetland communities in the Santa Clara Valley, Califomia.

The Black Phoebe is one of the few native avian species to benefit from man's settlement of the West. Black Phoebes have historically constructed adherent nests of mud and grass stems that were cemented to the vertical face of a rock or dirt bank. In the last 100 years, man-made structures have largely either replaced or augmented traditional nesting sites in many locales. The construction of buildings, bridges, and culverts has dramatically increased the number of suitable nesting sites. These man-made structures have facilitated the Black Phoebe's colonization of many previously unoccupied geographic areas and provided the opportunity for an intensive study of a local population.

This is a study of the reproductive biology and natural history of a population of Black Phobes breeding along Coyote Creek approximately three kilometers upstream from its entrance into the south end of the San Francisco bay (Figure 2). Data were collected during the spring and summer of 1988, 1989, and 1990 whiie the author was working at Coyote Creek Riparian Station (CCRS).

\section{Description}

The Black Phoebe is a medium sized flycatcher (Ridgway 1907). The weight of adult birds ranges from 14.7 to $20.9 \mathrm{gm}$, mean $18.2 \mathrm{gm}$ (this study). Males have a wing length's which average $91.5 \mathrm{~mm}$, and female wing length's average $85.2 \mathrm{~mm}$ (Irwin 1985). The Black Phobe's definitive basic plumage (terminology follows Humphrey and Parkes 1959) is predominantly a plain dark sooty, slate to black above, with the head being darker than the rest of the body (colors are those of Ridgway [1907] unless otherwise noted). The 


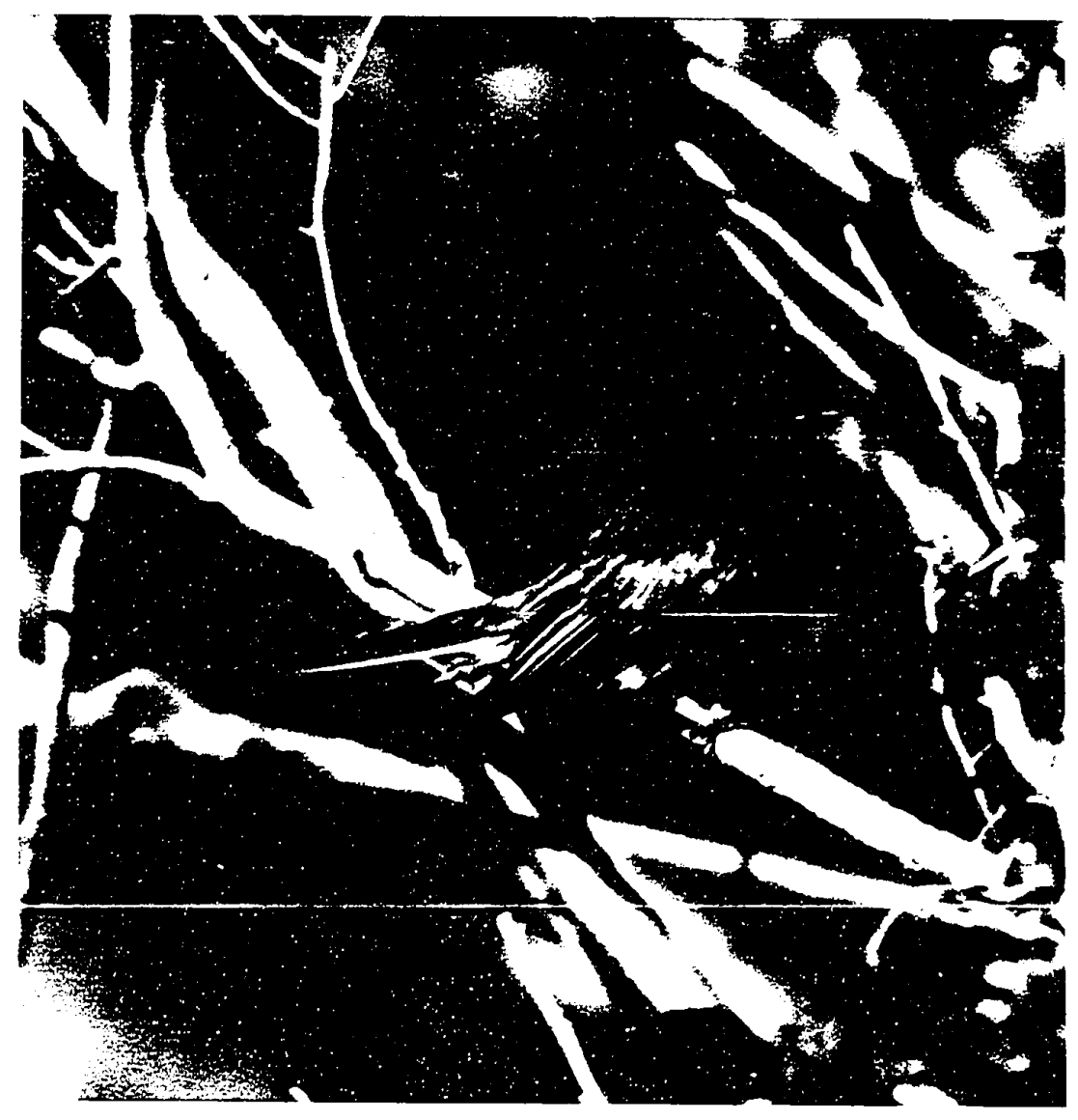

Figure 1. Adult Black Pheobe (Sayornis nigricans) perched in a coyote bush (Baccharis pilularis). 


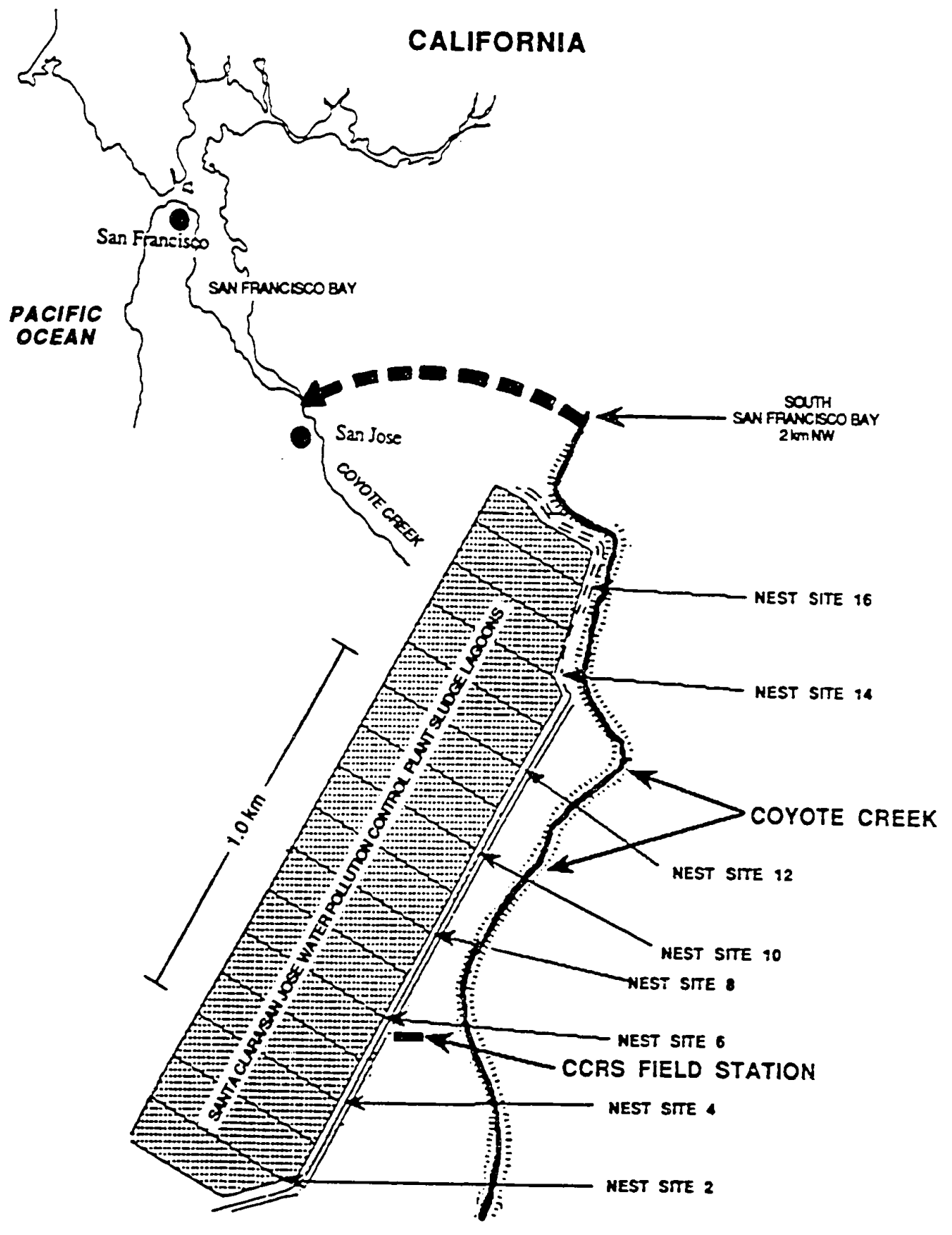

Figure 2. Map showing the location of Coyote Creek Riparian Station in relation to the $S a n$ Franciso Bay, Califomia and a diagram of the immediate study area. 
flanks, thighs, undertail coverts, and belly are white; the white on the belly forms an inverted $V$ as it extends up onto the lower breast. The scapulars, back, and rump are a brownish slate. The remiges and rectrices are also a dark sooty or brownish slate with vanes that appear translucent when the bird is in flight. The inner webs and tips of the secondaries are pale brownish gray as are the tips of the greater secondary coverts. The tail is of moderate length relative to other tyrannid flycatchers and is square with rounded comers. The outer vane of rectrice number six is white. The wingtips of the male, when folded, typically extend approximately $5 \mathrm{~mm}$ past the tips of the upper tail coverts. The wingtips of the female, when folded, are typically even with the tips of the upper tail coverts (Irwin 1985).

The mandibles are black, and the upper mandible has a smali hook at the tip. The nares are oval and rictal bristles are found on either side of both mandibles. The gape is chrome orange (Smithe 1975). The iris is brown. The feet and tarsi are also black and the toes bear well curved, sharp claws.

The juvenal plumage is similar to that of the adult with the following exceptions; the dark contour feathers of the body are edged with a medium cinnamon, the greater secondary coverts are tipped with cinnamon forming wingbars, and the white border on the belly and lower breast is suffused with cinnamon.

\section{Distribution}

The breeding range extends from northwestern California, south and east through southern Nevada, central Arizona, south-central Colorado, central New Mexico, and Trans-Pecos Texas, and continues south to southem Baja California and through Mexico (except the Yucatan Peninsula) and middle America, and South America east to northem Venezuela and south through Colombia, Ecuador, Peru, Bolivia and terminates in northern Argentina (AOU 1983). In California, the Black Phoebe breeds primarily west of the 
Sierra Nevada and ranges north along the humid coast range to the Oregon/California border (Grinnell and Miller 1944). This species is considered partiaily migratory (AOU 1983) with the northemmost populations moving south after breeding and some tropical populations, which breed at higher elevations (to 2690 meters), moving to lower elevations (Miller et al. 1957).

\section{Taxonoiny}

The Black Phoebe is a member of the Family Tyrannidae (AOU 1983). This family comprises approximately 375 species in 90 genera and is primarily Neotropical in distribution (Campbell and Lack 1985). The Black Phoebe has been assigned to the Subfamily Fluvicolinae along with two other primarily North American genera: Empidonax and Contopus (Traylor 1977). The Black Phoebe is one of three species of the genus Sayornis, the other members are the Eastern Phoebe (S. phoebe) and the Say's Phoebe (S. saya).

\section{Literature Review}

In spite of the Black Phoebe's close association with man, many aspects of its biology are poorly documented (Bent 1942). Popularized accounts of the benavior and reproduction of the Black Phoebe have been published by Jewett 1899, Finley 1907, Dawson 1923, Baily 1927, and Hoffman 1927. Bendire (1895) described the species breeding range, and made detailed observations on the nest and eggs.

Other typically short, but useful, articles peraining to the biology of the Black Phobe and its occurrence in Califomia include: nesting dates for Butte County (Davis 1933), Fresno County (Tyler 1913), Imperial County (Cardiff 1950), Los Angeles County (Willett 1933), Plumas County (Grinnell et. al. 1930), Tuolumne County (Grinnell and Storer 1924), the species distribution in the Mojave desert and southern California (Fisher 
1893) as well as the southem Califomia islands (Howell 1917); late nesting in Humboldt County (Fraser 1931); nest site selection, including the placement of nests in abandoned wells and the variation in egg coloration with laying sequence as reported on by Tyler (1913); a description of a Black Phoebe's nest and eggs in Solano County with eggs of three species (Western Flycatcher (Empidonax difficilis), Dwarf Cowbird (Molothrus ater) and the Black Phoebe) (Stoner 1935); joint use of a Black Phoebe's nest by House Finches (Carpodacus mexicanus) and Black Phoebes (Holland 1923); unusual nests (Robertson 1933, Quigley 1954); clutch size manipulation and the effects of switching of young and eggs between nests (Kinsey 1935); and nestling predation by an American Kestrel (Falco sparverius) in Los Angeles County (Cowles 1928).

The Black Phoebe is invariably associated with water. Coastal cliffs, the banks of rivers, creeks, and streams, the borders of lakes and ephemeral ponds, fountains in parks, and cattle troughs, are all favored sites (Grinnell and Storer 1924, Oberlander 1939, Skatch 1960). Recorded elevations range from sea level to $2150 \mathrm{~m}$ (Willet 1912). Almost any semi-permanent water supply with an accompanying source of mud, which is required for nest construction, is attractive to this species. Man-made structures have supplemented the traditional nest sites such as sheltered rock faces, stream-side boulders and hollow cavities in trees. In addition, human activities have increased breeding densities in many habitats to above those found under natural conditions where the lack of suitable nest sites is a limiting factor. Grinnell and Storer (1924) note that the irregular distribution of Black Phoebes in an area is probably due to their specialized nesting requirements.

The first extensive work on the general biology of the Black Phoebe was done at Berkeley, California by Oberlander (1939). His study concentrated on the daily routine of phoebes living on the University of California campus. Included in the study were detailed accounts of foraging behavior, pellet casting, and the relationship between time of sunrise 
and sunset, in relation to the time of entering and leaving the roost. Additionally, Oberlander made fragmented observations on pairing, nesting, and the behavior of fledgling Black Phoebes.

In Costa Rica, Skutch (1960) made noteworthy observations of various aspects of the behavior of a pair of Black Phoebes over a period of several weeks. Nest construction, egg laying, and incubation, as well as vocalizations and roosting behavior were documented.

Nesting habits, ecological distribution, and diets of sympatric Black and Say's Phoebes (Sayornis saya) in the Trans-Pecos region of Texas were studied and compared by Ohlendorf (1976).

Vocalizations and displays in Sayornis species were identified, named and discussed extensively in a series of papers by Smith (1970a, 1970b). Smith(1970a) compared the song-like displays of the Eastem Phoebe, the Black Phoebe and the Say's Phoebe. He found variation in the message assortment of some song-like displays among the three species. Smith (1970b) documented message assortment of visual displays and found that the displays were used in similar contexts by all three Sayornis species.

The foraging behavior and prey taken by Black Phoebes have been reported on by a number of observers. Beal (1912) found that the stomach contents of Black Phoebes from Califormia ( $n=343$ ) contained $99.41 \%$ animal matter. Insects were grouped by order, and Hymenoptera (primarily wasps and various wild bees) were the most frequently taken group accounting for $30.82 \%$ of total prey items. The proportion of prey items from this group peaked in August when they accounted for 58.72\% of the total. Insects of the Order Diptera (flies) were the second most frequendly taken prey and the most evenly distributed throughout the year. Dipterans accounted for $28.26 \%$ of the total prey items counted with a peak in April of $64.36 \%$ of the total prey for that month. Members of the Orders 
Coleoptera and Lepidoptera were the next most frequently observed prey items accounting for $13.30 \%$ and $8.22 \%$ respectively of the total prey items observed. Orthopterans accounted for $2.45 \%$ of total prey items; other arthropod groups were responsible for the remaining $5.78 \%$ of animal matter consumed.

Plant materials accounted for only $0.59 \%$ of total items recovered. Oniy blue elderberry berries (Sambucus gluaca), which were found in 16 stomachs, may have been taken intentionally.

Food items given to nestlings differed in proportion from those found in the stomachs of adults (Beal 1912). "Soft " food items (Hymenoptera, Diptera, and Lepidoptera) accounted for $87.64 \%$ of total items in nestlings versus $67.3 \%$ of the total items found in adult stomachs.

Surprisingly, honey bees (Apis meiiifera) were not found in the stomachs of any Black Phoebes examined by Beal. A unusual case of observed mortality (Ross 1933) of a Black Phoebe after consuming a honey bee suggests that honey bees may be unpalatable and dangerous prey.

Other notable observations on food preferences of the Black Phoebe include observations of fish catching. Attempted captures were observed in Pasadena, California (Howell 1924) at a goldfish pond where a Black Phoebe repeatedly dived into the pond apparently trying to capture the young fish. Oberlander (1939) observed minnows taken in Berkeiey, California, and C. S Lawson and J. O'Connell (Lawson 1975) observed a Black Phoebe hovering above the water of a sewage pond and immersing its bill to the base while capturing Mosquitofish (Gambusia affinis) in Clark County, Nevada. This behavior was also observed at a fish hatchery in Humboldt County, California (Irwin 1985). These phoebes were observed fishing regularly and used the fingerlings to provision their nestlings during the breeding season. 
Gander (1928) observed Black Phoebes in Balboa Park, San Diego, Califomia in September, feeding on the berries of a lantana, and the orange berries of an unidentified shrub on several occasions.

The comparative foraging ecology of the Black Phoebe, Westem Flycatcher, and Western Wood Pewee (Contopus sordidulus) was studied by Verbeek (1975a) in Monterey County, California. He investigated the niche relationships among these three sympatric species. Spatial and temporal aspects of foraging behavior of each species were recorded and compared in an effort to examine the extent of competition among these flycatchers. Nest site selection and egg dates were also summarized and compared. The Black Phoebe showed the widest diversity of feeding substrates, tending to stay in open areas, and foraging primarily close to the ground. Based on the parameters examined, the Black Phoebe was considered the most versatile. Few signs of interspecific competition were noted among the three species.

Verbeek (1975b) continued his earlier study with an investigation of the factors that allow the Black Phoebe to overwinter in Northern California. He found that an expanded winter territory, which was occupied by only a single phoebe, and an increased use of the ground as a foraging substrate contributed to the successful overwintering of this species. The Black Phoebe also added a greater vertical component to its feeding niche and used a greater variety of perch types for foraging than either the Western Flycatcher or Western Wood Pewee, both of which migrate.

The most recent investigation concerning the Black Phoebe was conducted by Irwin (1985) in Humboldt County, California. The foraging ecology and reproduction of the Black Phoebe were studied in the coastal grasslands between the Mad River and the city of Eureka. Phoebes tended to forage under the canopy of vegetation on cold momings and evenings and in the open areas during mid-day in the winter. With increasing temperatures 
mean height above the ground at which prey were captured, and flight distance to prey increased. Winter prey capture rates were highest between mid-morning and midafternoon.

In his study Irwin (1985) found that phoebes maintained individual territories, which were between 9 and 11 hectares in size, during the fall and winter, and paired with neighbors in the early spring. Nests were constructed under the eaves of buildings on one of the territories. Egg dates varied from 20 March to 24 June and clutch size varied from three to six eggs with an average for 32 clutches of 4.2 eggs. In 1978, eleven of sixteen pairs of Black Phoebes under observation laid two clutches of eggs. Seven of these first clutches failed and of these seven, nests or eggs of four clutches were destroyed. In the remaining three nest failures, the nestlings or the female died from exposure or starvation.

One pair of phoebes (Irwin 1985) breeding at the Mad River Fish Hatchery laid three clutches of eggs, including one clutch of six eggs. Four pairs of phoebes, which nested late after a proionged period of rainfall, laid only one clutch of eggs during the 1976 breeding season. All phoebes observed in Irwin's study laid their eggs on consecutive days between 07:00 and 08:30. In all but three nests, the females incubated the eggs and brooded the nestlings alone. The incubation period was 16 to 18 days in length, with a mean of 16.9 days and started after the laying of the last egg. Nest attentiveness varied from 2.0 minutes to 19.5 minutes, with an average of 13.8 minutes per session. The parent spent $68 \%$ of the daylight hours incubating during the observation period. The eggs within a clutch hatched inside a period of 36 hours.

Irwin (1985) found that the parent birds brooded the young until the tenth or eleventh night. Feeding visits to the nest varied from two to eighteen per hour with an average of 8.7 visits per hour. The nestling period ranged from eighteen to twenty-one days with an average of 19.9 days to fledging. The second clutch of eggs was started from one to 
twenty-three days after fledging of the first brood and averaged ten days. The fledglings were independent seven to eleven days after fledging. The birds breeding at the fish hatchery, where fingerlings were a large part of their diet and provided a constant supply of food, nested earlier and laid more eggs than any other pairs of phoebes observed.

\section{Scope of this Investigation}

This study documents some specific aspects of the reproductive biology of the Black Phoebe in the Santa Clara Valley, California. As the previous review indicates, several researchers have studied the biology of this species. These investigations have concentrated on topics such as communication and displays within the genus (Smith 1970a, 1970b), foraging biology (Verbeek 1975a, 1975b, Irwin 1985) and diet (Beal 1912). Anecdotal accounts make up a major portion of the literature concerning the reproductive biology of this species. While valuable, these anecdotal references generally lack the repeated observations and quantitative data needed to accurately and usefully report the many facets of the reproductive biology of avian species.

In this study, I address the following aspects: 1) the chronology of the reproductive cycle; 2) the behavior associated with nest site selection, nest placement and construction, including the role of both sexes in these activities; 3) the iming of egg laying, and some of the temporal and behavioral aspects of incubation; 4) variation in egg size between clutches and variation in clutch size; 5) hatching, nestling growth and development; 6) nesting success and nestling mortality. 


\section{THE STUDY AREA}

\section{General Characteristics}

The area used for this study lies at the north end of the Santa Clara Valley on the flood plain immediately west of Coyote Creek (Figure 2), approximately three kilometers from its entrance into the south San Francisco Bay. The valley floor consists of confluent alluvial fans and flood plains deposited by the many tributary streams that enter the valley (USDA et al. 1968).

The Diablo Mountain Range rises ten kilometers to the East of the valley floor, lying in a northwesterly to southeasterly direction; it is characterized by low rolling foothills which give rise to a series of steep parallel ridges, with slopes of 20 to 60 percent. This mountain range, with a maximum elevation of 1,325 meters, separates the Santa Clara and San Joaquin Valleys. The main drainage system for the west slope of the Diablo Range is Coyote Creek which flows from the south end of the county north along the east side of the valley floor and out into the San Francisco Bay.

Twenty kilometers to the southwest of the study area lie the Santa Cruz Mountains; this coastal mountain range consists of a number of small "but rugged" ranges. Elevations of this mountain range vary from 600 to 1025 meters with the highest peak in the range (Loma Prieta Peak) reaching 1146 meters. The Guadalupe River is the main drainage for the east slope of this range and enters the bay at the town of Alviso. Many smaller seasonal streams drain the remainder of the valley (USDA et al. 1968).

The climate is Mediterranean and is characterized by warm, dry summers and cool, wet winters. In summer, fog tends to blanket the valley during the nighttime hours. The orientation of the flanking mountain ranges results in a predominantly north-westerly flow of marine air through the valley. Wind speeds frequently reach $30 \mathrm{kmph}$ or greater. In the winter, air flow is primarily from the southwest. Average annual rainfall for the Alviso 
area is a reported $41 \mathrm{~cm}$ a year, with most precipitation occurring between November and March. The average annual temperature for the Alviso area is $14 \mathrm{C}$. Extremes in temperature range from -5 to $40 \mathrm{C}$ (USDA et al. 1968).

\section{Study Area Habitats}

General Overview. - This study was carried out at Coyote Creek Riparian Station which is located on buffer land (Figure 2) belonging to the San Jose/Santa Clara Water Pollution Control Plant (SC/SJWPCP) and lies immediately to the west of Coyote Creek. The study area may be divided into three distinct zones: farthest to the east along the creek is the foothill/valley riparian community. This disturbed community is dominated by cottonwood, box elder, and willow trees and varies in width from 3 to 25 meters. Centrally located on the flood plain, lies the valley grassland community, which is dominated primarily by poison hemlock (Conium macularum), summer mustard (Brassica geniculata), coyote bush (Baccharis pilularis), and various thistle species (Cirsium sp.). Once a pear orchard, this ruderal field varies in width from 20 to 200 meters. To the west, lie the sludge lagoons and their supporting system of levees; included in this area is a concrete culvert with a series of crossovers within which the Black Phoebes built their nests (Figure 3). Coyote bush, poison hemlock, and hoary cress (Cardaria draba) dominate this area.

The FoothillValley Riparian Community.-This community rests on the remains of an old levee system of imported rock and soil and is composed of a fragmented canopy and an understory of diverse species. It varies in width from 3 to 25 meters and in height from 0.5 to 30 meters.

The canopy is dominated by fremont cottonwoods (Populus fremontii), of which the larger trees are about 35 years old, box elder (Acer negundo), and the blue elderberry 

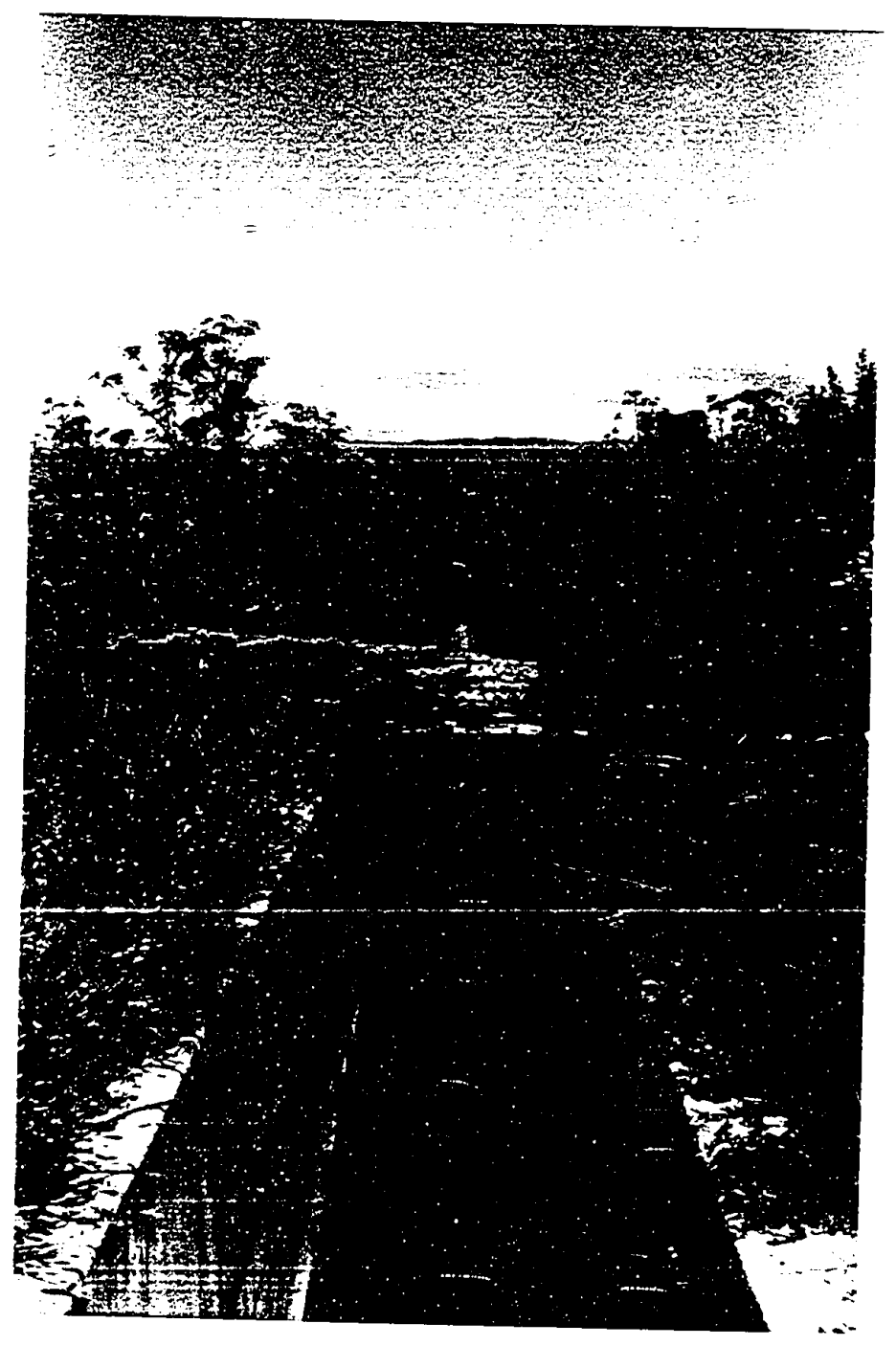

Figure 3. Photograph of one of 16 Black Phoebe nest sites. Poison Hemlock (Conium maculatum) dominates the areas adjacent to the culvert. 
(Sambucus mexicanus). Other canopy species that occur with less frequency include the california black walnut (Junglans hindsii) and weeping willow (Salix babylonica).

The scrub understory is dominated by red willow (Salix laevigata), arroyo willow (Salix lasiolepis), califomia wild rose (Rosa californica), and giant reed (Arundo donax). Understory plants include various woody and herbaceous species such as: california blackberry (Rubus vitifolius), poison hemlock, coyote bush, hoary nettle (Urtica holosericea) and common cattail (Typha latifolia).

This area has been augmented by $a 4.3$ acte revegetation plot, in which various riparian species of trees and shrubs were planted in the winter of 1985-86. This revegetation plot partially mitigates for losses of riparian habitat along Coyote Creek. These losses were incurred as a result of an ongoing flood control project sponsored by the Santa Clara Valley Water District (SCVWD).

The Valley Grassland Community. - This community is composed of a mosaic of primarily nonnative annual plants which often occur in relatively pure stands. Of these, four annual species predominate: poison hemlock, summer mustard, wild radish (Raphanus sativus) and bull thistle (Cirsium vulgare). Also common are woody shrubs such as the coyote bush and tree tobacco (Nicotiana glauca). During October of 1990 most of this area was scraped to bare earth as required for the flood control project.

The Levee System, Adjacent Culvert, and Sludge Lagoons. - The main levee road is paralleled for much of its length by a concrete culvert, which sits on the levee above and adjacent to the sludge lagoons (Figure 2). This culvert is oriented in a general north-south direction and roughly parallels the creek for most of its length, although the distance between the culvert/levee and creek vary from 25 to 300 meters. The culvert is approximately 0.9 meters wide and 1.12 meters deep and generally has a water/sludge mixture flowing through it. 
At intervals of approximately $75-115$ meters along the levee road, a concrete crossover bridges the culvert and allows vehicular access to the roads running between the sludge lagoons, as well as into the sludge lagoons themselves. The lengths of these crossovers altemate between 5.15 meters and 30-36 meters; the short crossovers are placed in the middle of the lagoons and are artifacts resulting from the division of the present lagoons into two smaller lagoons. The long crossovers provide access to the levees running between the sludge lagoons and have access roads passing over them.

The short crossovers are the Black Phoebe's preferred nest sites and are not subject to motor vehicle traffic. The top of the culvert stands at the same level as the gravel levee road located immediately to the east. Along the length of this culvert there are 15 crossovers and 16 potential nest sites. Nest site 1 is at the south end of the culvert and is a concrete basin with a gate valve which allows for draining of the culvert. The nest sites were numbered from south to north from 1 to 16 . The distance along the levee road from nest site 1 to nest site 16 is 1.46 kilometers.

The twenty-three Black Phoebe pairs observed in this investigation all placed their nests on the vertical walls of the concrete culvert (Figure 4) under the crossovers. These crossovers provide suitable protection from predators. This culvert is used by water pollution control plant personnel for removal of surface water from the sludge drying lagoons which lie immediately to the west. Water pumped from these lagoons carries varying amounts of sludge and hence is a soupy mixture. A large quantity of this effluent typically remains in the culvert after pumping is completed due to poor drainage caused by the upward slope of the culvert.

Yearly pumping regimes vary, depending on the timing and quantity of rainfall which in turn determines how much water collects in the drying lagoons. During the 1988 and 1989 breeding season, as a result of moderate rainfall and subsequent pumping, the water 


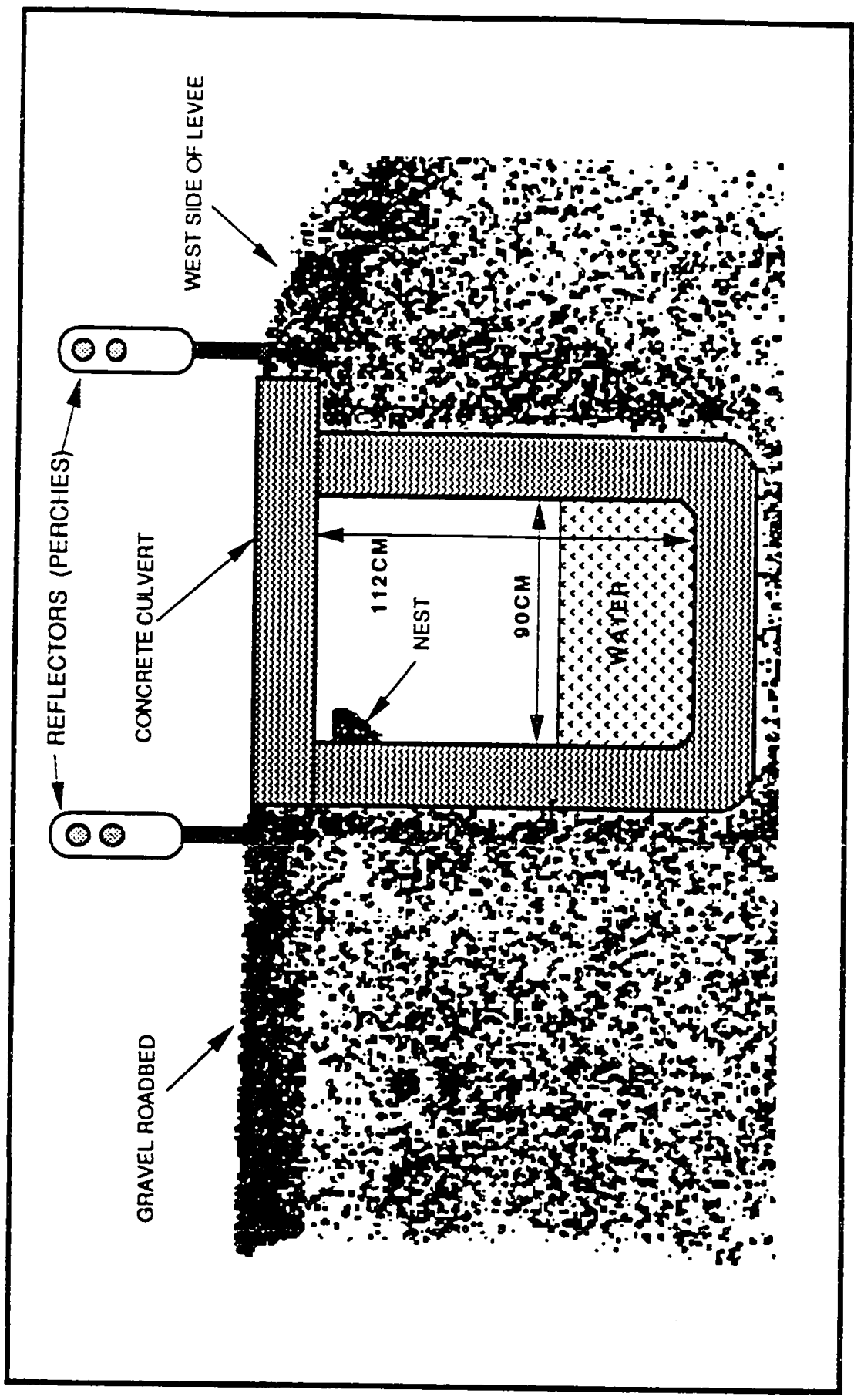

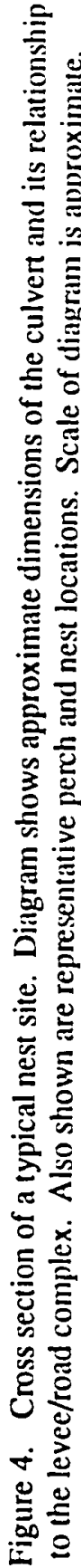


level in the culvert fluctuated between a height of $10 \mathrm{~cm}$ and $100 \mathrm{~cm}$. This contrasted sharply with the 1990 breeding season which had little rainfall and no pumping and when the culvert remained essentially dry during the major portion of this breeding season.

On the east side of the levee, just south of nest site 6 , are large, dense stands of coyote bush; scattered patches also occur on the west side of the levee at nest sites 4,6 , and 8. To the north of nest site 6 , poison hemlock, summer mustard, farmer's foxtail, and hoary cress dominate to varying degrees the steeply sloped sides of the levee. 


\section{MATERIALS AND METHODS}

\section{Chronology}

Data for this study were collected almost daily from mid-February to mid-June of 1988 , 1989, and 1990.

\section{Measurements and Banding}

Nest Measurements. - In 1989 and 1990 measurements were taken of nests and their placement within the culverts. Nest measurements included: nest depth, the distance from the top outer edge of the nest to the wall; nest width, maximum width of the top of the nest measured along the wall; nest height, the distance from the bottom of the nest to the top of the nest measured along the wall; cup depth, measured from the bottom of the cup to the top of the nest; cup width, the inside diameter of the cup (the latter two measurements were subject to added variation because some nests were measured at the end of the nesting cycle and some at the beginning).

Nesi Placement. $\rightarrow$ Nest placement measurements included distance from the cuiver ceiling to the top of the nest and nest distance from the nearest culvert entrance. Nest measurements were taken with a transparent $150 \mathrm{~mm}$ ruler to the nearest millimeter. Placement of nests were measured with a Stanley 3 meter Tape Measure. Notes on nest materials and construction were also recorded as well as photographs of selected nests.

Egg Measurements.-During the 1989 and 1990 breeding seasons, egg measurements were taken from most nests under study. Egg length and width were measured to the nearest $0.01 \mathrm{~mm}$ with a Mitutoyo model \# 505-633 $150 \mathrm{~mm}$ dial caliper. Initial egg weights were taken from all nests within a day of completion of the clutch. A second set of weights were taken from selected clutches at approximately the midpoint of the incubation period; these were followed by a third weighing on the day before, or the 
day of hatching. In a few cases a fourth set of weights were taken if the clutch did not hatch on the day that the third weights were taken. Eggs were removed from the nest for periods varying from 15 minutes to 40 minutes for the first measurements; for subsequent measurements the period varied from 7 to 15 minutes. The eggs were transported in a container lined with cotton. Care was taken wo prevent excessive chilling of the eggs. More than $95 \%$ of the weighed eggs hatched and observer impact was probably limited to the loss of one egg which was dropped. Egg weights were determined using a RollerSmith precision balance with a $0.2 \mathrm{mg}$ vernier scale.

The color and pattem of speckling on each egg were also noted and scored accordingly: \#0 eggs had no speckling; \#1 eggs had less than 15 very small (approximately $0.1 \mathrm{~mm}$ in diameter) light brown speckles, and possibly an occasional small speckle (approximately $1 \mathrm{~mm}$ in diameter); \#2 eggs had more than 15 very small to small light brown speckles.

Adult and Nestling Measurements.-Adult Black Phoebes were captured opportunistically during normai operation of the banding lab throughout the duration of the study. Measurements of adults were recorded at the banding station. Wing length was measured to within $\pm 1 \mathrm{~mm}$ with a $150 \mathrm{~mm}$ metal wing ruler and body mass was measured to within $0.1 \mathrm{gm}$ with a Whaman micro line PDB200M electronic scale. Tail length, tarsus length, length of bill from nostril, and width of the bill at the nostrils were measured on most adults (Baldwin 1931). In addition, data on age, sex, sexual condition (brood patch or cloacal protuberance), plumage and molt and capture location were also recorded.

During 1989 and 1990, nestling phoebes were weighed and measured nearly daily at several nest sites. Data was recorded at the nest site. Nestlings were measured as described above, and weighed with a portable Whatman electronic scale if conditions permited or a Pesola $10 \mathrm{gm}$ or $50 \mathrm{gm}$ (0.1gm resolution) spring scale if the wind disturbed 
the electronic scale excessively. Measurements recorded on arbitrarily selected nestlings included body weight, wing chord, length of primary teleoptiles number 1, 3 and 10, sheath length of the same primary feathers, rectrice length of rectrices number 1 and 6 , and their sheath length. Other data such as development of pterylae, presence and location of neossoptiles, presence of egg tooth, color of skin, feathers, feet and bill, time of opening of eyes, and nestling behavior were also recorded for selected individuals. Nestlings were removed from the nest for measurements for periods ranging from 5 to 45 minutes. In no case did removal of nestlings result in desertion by adults or subsequent predation within a day of removal. In four cases spontaneous fledging occurred as I approached the nest. In neither case was there apparent fledgling loss.

Banding.-All pheobes captured during the normal course of operation of CCRS's banding station were banded on the tarsus with a size \#1 Fish and Wildlife Service band. On 30 December 1987 an auxiliary marking permit was issued by the U.S. Fish and Wildlife Service Bird Banding Laboratory allowing CCRS to colorband Black Phoebes in order to identify individual birds. Plastic split ring colorbands, size XCS, were obtained from A.C. Hughes, Hampton Hill, Great Britain. The following colors were used: red, yellow, blue, green, white, black, orange, and pink. During 1988 and 1989, three colorbands which supplemented the FWS band were placed on the left and right tarsi of each phoebe banded in the following order: position \#1; right leg lower, position \#2; right leg upper, position \#3; left leg upper, position \#4 left leg lower. Bands were read in the field in ascending order, 1234 using the first letter from each color or two letters in the case of the black colorbands. In 1988 and 1989 the FWS band occupied position \#4 and in 1990 in most cases the FWS band occupied position \#1. 
A computer program (Appendix 1) was written in BASIC to generate a list of all possible color combinations for the eight colors selected. This list was then used to assign colorband combinations to individual phoebes.

In 1988 and 1989, 122 adult and immature Black Phoebes were colorbanded. These birds were captured in mist nets (Eastem Bird Banding Association $36 \mathrm{~mm}$ nylon) during the normal course of operation of CCRS's banding station. During 1988 and 1989 , nestling phoebes from nests under observation were colorbanded where possible before they fledged. In 1990, a lesser effort was made to colorband and only selected nestlings were so marked.

\section{Observational Data}

Observations of nest construction, laying and incubation behaviors were recorded in 1989 and 1990 . Observations were timed such that a representative sample of the forementioned behaviors were obtained from several individuals over the duration of the breeding cycle. Observation periods ranged from 0.5 to 10 in hours duration. During 1989 observations were made with Zeiss 10X40 GAT binoculars from distances of 40 to 75 meters with the observer unconcealed. Distances were adjusted until no overt reactions to the observer's presence were noted by the investigator. In 1990, most observations were made from a portable blind using binoculars and a Zeiss 30X60 GAT spotting scope mounted on a tripod. The use of the blind allowed observational distances to be reduced to 25 to 30 meters with no apparent interference in the activity of the birds under observation. In fact, in many instances the phoebes would range within a few meters of the blind during foraging bouts.

Eight active nest sites were checked almost daily between 0600 and 1200 from March to June during all years, with the exception that in 1989 three sites were checked weekly to monitor possible observer impact. During the hatching period nests were checked 
throughout the day in order to determine the time of hatching. The durations of various activities were recorded using one or more digital LCD stopwatches.

Photographs were taken of nests, eggs, and nestlings with a Nikon FG camera and a $55 \mathrm{~mm}$ micro Nikkor lens. Environmental temperature was measured with a Miller and Webber quick reading cloacal celsius thermometer and wind velocity was measured with a Dwyer wind meter.

Observations in the field were recorded on a portable tape recorder and transcribed onto a personal computer later that same evening. Observations recorded include descriptive and temporal aspects of: territorial and mairienance behaviors, observation of courtship and nest site selection, nest building and egg laying (including time of laying and laying rate for selected individuals), incubation behavior, hatching and nesting growth and development as well as fledging.

\section{Statistical Analysis}

Statistical analysis were carried out using the SYSTAT TM statistical software package. 


\section{RESULTS}

\section{Reproductive Chronology}

The chronology of the reproductive cycle for Black Phoebes nesting on Coyote Creek in 1989 and 1990 are presented in Figures 5 and 6, respectively.

\section{Prenesting Courtship Behavior}

During 1989 and 1990 behavioral observations were started in mid-January when phoebes began showing reproductive behavior. Black Phoebes were already paired and their activities were restricted to well defined territories. Most activities were centered around the nest site and both members of the pair spent a major portion of their day perched on reflectors and vegetation directly above or adjacent to the nest site or foraging nearby.

Nest Site Showing.-Starting in mid-February phoebes engaged in prenesting courtship displays. The Nest Site Showing (N-S-S) display (Smith 1969) was one of the most frequently observed. N-S-S displays were observed beginning in mid-February and continued through early March. Males usially initiated the behavioral sequence.

Typically, it started with both members of the pair perched directly above or adjacent to the nest site. The male in view of the female flew under the crossover and hovered, for 5 or 10 seconds, in front of an old nest or a section of bare wall, with his body held vertically and tail fanned. In more than half of these displays he was immediately followed under the crossover by the female. She either landed on the old nest or perched in the bottom of the culvert. Alternately, if no old nest was present, the female would cling to a part of the wall and hang propped up by her tail. If the female landed on the nest, she was immediately joined by the male. Often times he repeatedly ( 3 or 4 times) hovered and landed on the nest before he retumed to his perch above the crossover. The female usually exited the crossover a few seconds later. These displays were sometimes accompanied by soft 


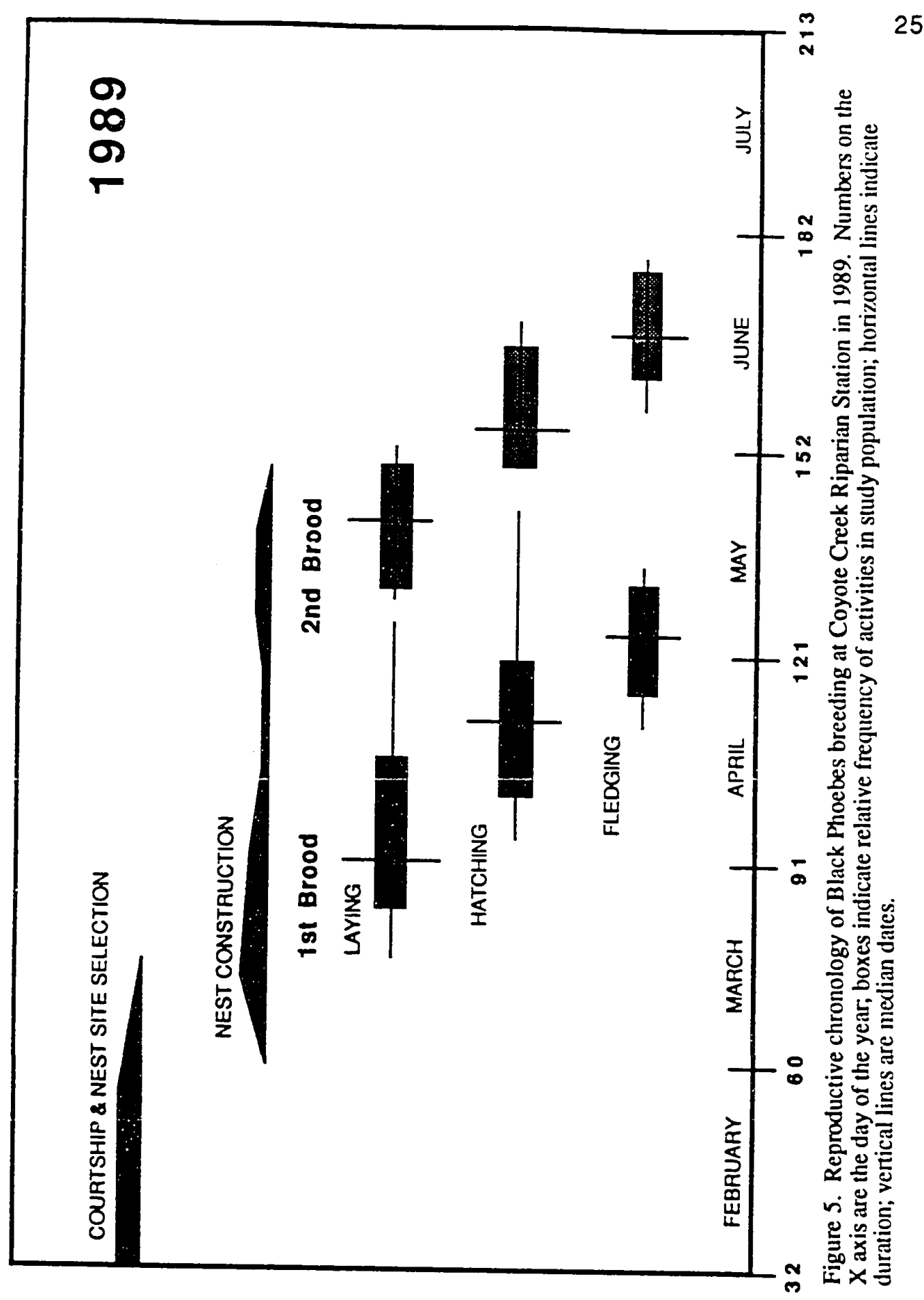




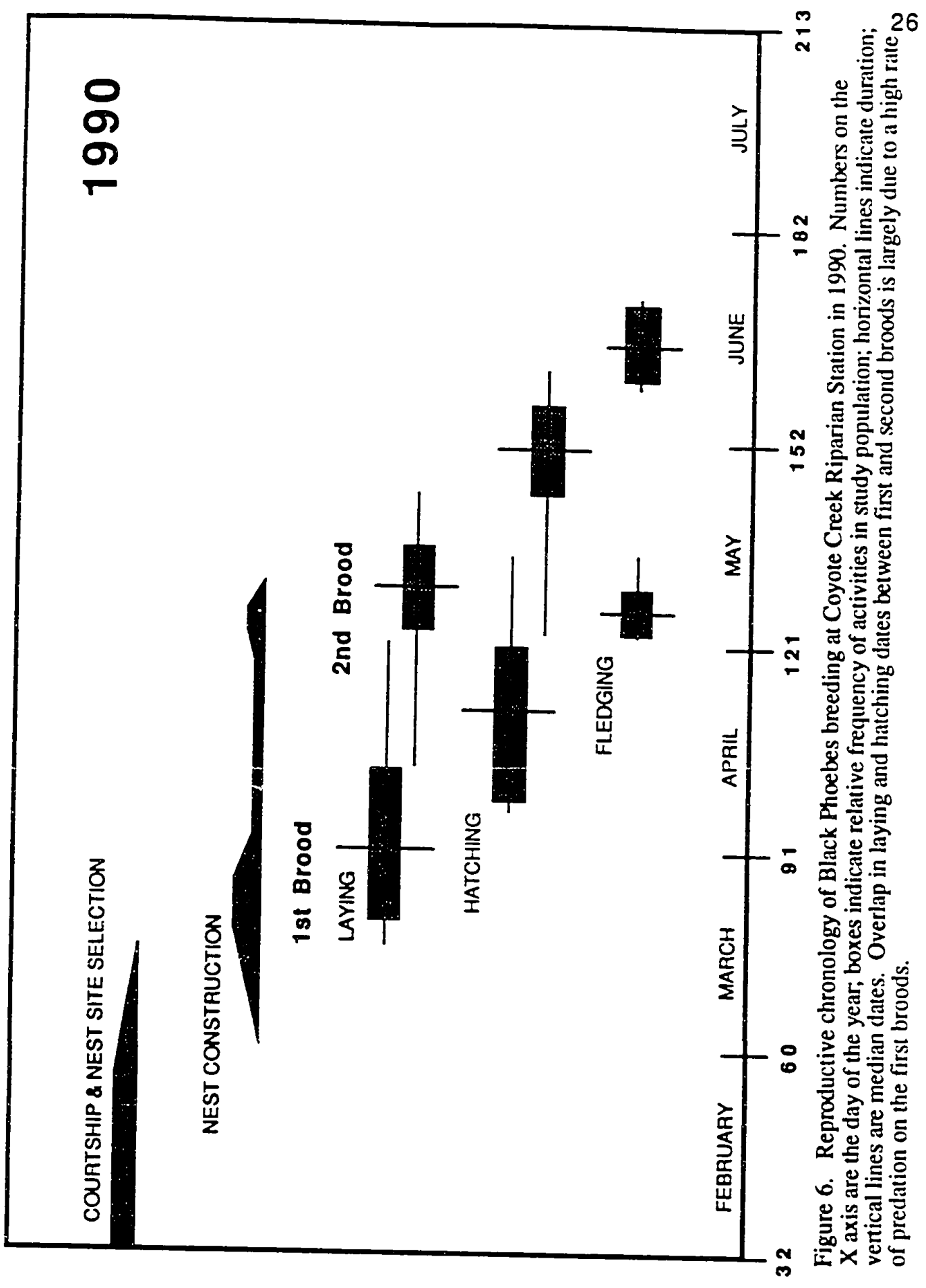


Chatter Vocalizations (CV) (Smith 1969) while the birds were under the culvert. This display was observed several times in a period of half an hour. Occasionally, the female initiated the display by flying under the crossover, the male immediately followed her to the nest.

Supplanting \& Chasing.- Other displays observed during this period include the supplanting of one member of the pair from a perch. This behavior was sometimes followed by chasing. Supplanting was initiated by either sex, but as with the N-S-S was most frequently initiated by the male. Each pair had from three to five favored perches within a 5 meter radius of the nest site. At Coyote Creek these perches were frequently road reflectors (Figure 4) Perches were used for foraging and other maintenance activities as well as resting. Supplanting is simply the flight of one member of the pair to a perch where the other bird is sitting, which resulted in the perched bird being displaced. In all instances observed, the bird that was displaced left its perch when the approaching bird was within a meter of the perch, and only on one occasion did a female refuse to be displaced from a perch. Miales typically approached females with a shallow fluttering flight and did not vocalize.

Chasing occurred with less frequency than supplanting and was most commonly observed following supplanting. During a supplanting sequence, the approaching bird would start chasing the sitting phoebe as it left its perch. Chases between pairs typically involved a short ( 5 to 20 meters in length) rapid flight that sometimes included one or two cork screw type maneuvers. Often the chase was broken off when one of the phoebes suddenly flew up vertically into the air and then the birds fiuttered to separate perches. Either sex initiated this behavior and only rarely were vocalizations heard. 
Nest Site Selection

Black Phoebe pairs used the shor ( 5 meter) crossovers as nest sites. As a resulth nest sites were spaced at intervals of approximately 175 meters. In only 2 of 41 observed nesting attempts did the pair select one of the long crossovers (30-36 meter) as a nest site. In one case this was in response to a nest failure (predation). The second instance resulted in three pairs with nest sites spaced only 75 to 110 meters apart. In this latter case it is potentially important to note that of the 16 nest sites on the study area these 3 sites are in closest proximity to the creek (approximately 25 meters); all others are from 100 to 300 meters distant (Figure 2).

\section{The Nest and its Placement}

General Description.-Nests consisted of a primarily mud base and outer shell surrounding an open cup lined with dry grass stems and plant fibers (Figure 7). All nests were invariably cemented to the verical wall of the culvert running adjacent to the main levee and protected from above by the concrete crossover. Nests varied somewhat in height and width, and in the relative proportions of mud and dried grasses used in the construction of the base and outer shell. Considerable variation also existed in the composition of the rim of the nest. Old nests were generally repaired and relined from year to year and between first and second broods. Most nests were hidden from view of observers outside the culvert.

Nest Base and Outer Shell.-Small mud pellets that were gathered from nearby sources were the principal material used in construction of the nest base and shell. Dry grass stems and other plant fibers were mixed with the mud. These materials were incorporated into all nests and provided added strength to the shell as it dried. As the nest cup neared completion, some birds tended to integrate more plant material and less mud into the upper portion of the cup and rim. This tendency varied considerably between 


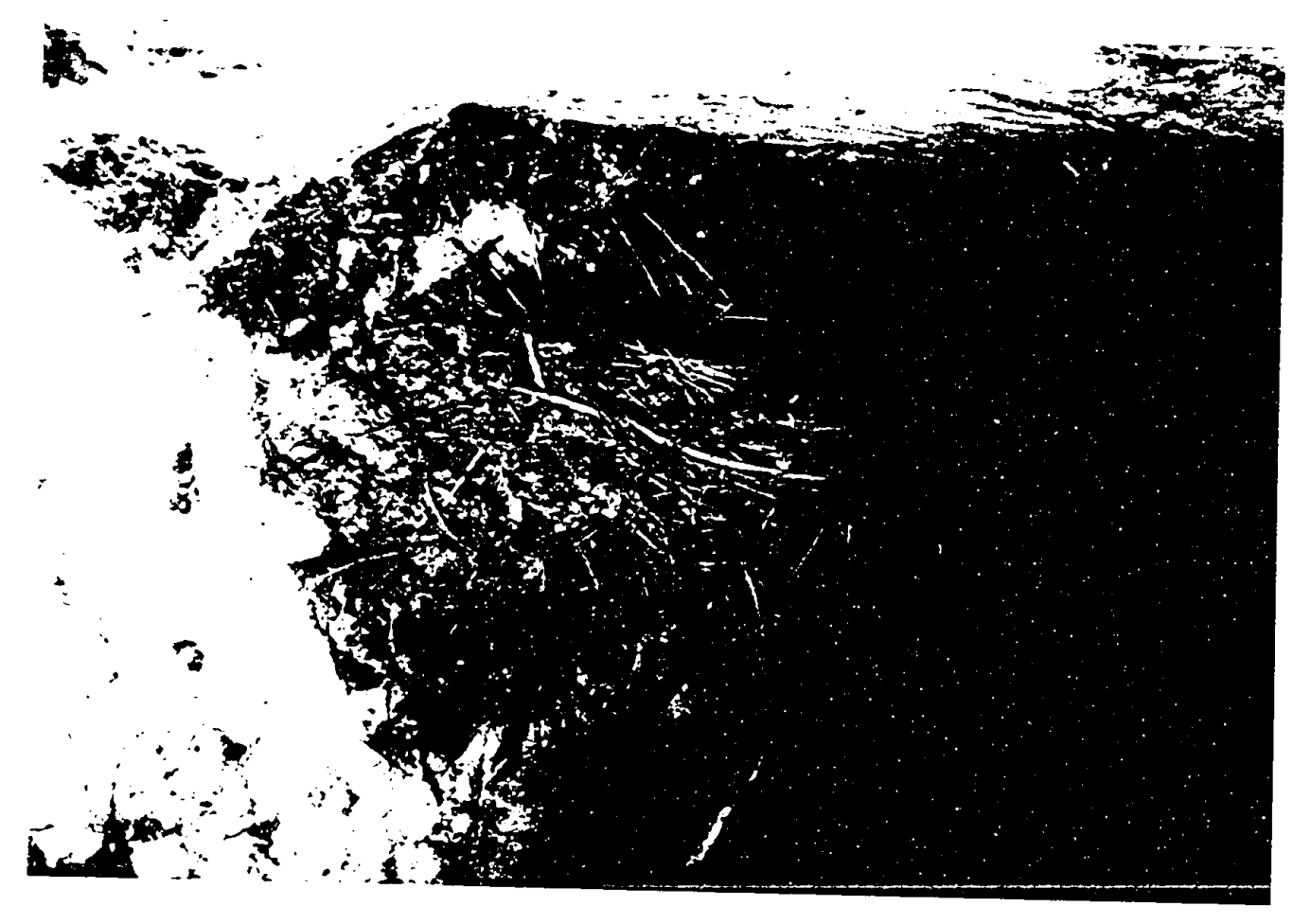

Figure 7. Newly constructed Black Phoebe nest shown in a typical nest site on the study area. 
birds, and in many nests the relative proportions of mud and plant material did not change from base to rim. In others, however, the rim and occasionally the entire upper two-thirds of the cup consisted of only tightly woven plant fibers. When reconstructing old nests the birds always started by building up the rim of the nest with fresh mud and then relining the nest.

Nest Lining. - Nests were lined with a pad of tightly woven plant fibers, the thickness of which varied from approximately 10 to $20 \mathrm{~mm}$. Occasionally, manmade fibers were also incorporated into the nest lining and in one case, these fibers were responsible for the strangulation and death of a nestling. In several instances, when females relined old nests they would cover any unhatched eggs left remaining in the nest from other seasons or nesting attempts.

Nest Dimensions. - Dimensions of representative nests are summarized in Table 1 and the relationship of each dimension to the nest are shown in Figure 8. Nest size variation was greatest in height and width.

Nest Placement.-All nests were located on one of the verical walls of the culvert under the crossover and within $2.25 \mathrm{~m}$ of an entrance. Nests were usually placed within $70 \mathrm{~mm}$ of the crossover ceiling (Figure 9). In the five meter crossovers, nests tended to be located near the center of the crossover. Nests were typically placed above the high water mark even if the culver was dry when the nest was constructed. Placement near the ceiling made nests difficult to detect from the outside due to the darkened crossover interior and the interference caused by an abundance of black widow spider webs and moth cocoons where the ceiling and walls converged.

Re-use of Old Nests. - In order to facilitate observations of new nest construction, old nests were removed from the following nest sites: $2,3,4$, and 12 , during the first week of March in 1989. In 1990, old nests were removed from nest sites 
Table 1. Nest dimensions for several nests measured prior to laying in 1989 and 1990. All dimensions are in $\mathrm{mm}$ and correspond to Figure 8. measurement mean $(\mathrm{mm})$

\begin{tabular}{lccl}
\multicolumn{1}{c}{ measurement } & mean $(\mathrm{mm})$ & range & $n$ \\
\hline Height & 130 & $80-210$ & 8 \\
Width & 100 & $90-120$ & 8 \\
Depth & 125 & $100-170$ & 8 \\
Cup diameter & 65 & $63-68$ & 3 \\
Cup depth & 31 & $30-33$ & 3 \\
\hline
\end{tabular}




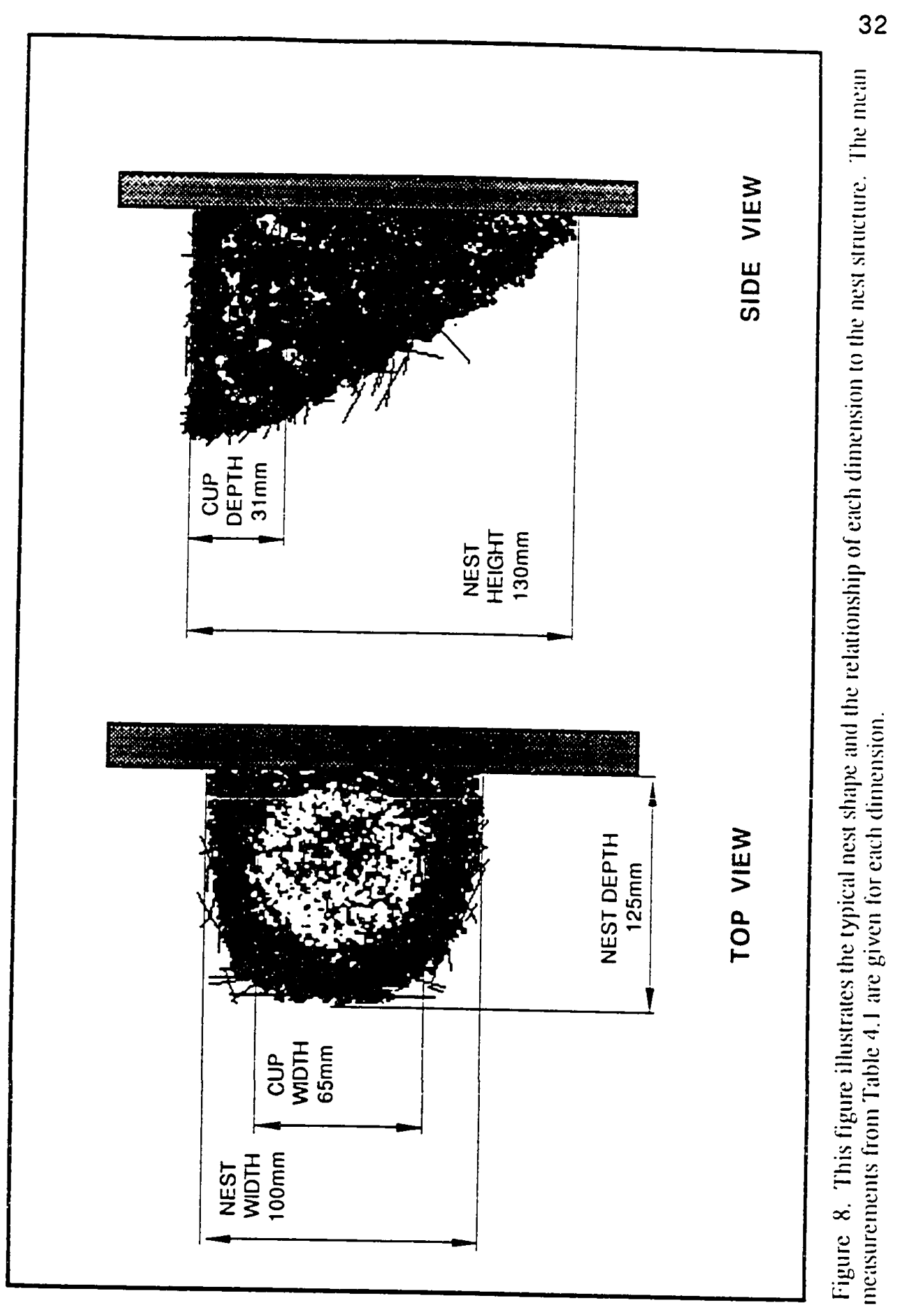




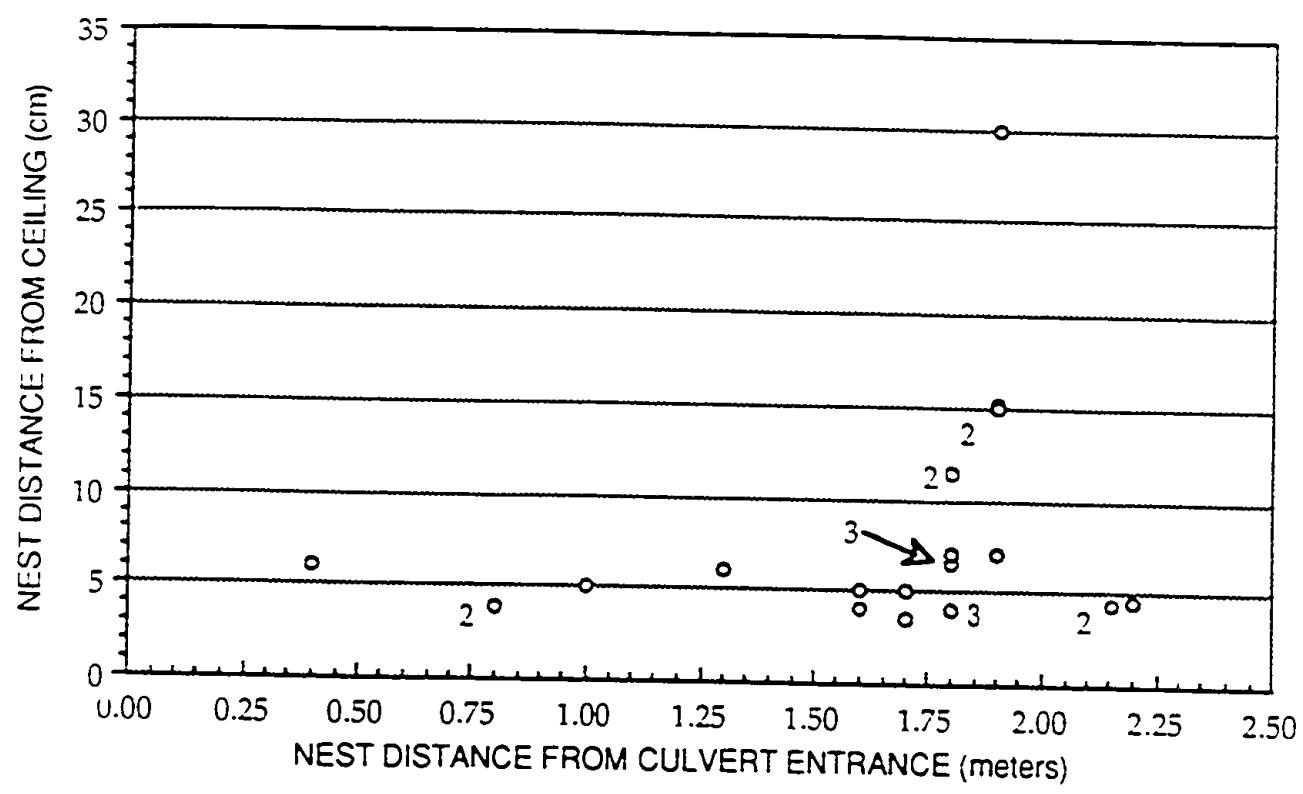

Figure 9. Placement of nests in concrete culvers. Distance from the top of the nest rim to crossover ceiling and distance of nest from crossover entrance are indicated. Numbers next to data points indicate more than one nest at that position. 
14 and 16. The remaining nests were monitored for nest re-use and duration of the refurbishment period. Data for nest re-use were combined for 1989 and 1990 due to the small sample size. Most pairs of Black Phoebes clearly favored the re-use of old nests. Eight out of ten pairs chose to rebuild old nests in their first nesting attempt of each season. Of the 13 pairs making a second nesting attempt 11 pairs chose to rebuild old nests.

\section{Nest Building Behavior}

Gathering Behovior.-Several observations of nest material gathering behavior are summarized below. During the nest building phase of 1989 and 1990, parts of the culver held no standing water. During this period, mud and plant matter which had settled to the bottom of the culvert were sometimes used as materials for nest construction. During one 75 minute period of observation on April 7, the female at nest site 12 used mud exclusively from the bottom of the culver. This bird typically would drop from the nest to the mud in the culvert below. Mud occasionally mixed with some plant material was scooped up with her bill and pulled from the substrate as the bird pulled backwards with her legs extended and wings fluttering above her back; her tail was usually cocked upwards at a 45 degree angle from horizontal. The bird would then fly directly up to the nest and place the material on the bead she was constructing. During this observation period the male was seen on six occasions attempting to gather material in the same manner. He made two trips to the nest, but did not appear to deposit material. During most of the observation period he remained perched and foraged outside the culvert without vocalizing. The female made 39 trips to the nest with material. She stayed on the nest for periods ranging from 3 to 87 seconds, with an average time on the nest of 32 seconds. The 38 bouts away from the nest ranged in length from 4 to 284 seconds and averaged 79 seconds. The female worked sporadically during this time and would make 5 to 10 trips of short duration (5-70 seconds) away from the nest for nest materials, and then would spend several minutes foraging adjacent to the 
nest site or would fly out of sight into the overflow channel or riparian area and retum several minutes later to the nest. Two or three times the female gathered dry plant stems from plants growing adjacent to the culvert and rearmed to the nest with these materials. In one instance the male chased the female in a short twisting flight as she left the nest. After the chase, the male landed in a willow tree $30 \mathrm{~m}$ east of the nest site and sat gaping with his wings drooped; after several seconds he fluttered back to the nest site and landed, continuing to gape and droop his wings. During this period, the female had continued to gather nest material. Birds were seen at two other nest sites gathering mud and wet vegetation for construction of the nest shell.

The female at nest site 8 was observed gathering mud from a more distant source even though mud was available directly below the nest. This bird travelled from 50 to 75 meters to a patch of mud adjacent to the creek.

Female phoebes were also observed collecting material for the nest lining on several occasions. A female relining an old nest at nest site 6 was observed briefly on two consecutive days collecting nest material in the overflow channel. This bird would fly directly out into the channel and land 40 or 50 yards from the nest in the low weedy growth. The bird would then jump from perch to perch while tilting her head from side to side searching for nest materials. Occasionally, she would tentatively pickup a grass stem or some other object and then a few seconds later discard it for another. Then the bird flew directly back to the nest site with the material. This selection process generally took less than a minute and the bird would frequently retum to the same general area during a given gathering period. At nest site 14 another female was observed making repeated trips to the canopy of a cottonwood tree $30 \mathrm{~m}$ to the east of the nest site for nest lining. The exact nature of the material gathered could not be determined because of the distances involved. 
Nest Construction.-The pace of nest construction varied among individuals and among days. Construction of a new nest typically started with the tentative placement of small mud pellets in a horizontal line 100 to $120 \mathrm{~mm}$ in length at from one to several locations under a given nest site or nest sites. Females might work on several nests for the first few days of the construction period, but by the end of the fourth or fifth day of construction, the female had centered her activities on only one nest. Mud pellets and frequently grass stems or other plant materials were incorporated into a wedge shaped platform extending upwards and outwards from the initial bead. When the platform extended outwards 70 or $80 \mathrm{~mm}$, the bird started forming the nest cup by extending it up from the base of the nest. As the construction of the cup neared the last 20 or $30 \mathrm{~mm}$ towards the top of the rim, the female often tended to incorporate more plant materials into the nest shell. In some nests, the rim was constructed entirely from tightly woven grass stems, but in the majority a mixture of mud and grass extended to the top of the rim.

As the shell neared completion the female started lining the nest cup. When returning from a trip with material the female would frequently land on the rim of the nest momentarily before dropping into the nest cup. After placing the stem or other object on the nest tine bird would sit down in the cup with her tail cocked up at a 45 degree angle and her back level with the rim and rotate from side to side, apparently shaping the inside of the cup.

Temporal Aspects of Nest Construction. - The times required to complete nest construction are summarized in Table 2. Data for 1989 and 1990 were combined and the median date for the start of nest construction was March 15 at Coyote Creek. The earliest date for the start of nest construction for a first nesting attempt was March 4 and the latest date was March 28. 
Table 2. Mean number of days required to construct or reconstruct a nest. Data for 1989 and 1990 are combined.

\begin{tabular}{lccc}
\hline \multicolumn{1}{c}{ nest construction casegory } & days (mean) & std error & $n$ \\
\hline 1st clusch old nest rebuilt & 7.5 & \pm 1.2 & 8 \\
1st clusch new nest & 18.8 & \pm 3 & 6 \\
2nd clutch old nest rebuilt & 5.4 & \pm 1.1 & 5 \\
2nd clutch now nest & 10 & - & 1 \\
\hline
\end{tabular}


Laying Behavior.-The following observations of laying behavior (Tables 3 and 4) were made at nest site 14 during April of 1990. Another observation of laying behavior was made at nest site 13 on April 15 immediately following a nest check. At 0645, I checked to see if the third egg had been laid. Normally, if a bird had been on the nest when I arrived she would have immediately flown off the nest when I entered the culvert, but in this case the bird did not leave her nest until I tried to enter the crossover. I checked the nest and found only two eggs present. The bird landed $30 \mathrm{~m}$ to my south on the top of the culvert wall. When she landed, she immediately fanned her tail and started pumping it slowly up and down in a 30 degree arc. After approximately 15 to 20 seconds she deposited her third egg on the top of the culvert and then flew off. I marked the egg and placed it in the nest.

Temporal Aspects of Laying. - Laying dates for first eggs in first and second clutches are provided in Table 5. The intervals between a) nest completion and laying of the first egg, b) fledging of the first brood and laying of the first egg of the second brood, and c) the time after the destruction of a ciutch or brood to the subsequent laying of the first egg of the replacement clutch are given in Table 6.

All eggs were laid within a few hours of civil sunrise. Selected nests were repeatedly checked at intervals of 15 to 30 minutes until an egg was laid to determine the time of laying. The time of laying of the last egg in a clutch tended to be later than the time of laying of all other eggs (Table 7). Eggs were laid at a rate of one egg per day with the following exceptions. During the period from May 20, 1989 to May 27, 1989, birds at three nest sites skipped laying for one to three days. All three clutches were second clutches: a) at nest site 6 the female laid the fourth egg on May 20 and the fifth egg on May 22 after skipping one day; b) at nest site 8 the female laid her first egg on May 23 and her 
Table 3. Observations of laying behavior of the female at nest site 14 on April 4, 1990. Observations were made from a portable blind that was located $30 \mathrm{~m}$ to the east of the nest site. The position of the blind was such that the nest could be observed directly.

\begin{tabular}{cc}
\hline time & observation \\
\hline 0625 & $\begin{array}{c}\text { Inspected the nest and found two eggs; both phoebes had just arrived at the nest } \\
\text { site as I approached for the nest inspection. }\end{array}$ \\
0627 & $\begin{array}{c}\text { Female flew to the rim of the nest and a few seconds later settled down on the } \\
\text { eggs. }\end{array}$ \\
0631 & The female was sitting quietly. \\
0633 & $\begin{array}{l}\text { Female extended her legs slightly and shuffled from side to side several times } \\
\text { and then settled back down on the nest. }\end{array}$ \\
0635 & The bird stood up and remained motionless for several minutes. \\
0638 & $\begin{array}{l}\text { The female stood up again shuffled from side to side several times while slowly } \\
\text { pumping her tail up and down in an arc of approximately } 30 \text { degrees, at the } \\
\text { same time she briefly raised her wings directly above her back without } \\
\text { extending the primaries and then refolded them, she then rotated her body } \\
\text { 180 degrees and raised her tail slightly before settling down again. At this } \\
\text { point the phoebe appeared to sitting higher in the nest than an incubating } \\
\text { bird would normally sit. }\end{array}$ \\
& The female left the nest and I found a third egg present. The female was on the \\
nest for approximately 15 minutes
\end{tabular}

Table 4. Observations of laying behavior of the female at nest site 14 on April 5, 1990.

Observations were made from a portable blind that was located $30 \mathrm{~m}$ to the east of the nest site. The position of the blind was such that the nest could be observed directly.

\begin{tabular}{|c|c|}
\hline time & observation \\
\hline 0626 & $\begin{array}{l}\text { I arrived at the nest and found three eggs present. I started observations } \\
\text { immediately. }\end{array}$ \\
\hline 0630 & $\begin{array}{l}\text { The female came to the nest, but remained perched on the rim. } \\
\text { Female settled down into the nest. }\end{array}$ \\
\hline $\begin{array}{l}0633 \\
0639\end{array}$ & $\begin{array}{l}\text { Female was sitting quietly. } \\
\text { The bird shuffled from side to side and raiced her win }{ }^{2} \text { a }\end{array}$ \\
\hline 0740 & $\begin{array}{l}\text { The female stood up in the nest with her tail pumping and remained in this } \\
\text { position. }\end{array}$ \\
\hline 0643 & $\begin{array}{l}\text { Female raised her wings above her back two times in rapid succession and then } \\
\text { again } 10 \text { seconds later, she immediately followed the wing raising with a } \\
\text { vigorous shake of her body the first time. }\end{array}$ \\
\hline $\begin{array}{l}0645 \\
0645\end{array}$ & $\begin{array}{l}\text { The female lowered herself down on the nest. } \\
\text { Female again raised her wings above her back once, but is otherwise sitting } \\
\text { quietly. }\end{array}$ \\
\hline $\begin{array}{l}0646 \\
0649 \\
0650\end{array}$ & $\begin{array}{l}\text { The bird has started to look around actively after a period of inactivity. } \\
\text { Female is sitting quietly. } \\
\text { Female left the nest and a fourth egg is present. The female was on the nest on } \\
\text { this occasion for approximately } 19 \text { minutes. }\end{array}$ \\
\hline
\end{tabular}


Table 5. Provided are the ranges of first egg dates for first and second clutches for the years 1989 and 1990. The number of clutches in each sample (n) are given next to the range.

\begin{tabular}{lcc}
\hline \multicolumn{1}{c}{ clutch number } & year & Ist egg dates-range; $(n)$ \\
\hline Ist clutch & 1989 & March 18-May 6; (7) \\
Ist clutch & 1990 & March 18-April 28; (8) \\
2nd clutch & 1989 & May 8-May 31; (6) \\
2nd clutch & 1990 & April 13-May 24; (6) \\
\hline
\end{tabular}

Table 6. Provided is a summary of the mean number of days before the first egg was laid under the following conditions: after completion of nest construction for the first nesting attempt of the season, after the first brood fledged, and after a nest was destroyed. Data for 1989 and 1990 are combined.

\begin{tabular}{lcccc}
\hline \multicolumn{1}{c}{ category } & $\begin{array}{c}\text { days } \\
\text { (mean) }\end{array}$ & $n$ & $\begin{array}{c}\text { std } \\
\text { etror }\end{array}$ & range \\
\hline number of days after nest completion & 4.4 & 13 & \pm 0.6 & $2-8$ \\
number of days after the first brood fledges & 12.4 & 8 & \pm 1.6 & $7-18$ \\
number of days after nest destruction & 9.8 & 5 & \pm 2.6 & $6-11$ \\
\hline
\end{tabular}

Table 7. The mean time of laying in minutes after civil sunrise of the last egg laid within a clutch and all others a within a clutch. Data are from 1990 and include first and second clutches.

\begin{tabular}{lcccc}
\hline \multicolumn{1}{c}{ egg \# } & $\begin{array}{c}\text { minutes after sunrise } \\
\text { (mean) }\end{array}$ & sid error & range & $n$ \\
\hline Last Egg & 173 & \pm 24 & $56-252$ & 7 \\
All Other Eggs & 91 & \pm 15 & $13-235$ & 18 \\
\hline
\end{tabular}


second egg on May 27 after skipping three days; c) at nest site 10 the female laid her third egg on May 24 and her fourth egg on May 27 after skipping two days.

\section{The Egg: Description, Measurements and Variation.}

General description.-Freshly laid Black Phoebe eggs were pure white with a moderately glossy appearance. They were smooth in texture and the yolk was faintly visible through the semi-translucent shell (Figure 10). After they had been incubated for approximately 4-5 days live eggs lost their translucence (which remained in nonliving eggs) and took on a more opaque appearance.

In most clutches, the last egg and sometimes the penultimate egg had a cap of sparsely distributed, small to medium sized, reddish-brown spots on the large end. All eggs were unmarked in 3 of the 26 clutches. In 4 of the 26 clutches all eggs were spotted to some degree.

The shapes of the eggs examined varied somewhat, but the majority were classified as ovate or short ovate or occasionally short subelliptical (Palmer 1962).

Dimensions.-All measurements are from 123 eggs from 24 complete clutches examined during the course of this study. Lengths and breadths (width of egg at the widest point) were measured to within $0.01 \mathrm{~mm}$ with a metric dial caliper and actual weights to within $0.2 \mathrm{mg}$ with a precision balance. The mean egg size was $18.90 \mathrm{~mm} \times 14.56 \mathrm{~mm}$; the largest egg measured $20.07 \mathrm{~mm} \times 15.31 \mathrm{~mm}$ and the smallest $17.71 \mathrm{~mm} \times 13.64 \mathrm{~mm}$ Elongation is egg length divided by egg breadth. Dimensions for all eggs laid in 1989 and 1990 are summarized in Tables 8 and 9, respectively.

Actual volumes were not measured due to technical difficulties of measurement in the field, but were calculated using the formula $\left\{\right.$ Volume $\left.=\mathrm{Kv}\left(\mathrm{LB}^{2}\right)\right\}$ where $\mathrm{Kv}$ is a constant equaling $0.51, \mathrm{~L}$ is egg length and B is egg breadth (Hoyt 1979). This formula provides estimates of volume within $2 \%$ of actual volumes for egg shapes such as those of the Black 


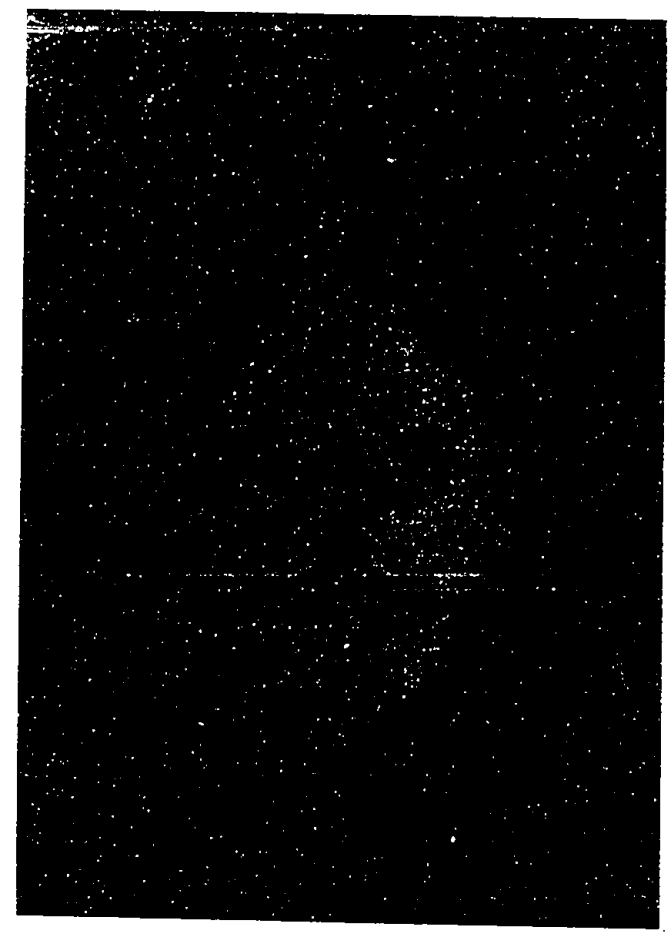

A

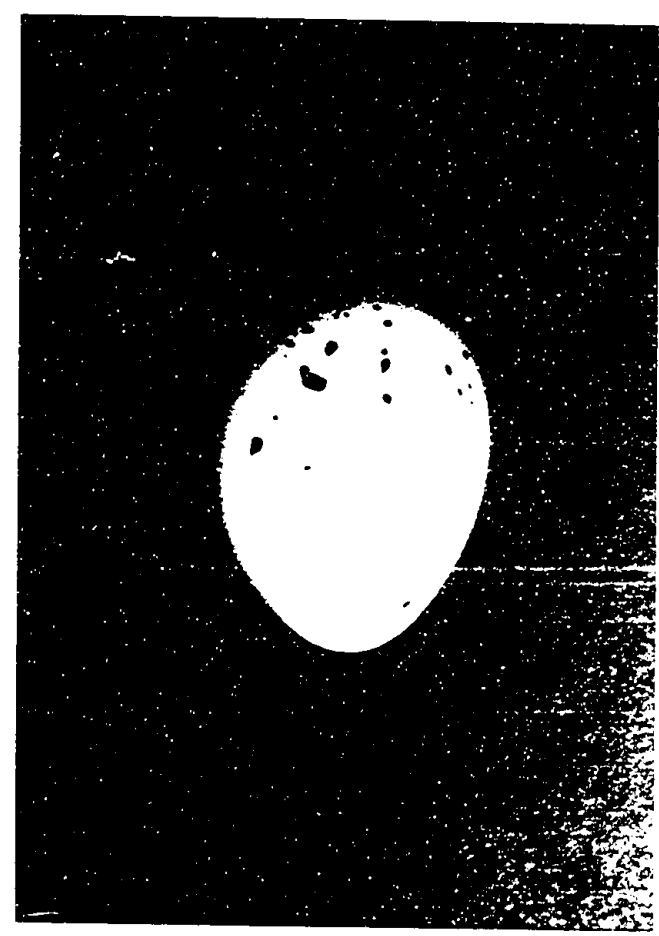

B

Figure 10. Photo A shows a freshly laid Black Phoebe egg that has no spotting (score 0). Photo B shows a freshly laid Black Phoebe egg with "heavy" spotting (score 2). 
Table 8. Characteristics of all eggs laid in 1989. Calculated fresh egg weights are also given.

\begin{tabular}{cccccc}
\hline & Length(mm) & Breadth $(\mathrm{mm})$ & Elongation & Volume(cc) & $\begin{array}{c}\text { Calc. Wt } \\
\text { (gm) }\end{array}$ \\
\hline mean & 18.81 & 14.49 & 1.30 & 2.018 & 2.0709 \\
max & 20.14 & 15.24 & 1.38 & 2.386 & 2.448 \\
min & 17.71 & 13.64 & 1.22 & 1.680 & 1.724 \\
sid error & \pm 0.08 & \pm 0.04 & \pm 0.04 & \pm 0.018 & \pm 0.019 \\
$n$ & 63 & 63 & 63 & 63 & 63 \\
\hline
\end{tabular}

Table 9. Characteristics of all eggs laid in 1990. Calculated fresh egg weights are also given.

\begin{tabular}{cccccc}
\hline & Length $(\mathrm{cm})$ & Breadth $(\mathrm{cm})$ & Elongation & Volume $(\mathrm{cc})$ & $\begin{array}{c}\text { Calc. Wt. } \\
(\mathrm{gm})\end{array}$ \\
\hline mean & 18.99 & 14.63 & 1.30 & 2.075 & 2.129 \\
$\max$ & 20.07 & 15.31 & 1.41 & 2.399 & 2.462 \\
$\min$ & 17.50 & 14.03 & 1.20 & 1.851 & 1.899 \\
std error & \pm 0.07 & \pm 0.04 & \pm 0.05 & \pm 0.015 & +0.015 \\
$n$ & 59 & 60 & 59 & 59 & 59 \\
\hline
\end{tabular}


Phoebe (Hoyt 1979, Preston 1974). Egg voiumes were used as the primary measure of egg size.

Fresh egg weights were needed to calculate weight loss over the incubation period. Fresh egg weights were calculated because it was not practical to measure each egg on the day it was laid. Eggs start losing weight on the day of laying and continue to lose weight throughout incubation. The densities of five eggs, which were weighed on the moming they were laid, were calculated by dividing the calculated volume by the fresh weight. The mean density of these eggs were then calculated (mean density $1.026 \mathrm{gm} / \mathrm{cc}$, std error \pm 0.002 , and range 1.022-1.031). This value was used to calculate fresh egg weights (1.026 $x$ Egg volume) of all other eggs. This method yielded estimated fresh egg weights which were within $0.8 \%$ ( $n=5$, range $0.3-0.8 \%$ ) of the actual measured weights. Another method (Hoyt 1979) for estimating fresh egg weights was tried, but yielded less satisfactory results ( $2 \%$ variation from actual).

Variation in Egg Size.-Differences in egg size (volume) were examined for clutches in 1989 and 1990 by two-way ANOVAs and multiple regression. Egg size tended to increase with laying sequence in 1990, and clutch number in 1989 and 1990. Analysis of egg volume versus laying sequence and clutch number indicated that egg volume did not vary significantly with laying sequence (Figure 11) (two-way ANOVA; $F=0.375, \mathrm{df}=4$, $p=0.825$ ), but did vary significantly between eggs in first and second clutches (Table 10) (two-way ANOVA; $F=6.021, \mathrm{df}=1, p=0.018$ ) in 1989. Multiple regression analyses supported the ANOVA results; egg volume did not vary significantly with laying sequence (T- test; $T=0.873$, df $=2, p=0.4$ ), but did vary significantly with clutch number (T-test; $T=2.536, \mathrm{df}=2, p=0.015$ ).

Analyses of 1990 data were identical to those run on the 1989 data. Results of ANOVA indicated that egg volume did not vary significantly with laying sequence 


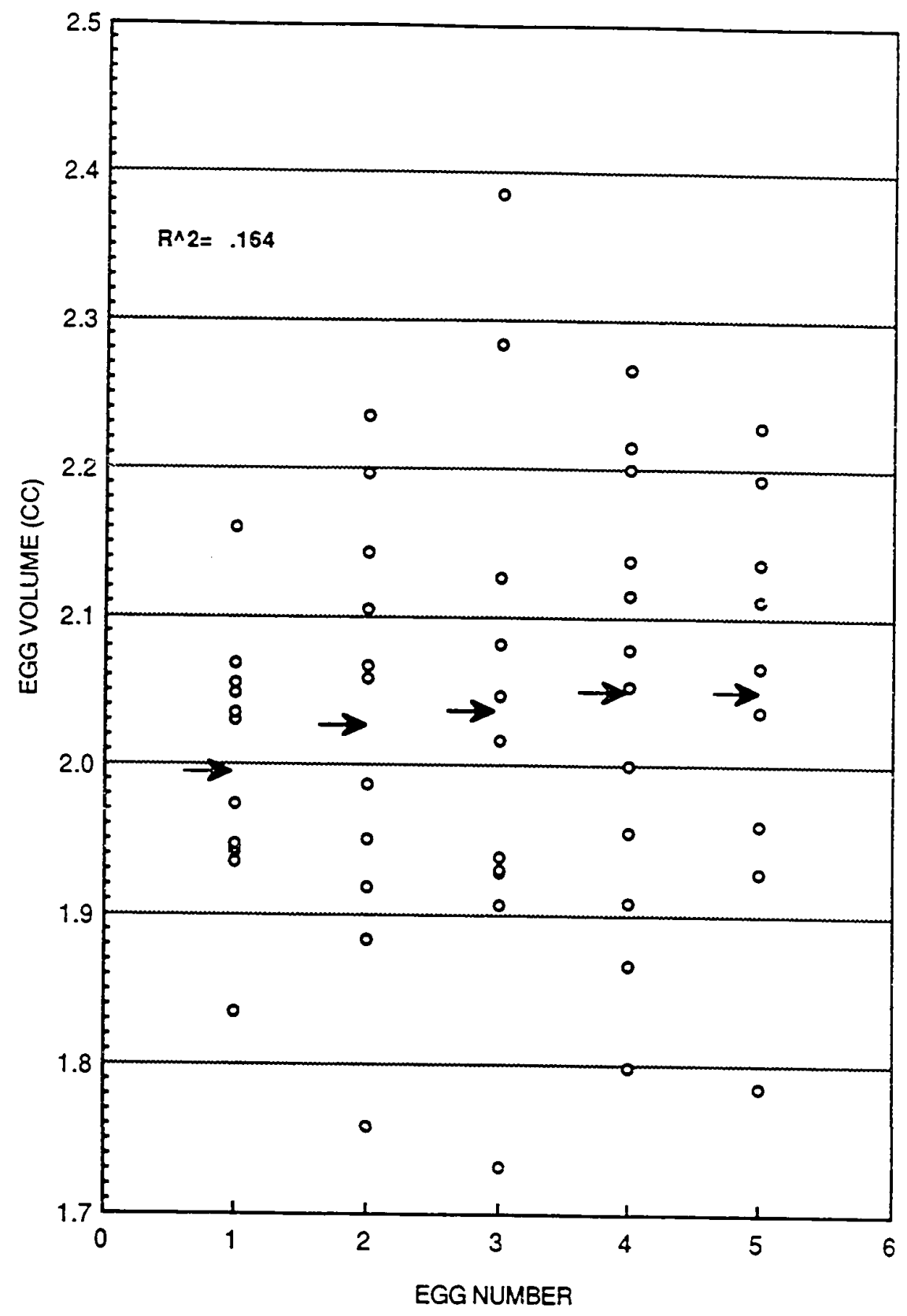

Figure 11. Egg volume as a function of laying sequence for all complete clutches in 1989. Arrows indicate mean values. 
Table 10. Variation in mean egg volume (cc) with laying sequence and clutch number for 1989.

\begin{tabular}{cccccc}
\hline \multicolumn{6}{c}{ lst clutches } \\
& egg\#1 & egg\#2 & egg\#3 & egg\#4 & egg\#5 \\
\hline egg volume & 1.963 & 2.003 & 2.013 & 2.037 & 2.001 \\
std error & \pm 0.032 & \pm 0.036 & \pm 0.050 & \pm 0.072 & \pm 0.086 \\
$n$ & 6 & 6 & 7 & 6 & 4 \\
\hline \multicolumn{7}{c}{2 2nd clutches } \\
\hline egg volume & 2.032 & 2.057 & 2.044 & 2.061 & 2.129 \\
std error & \pm 0.034 & \pm 0.089 & \pm 0.067 & \pm 0.052 & \pm 0.040 \\
$n$ & 6 & 5 & 5 & 6 & 4 \\
\hline
\end{tabular}


(Figure 12) (two-way ANOVA; $F=1.240, \mathrm{df}=4, p=.307$ ), but variation in egg volume with clutch number was significant (Table 11) (two-way ANOVA; $F=4.025$, df $=1, p=$ 0.05 ). In contrast, multiple regression analyses of these data indicated that both variation in egg volume with: laying sequence (laying sequence; $T=2.128, \mathrm{df}=55, p=0.038$ ), and clutch number (clutch number, $T=2.386, \mathrm{df}=55, p=0.020$ ) were significant.

Analysis of combined data from 1989 and 1990 indicated there was no significant difference in egg volumes with laying sequence within first and second clutches among years (Figure 13) (two-way ANOVA 1st clutches; laying sequence $F=0.430, \mathrm{df}=4, \bar{p}=$ 0.786 , within clutches $F=2.647, \mathrm{df}=1, p=0.110,2 \mathrm{nd}$ clutches; laying sequence $F=$ $0.089, \mathrm{df}=4, p=.985$, within clutches $F=0.257, \mathrm{df}=1, p=.615$ ) Similarly no significant difference was found in egg volume with laying sequence among years (twoway ANOVA; $F=1.263, \mathrm{df}=4, p=.290, \mathrm{~T}$-test; $T=1.973, \mathrm{df}=106, p=0.051$ ). Significant differences were found in egg volume between first and second clutches among years (Table 12) (two-way ANOVA; $F=11.643, \mathrm{df}=1, p=0.001, \mathrm{~T}$-test; $T=3.526$, df $=106, p=0.001)$

Variation in Egg Coloration.-The presence and absence of spots on eggs varied significantly with laying sequence ( $G=22.095$ with the Williams correction factor, $\mathrm{df}=8$, $p<0.005$ ). When clutches were separated by clutch size, into those with four eggs or five eggs, only the five egg clutches showed a significantly different distribution of spotting with laying sequence ( 5 egg clutches, $G$ adj $=15.623, \mathrm{df}=8, p<0.05 ; 4$ egg clutches, $G$ $\operatorname{adj}=3.863, \mathrm{df}=6, p>0.5$ ). Of the 16 five egg clutches examined (Table 13), $87.5 \%$ of the last eggs were spotted (62.5\% were moderately spotted and $25 \%$ lightly spotted) and $25 \%$ of the penultimate eggs were sported. Of the remaining 48 eggs only $21 \%$ were lightly spotted and none were moderately spotted. In the 8 four egg clutches 


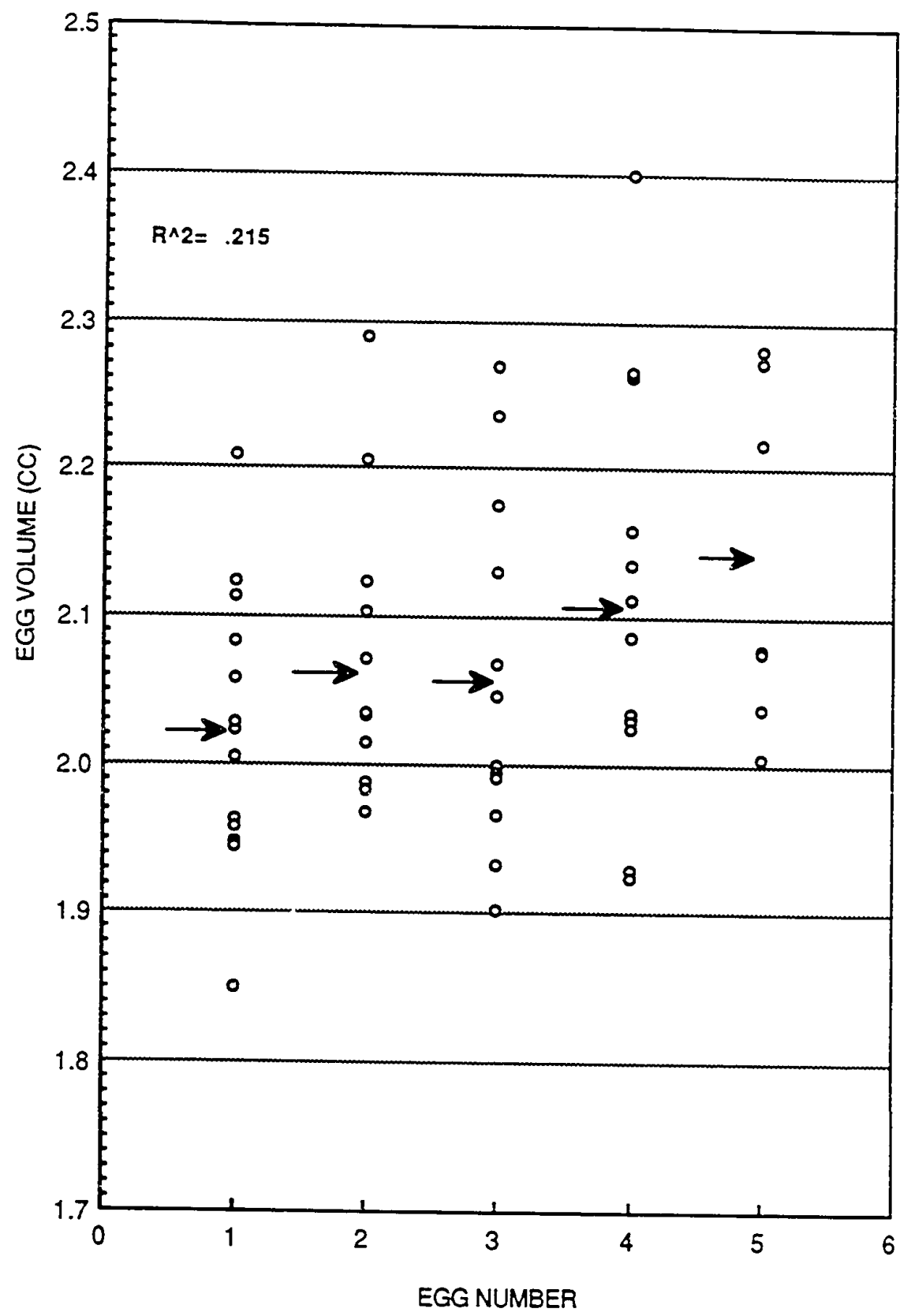

Figure 12. Egg volume as a function of laying sequence for all complete clutches in 1990. Arrows indicate mean values. 
Table 11. Variation in mean egg volume (cc) with laying sequence and clutch number for 1990.

\begin{tabular}{cccccc}
\hline \multicolumn{6}{c}{ lst clutches } \\
& $e g g \# 1$ & $e g g \# 2$ & egg\#3 & egg\#4 & egg\#5 \\
\hline egg volume & 1.991 & 2.014 & 2.031 & 2.079 & 2.145 \\
std error & \pm 0.029 & \pm 0.021 & \pm 0.037 & \pm 0.040 & \pm 0.063 \\
$n$ & 8 & 7 & 6 & 7 & 4 \\
\hline \multicolumn{7}{c}{2 nd clutches } \\
\hline egg volume & 2.076 & 2.155 & 2.087 & 2.140 & 2.129 \\
std error & \pm 0.044 & \pm 0.039 & \pm 0.052 & \pm 0.051 & \pm 0.073 \\
$n$ & 5 & 6 & 6 & 6 & 3 \\
\hline
\end{tabular}




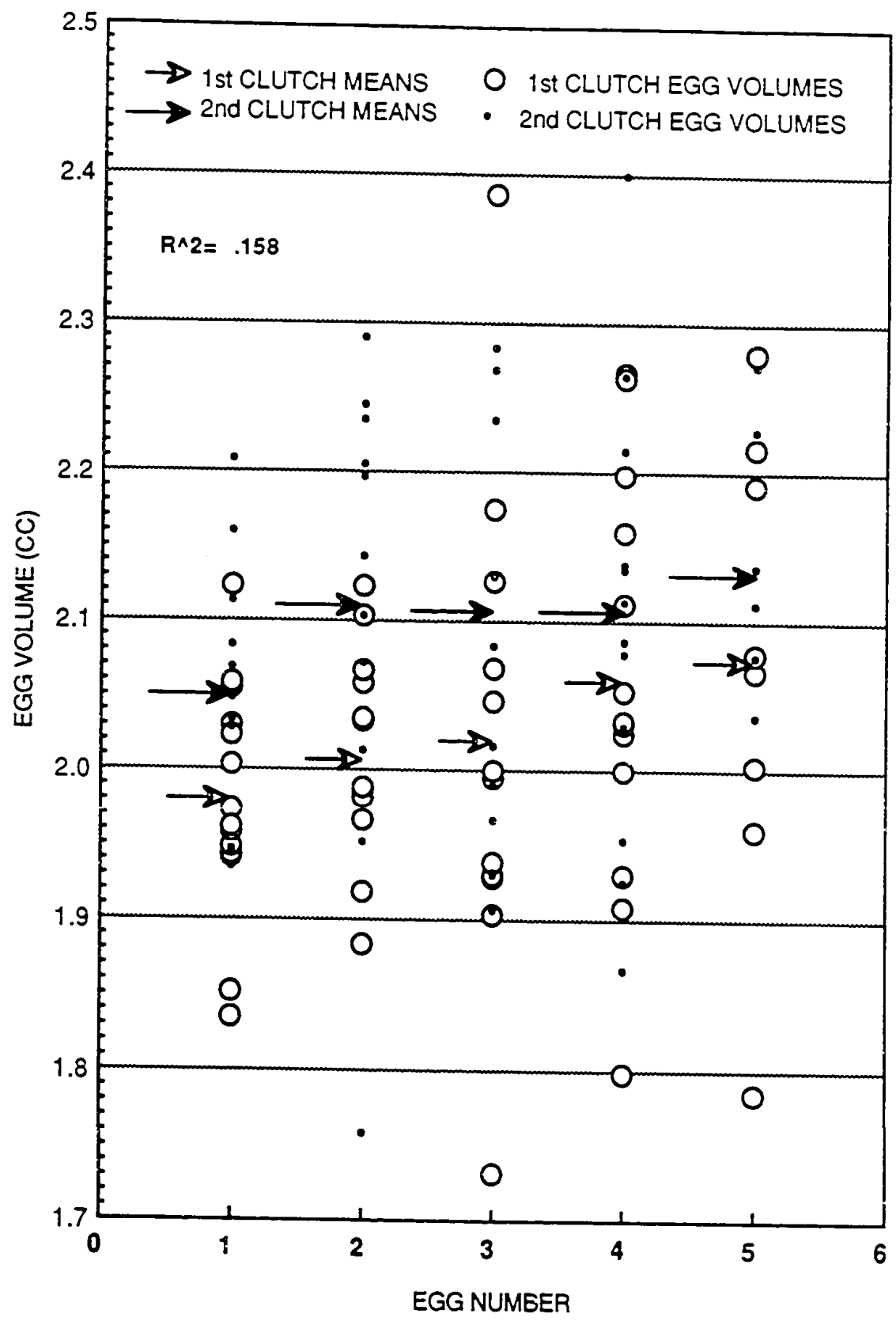

Figure 13. Egg volume as a function of laying sequence (egg number) and clutch number are presented. Data for 1989 and 1990 are combined. Egg volume means are shown with arrows as indicated for 1 st and 2nd clutches. 
Table 12. Mean egg volumes as a function of laying sequence and clutch number. Data for 1989 and 1990 are combined.

\begin{tabular}{cccccc}
\hline \multicolumn{7}{c}{ lst clutches } \\
& egg\#1 & egg\#2 & egg\#3 & egg\#4 & egg\#5 \\
\hline egg volume & 1.979 & 2.009 & 2.021 & 2.060 & 2.073 \\
std error & \pm 0.02 & \pm 0.019 & \pm 0.043 & \pm 0.039 & \pm 0.057 \\
$n$ & 14 & 13 & 13 & 13 & 8 \\
\hline \multicolumn{7}{c}{$2 n d$ clutches } \\
egg volume & 2.052 & 2.110 & 2.067 & 2.074 & 2.129 \\
std error & \pm 0.027 & \pm 0.047 & \pm 0.043 & \pm 0.037 & \pm 0.035 \\
$n$ & 11 & 11 & 11 & 11 & 7 \\
\hline
\end{tabular}

Table 13. The frequency and amount of spotting in 16 five egg clutches for 1989 and 1990 combined. The amount of spotting was scored from 0 to 2 , with 0 indicating no spotting present, 1 indicating light spotting and 2 indicating moderate spotting. See methods section for definition of spotting categories. The frequency of occurrence is presented below each egg number.

\begin{tabular}{cccccc} 
& \multicolumn{5}{c}{ frequency of spotting } \\
spotting score & egg\#1 & egg\#2 & egg\#3 & egg\#4 & egg\#5 \\
\hline 2 & 0 & 0 & 0 & 1 & 10 \\
1 & 2 & 4 & 4 & 3 & 4 \\
0 & 14 & 12 & 12 & 12 & 2 \\
\hline
\end{tabular}


examined there was a lesser tendency for the last egg to be spotted and spotting in earlier eggs was more prevalent (Table 14).

\section{Clutch Size}

Variation in Clusch Size.-Mean clutch size was calculated for all complete clutches for the years 1988, 1989, and 1990 (Table 15). Phoebes always laid clutches of four or five eggs. No significant differences were detected in clutch size between first and second clutches within (paired samples T-test: 1988-insufficient data, $1989 T=.542$, df $=5, P=$ $.611,1990 T=.535, \mathrm{df}=4, p=.621$ ) and between years (paired samples $T$-test, $T=$ $.808, \mathrm{df}=15, p=.432$ ).

\section{Incubation}

General Aspects. - Observations were made on incubating females at several nest sites during 1989 and 1990. Male phobes were not seen participating in incubation and thus all behavioral observations refer to females. In 1990, three females were observed continuously on four different days for a total of 35 hours. Observation periods ranged from six to ten hours in length.

Rhythm of Incubation.-Figure 14 and Table 16 summarize the cycle of incubation during each of the four observation periods. Attentive bouts averaged approximately two times the length of inattentive bouts. Thus attentive bouts accounted for $63 \%$ to $68 \%$ of the total duration of the observation periods. Statistical analyses of incubation thythm data were not pursued due to the small number of observations and the significant number of confounding variables such as: time of day, individual observed, air temperature, and day of incubation.

Incubation Behavior.-The behavior of incubating females and attendant males was observed for a total of 60 hours in 1989 and 1990. Males were not seen incubating 
Table 14. The frequency and amount of spotting in 8 four egg clutches for 1989 and 1990 combined. The amount of spotting was scored from 0 to 2 , with 0 indicating no spotting present, 1 indicating light spotting and 2 indicating moderate spotting. See methods section for definition of spotting categories. The frequency of occurrence is presented below each egg number.

\begin{tabular}{ccccc} 
& & \multicolumn{4}{c}{ frequency of spotting } \\
spotting score & egg\#1 & egg\#2 & egg\#3 & egg\#4 \\
\hline 2 & 2 & 2 & 1 & 5 \\
1 & 1 & 0 & 2 & 2 \\
0 & 5 & 6 & 5 & 1 \\
\hline
\end{tabular}

Table 15. Clutch sizes for first and second clutches laid in 1988, 1989 and 1990

\begin{tabular}{ccccccc}
\hline & 1988 & 1988 & 1989 & 1989 & 1990 & 1990 \\
& 1st clutch & 2nd clutch & 1st clutch & 2nd clutch & 1st clusch & 2nd clutch \\
\hline mean & 4.29 & 4.40 & 4.86 & 4.67 & 4.57 & 4.50 \\
std error & \pm 0.19 & \pm 0.25 & \pm 0.14 & \pm 0.21 & \pm 0.20 & \pm 0.22 \\
$n$ & 7 & 5 & 7 & 6 & 7 & 6 \\
\hline
\end{tabular}



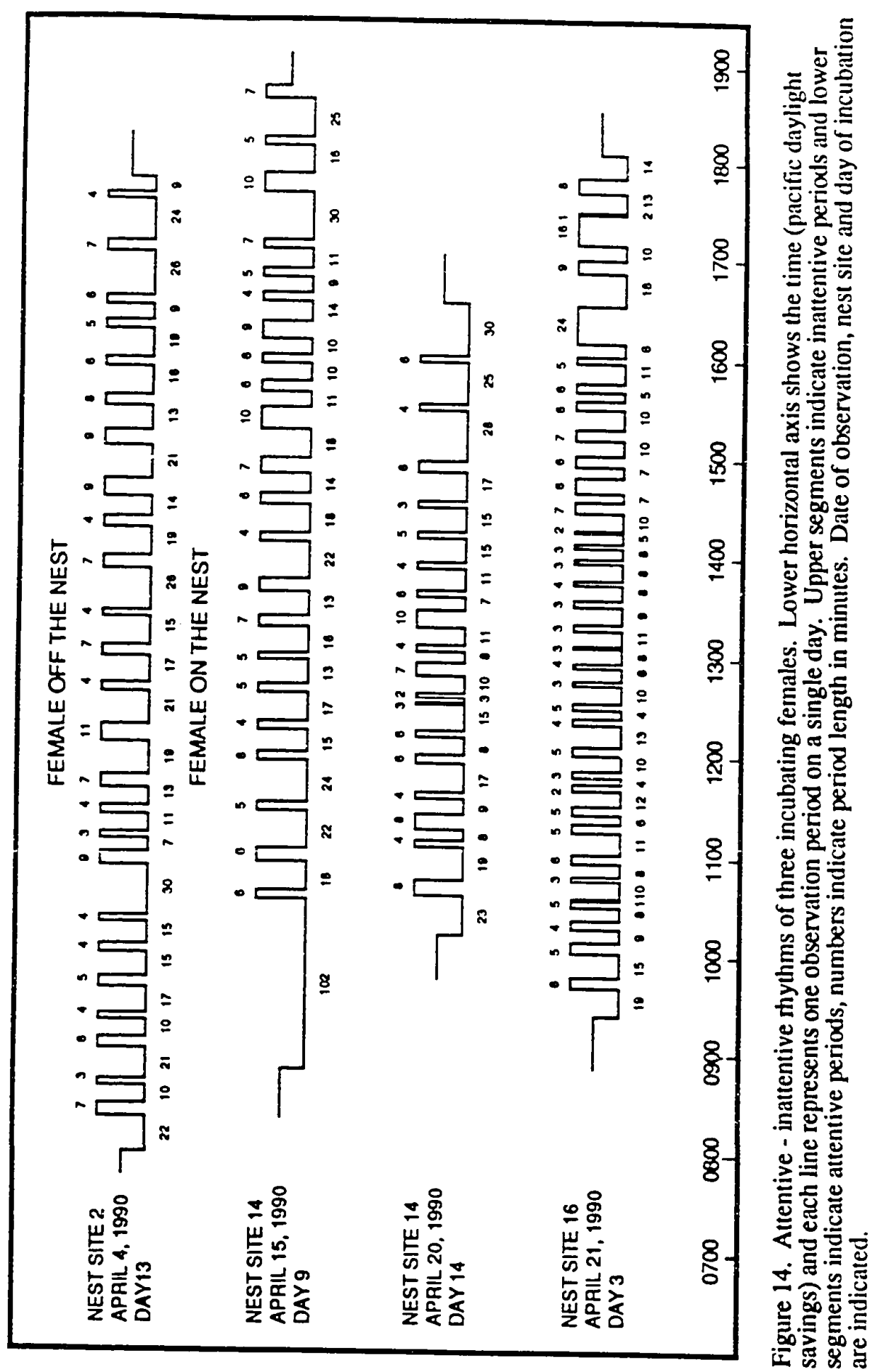

Table 16. Summary of temporal aspects of incubation at three nest sites over a period of
four days in 1990 .

\begin{tabular}{|c|c|c|c|c|c|c|c|c|}
\hline $\begin{array}{c}\text { nest site } \\
\text { day of incubation } \\
\text { Location of female rel. to nest }\end{array}$ & on & off & on & off & on & off & on & off \\
\hline average bout length (minutes) & 12.7 & 5.9 & 13.2 & 6.3 & 10.3 & 5.4 & 9.1 & 5.4 \\
\hline range (minutes) & $7-30.5$ & $3-11$ & $9-102$ & $4-10.3$ & 3-29.6 & $1.8-10$ & 1.5-18 & $0.3-24$ \\
\hline total number of bouts & 26 & 26 & 22 & 22 & 19 & 18 & 36 & 35 \\
\hline \# bouts from 10:00 - 16:00 & 16 & 16 & 15 & 15 & 18 & 18 & 29 & 29 \\
\hline percent of total time & 68 & 32 & 68 & 32 & 66 & 34 & 63 & 37 \\
\hline
\end{tabular}


eggs or entering the nest during the course of these observations. The behavior of females arriving at, and entering the nest varied with individual and incubation bout. Typically, when returning to the nest, females landed on the top of the culvert within a few meters of the nest or in the bottom of the culvert directly under the nest. After a brief pause the female then flew directly to the rim of the nest and settled onto the eggs within a few seconds. Occasionally, females flew directly to the nest rim from the foraging area where they were perched. If a potential nest predator such as a California ground squirrel (Spermophilus beecheyi) or Northern Mockingbird (Mimus polyglottos) was in the vicinity, the female would remain perched nearby the nest site, but would not enter the nest.

Upon arriving at the nest, females perched on the rim and briefly inspected the nest contents before dropping into the nest. Typically, females then settled down onto the eggs with a sideways shuffling motion. In the normal incubating posture, the top of the female's back was approximately level with the top of the nest cup and her tail extended out of the cup at a 45 degree angle. Females on the nesi appeared to remain alert and frequently moved their heads while incubating. When an intruder appeared, females became motionless and remained so until the intruder moved away.

Occasionally, flying insects were taken and eaten by the incubating bird if they approached close enough to be taken without interrupting incubation. Insects were simply snapped out of the air as they flew by or gleaned from the nest if they landed on it. In one instance, a female from nest site 4 ended a bout and left the nest to take a two centimeter long moth that was fluttering under the crossover. At nest site 2, however, the female repeatedly ignored a black widow spider which moved around on the culvert wall within 10 centimeters of the nest. 
While on the nest, females occasionally stood to inspect, turn, or probe the eggs. From 1300 to 1600 the female at nest site 14 stood up off the eggs and probed them eight times. During the period from 1000 to 1300 the same female showed no such interest and did not probe the eggs at all. Subsequent investigation of the nest revealed that eggs one, two and three were pipped. Most observations suggest that the eggs are inspected only infrequently during an incubation bout.

Females sometimes became more active just before terminating an incubation bout. As mentioned above, termination of an incubation bout was sometimes initiated by the appearance of a prey species. Male phoebes also prompted females to terminate incubation bouts on numerous instances. Males were usually perched directly above the nest site for the majority of the day. From time to time males would either make a short looping flight into the culvert where they could see the nest or fly under the crossover and hover in front of the nest as the female incubated. These behaviors elicited several responses. On the appearance of the male, the female frequently flew off the nest and immediately started foraging nearby. About as often, the female remained on the nest. Sometimes when the female did not leave the nest in response to the male, the male repeated the flights. After the third or fourth flight, the female frequently left the nest. On a few occasions, when the male repeatedly hovered in front of the nest, he received an aggressive snap from the female who remained on the nest.

After leaving the nest, the feriale either perched nearby the nest for several minutes and preened, or immediately started to forage in her preferred area. Foraging bouts were intense but short in duration. During observed incubation recesses on one afternoon the female at nest site 14 made 28 foraging flights in 4 minutes, 38 foraging flights in 4 minutes and 12 foraging flights in 2 minutes. Females did not interact directly with males on most recesses from the nest. Sometimes a female would engage in a short chase with 
the male as she left the nest, but the extent of most social behavior consisted of foraging within ten meters or so of her mate.

Males spent much of their time perched directly over the nest site either foraging, preening, singing or perching. Males were seen at the nest on only two accasions, and in both instances this involved momentary landings on the rim of the nest followed by a return to their regular perch above the crossover. In one case, the male was immediately supplanted from the nest by the female. No attempts to sit in the nest or warm the eggs by maies were observed. Males aggressively defended a small area 3-5 meters from the nest from potential nest predators and nest site competitors. A male at nest site 14 was observed to aggressively snap his bill while flying at a California ground squirrel which had walked to within 3 meters of the nest site along the top of the culvert; the female remained frozen on the nest during this encounter and the ground squirrel dropped off of the culvert into the grass following the waming. On two other occasions, as a mockingbird walked along the culvert towards the nest site, the male phoebe dropped from his perch above the nest site and landed on the culvert between the nest and the intruder, effectively blocking its further advance. At nest site 14, a dead Song Sparrow (Melospiza melodia) was found directly below an active phoebe nest, but the cause of its death is unknown. Several interactions with Barn Swallows (Hirundo rustica) were observed during the course of the study. In one instance, a male was seen chasing a Barn Swallow which was investigating the crossover as potential nest site and had flown under the crossover. The chase lasted only 10 to 20 meters during which time the male gave one bipeaked vocalization and the intruder left. The female remained on the nest during this altercation.

Length of the incubation period.-The length of the incubation period was calculated in hours and days from combined data for 1989 and 1990 (Table 17). The incubation period was defined as the interval between the laying of the last egg of a clutch 
Table 17. Length of incubation period. Data for 1989 and 1990 are combined.

\begin{tabular}{ccc}
\hline incubation period & hours & days \\
\hline mean \pm std error & $388 \pm 4$ & $16.2 \pm 0.15$ \\
range (min-max) & $373-426$ & $15.5-17.8$ \\
$n$ & 15 & 15 \\
\hline
\end{tabular}


to the time that egg hatched (Drent 1975). Nest progress was checked at least daily and frequently more often until hatching occurred. Only nests in which the date of clutch completion was known and in which the eggs had been numbered for identification were used for calculating the incubation period. When eggs hatched between nest checks, as was usually the case, the time of hatching was recorded as the time haifway between the last two nest checks. Because of this uncerainty in the time of hatching of some eggs a maximum error of \pm 0.5 days couid have been introduced to the length of the incubation period of these clutches.

Loss of Weight by Eggs. - All eggs started to lose weight immediately after laying. Weight loss for certain clutches was monitored in 1990 by weighing the eggs at selected times during the incubation period. Most eggs were weighed once at the beginning of the incubation period, a second time near the mid-point and a third time on the day of hatching. Eggs were weighed a fourth time if they did not hatch on the day of the third weighing.

In some cases eggs were not weighed until a day or two after the clutch had been completed and incubation had started. A similar problem also occurred with a few clutches at the end of the incubation period; in these clutches the eggs did not hatch until a day or two after their final weighing. In both instances the weights were adjusted using a correction factor. Water loss per day of each egg was calculated for two periods: the first period was from day 1 of incubation to day 9, the second period varied from day 7 to 18 of incubation. Water loss per day during the first half of incubation (mean 0.021 gm per day (days 1-9), $\mathrm{SE} \pm 0.001, \mathrm{n}=31$ ) was significantly less than (paired samples $\mathrm{T}$-test; $T=$ $3.479, \mathrm{df}=30, p=.002$ ) during the second half of incubation (mean $0.025 \mathrm{gm}$ per day, (days 7-18), $S E \pm 0.001, n=31$ ). To determine egg mass at the time of laying for eggs not weighed on the day of laying egg weights were corrected by multiplying the water loss 
Table 18. Egg weight loss (\%) during incubation for clutches monitored in 1990. Period one represented the first half of the incubation period and period two the second half. All eggs used for calculations hatched normally.

\begin{tabular}{cccc} 
& total wt. loss $(\%)$ & wt. loss; period 1 (\%) & wt. loss; period 2 (\%) \\
\hline mean \pm std err. & $17.5 \pm 0.5$ & $7.7 \pm .3$ & $10.0 \pm .4$ \\
$\max$ & 28.5 & 17.9 & 15.2 \\
$\min$ & 13.1 & 5.1 & 5.0 \\
$n$ & 39 & 39 & 34 \\
\hline
\end{tabular}


per day since the time of laying. Egg weight loss over the incubation period averaged $17.5 \%$ of the corrected egg weight at the time of laying (Table 18). The rate of weight loss was greater during the second half of the incubation period than during the first.

\section{Hatching}

General.-Hatching observations were made secondarily to other observations and thus are rather anecdotal in nature. Hatching was proceeded by pipping of the shell usually 24 to 48 hours in advance. Pips were made in the shell at approximately one third of the total length from the rounded end, near the shells' greatest circumference. Hatching most commonly advanced with sequential pipping of the shell along the line that demarked the greatest shell circumference until the two shell halves were separable by the hatchling. In some instances an oval approximately 1 centimeter in length and .5 centimeters wide was pipped from the large end of the shell during hatching. Hatching duration was not directly observed, but in ten cases eggs which were found with only a few pip marks early in the day had hatched from 4 to 11 hours later.

Harching Sequence.-The order in which eggs in a clutch hatched was recorded when possible. Eggs laid first tended to hatch first (in 6 of 7 cases) and eggs laid last tended to hatch last (in 9 of 10 cases). Hatching sequence of other eggs in the clutch was more difficult to determine because of the timing of nest checks and thus exact sequence is not known for the clutches observed.

Hatching Interval.- The duration of time over which the clutch hatched typically varied from 24 to 48 hours. Based on the frequency of nest checks some clutches may well have required less than 24 hours to hatch completely.

Eggshell Disposal.-In 1990, some effort was made to track the disposition of egg shells following hatching of the young. Egg shell removal was accomplished by one or both parents and was never observed directly. All egg shells located were found on or 
within the culvert at various distances from the nest. Of the 22 shell fragments found, 4 were found in the water directly below the nest, 2 were found from 1-5 meters from the nest, 4 from 6-10 meters from the nest, 5 from 11-20 meters from the nest, 5 from 21-40 meters from the nest, and one was found 45 meters from the nest. These fragments represented the remains of 5 or 6 clutches.

\section{Nestling Development}

Weight. - Change in weight was monitored for selected nestlings from hatching until fledging or disappearance during the 1989 and 1990 field seasons. Table 19 presents mean weights for nestlings throughout nestling period. Figure 15 shows change in weight as a function of age.

Growth of remiges and rectrices.- Growth of the wings and tail as a function of age are presented in Figure 16. Primary feathers (remexes) did not erupt from the feather papillae until day six of the nestling period. Earlier measurements of the wing represent growth of the manus. Feather eruption at the tail (rectrices) did not occur until day seven of the nestling period.

Description of nestling on the day of hatching.-The following nestling descriptions were accomplished from a simple visual inspection of live nestlings with the aid of a hand lens. This account is not intended as a definitive description of the natal plumage, but as a tool for identification and approximate aging of nestlings.

Nestling Black Phoebes are classified as altricial by Nice's (1962) work; that is they hatch with their eyes closed and are virtually helpless. Behaviors observed at hatching include; thythmic pedaling of the legs, grasping motions with the claws, gaping and raising of their heads and production of a weak peeping vocalization when disturbed. Young nestlings usually rested on their abdomen and head with their bill tucked under and facing posteriorly (Figure 17). 
Table 19. Weight of nestlings according to age in days. Ages are subject to a maximum error of 12 hours. The mean gain (gm) is the gain in weight from the previous day. The $\%$ mean gain is equal to the mean gain (gm) divided by the last preceding weight.

\begin{tabular}{ccccccc}
\hline age, days & \multicolumn{3}{c}{ weight, grams } & \multicolumn{2}{c}{ mean gain } \\
\cline { 2 - 5 }$D A Y$ & $N$ & Mean & Extremes & Std dev & grams & $\%$ \\
\hline 1 & 24 & 1.5 & $0.9-1.8$ & 0.19 & NA & NA \\
2 & 20 & 2.5 & $1.2-3.3$ & 0.47 & 1.0 & 67 \\
3 & 25 & 3.6 & $2.5-5.5$ & 0.81 & 1.1 & 45 \\
4 & 21 & 4.7 & 3.06 .0 & 0.81 & 1.1 & 31 \\
5 & 19 & 6.2 & $4.2-7.4$ & 0.92 & 1.5 & 32 \\
6 & 25 & 8.2 & $5.8-10.2$ & 1.14 & 2.0 & 32 \\
7 & 22 & 10.1 & $5.8-13.0$ & 1.67 & 1.9 & 23 \\
8 & 18 & 12.1 & $8.7-14.2$ & 1.27 & 2.0 & 20 \\
9 & 19 & 13.8 & $9.8-16.9$ & 1.80 & 1.7 & 14 \\
10 & 16 & 15.8 & $13.7-18.1$ & 1.20 & 2.0 & 14 \\
11 & 22 & 16.9 & $14.7-19.0$ & 0.97 & 1.1 & 7 \\
12 & 17 & 18.2 & $16.7-20.3$ & 1.10 & 1.3 & 8 \\
13 & 15 & 18.5 & $16.0-20.8$ & 1.36 & 0.3 & 2 \\
14 & 11 & 18.1 & $16.5-19.7$ & 1.07 & -0.4 & -2 \\
15 & 22 & 18.5 & $15.8-22.2$ & 1.59 & 0.4 & 2 \\
16 & 20 & 18.0 & $14.7-22.3$ & 1.67 & -0.5 & -3 \\
17 & 25 & 18.3 & $14.9-21.8$ & 1.79 & 0.3 & 2 \\
18 & 11 & 19.1 & $17.0-21.3$ & 1.55 & 0.8 & 4 \\
19 & 11 & 18.7 & $17.1-20.5$ & 1.18 & -0.4 & -2 \\
20 & $\mathrm{ND}$ & $\mathrm{ND}$ & $\mathrm{ND}$ & $\mathrm{ND}$ & $\mathrm{ND}$ & 0 \\
21 & 2 & 18.6 & $18.5-18.7$ & 0.14 & $\mathrm{ND}$ & $\mathrm{NA}$ \\
\hline & & & & & &
\end{tabular}




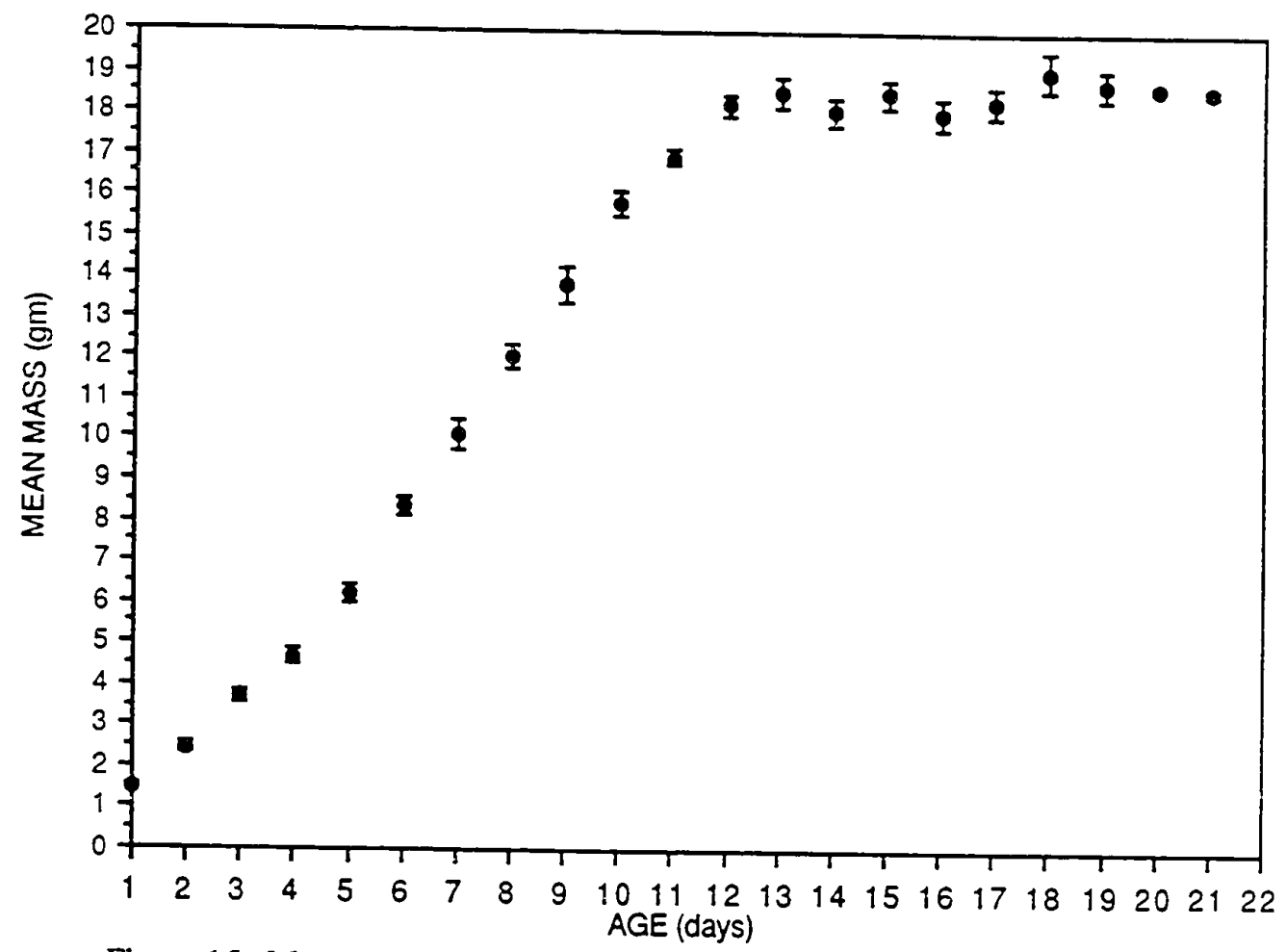

Figure 15. Mean nestling mass (grams) plotted against nestling age (days).

Maximum error in nestling age \pm 12 hours. Error bars represent one standard error. 


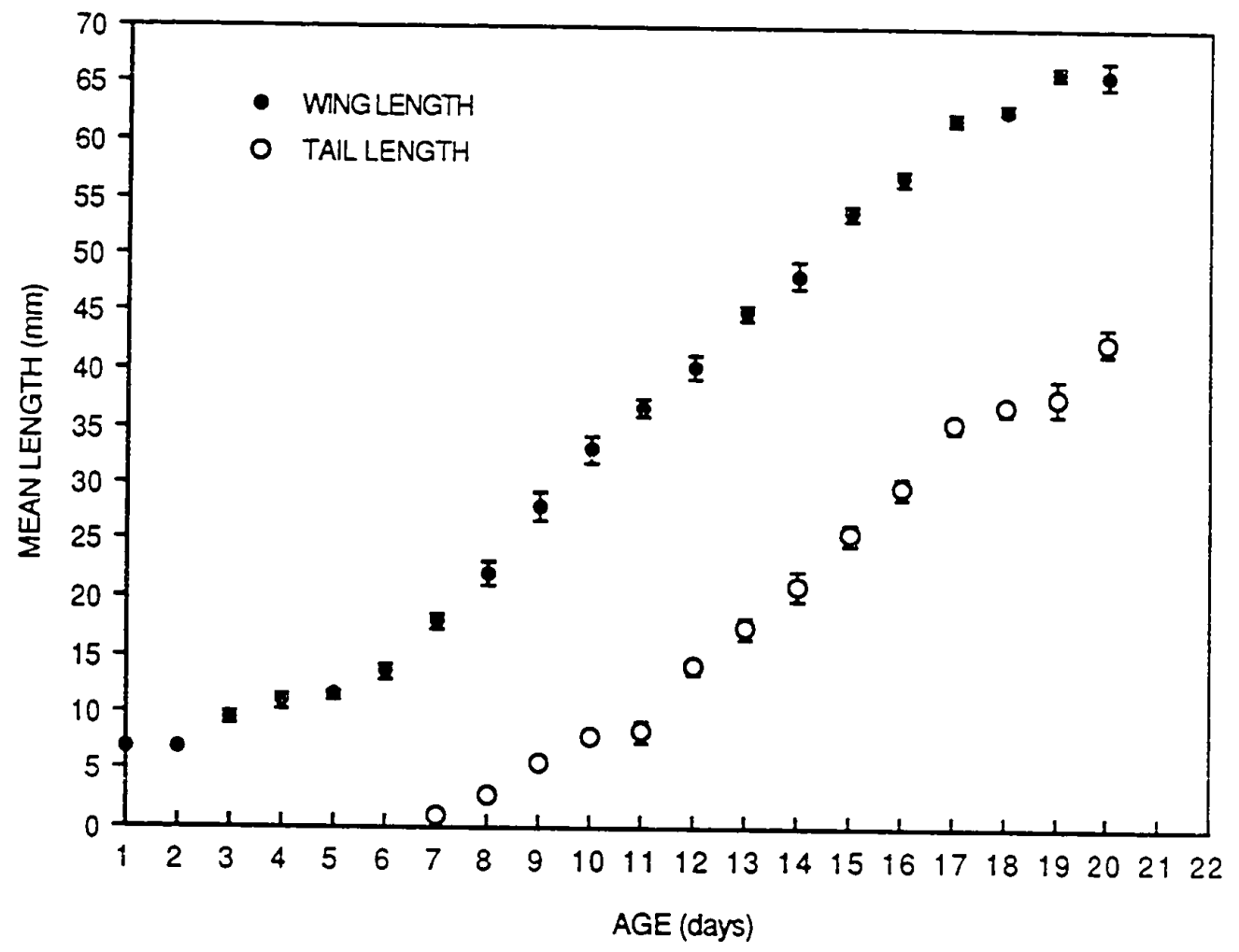

Figure 16. Mean wing length $(\mathrm{mm})$ and Tail length $(\mathrm{mm})$ plotted as a function of nestling age (days). Maximum error in nestling age of \pm 12 hours. Error bars represent one standard error. 


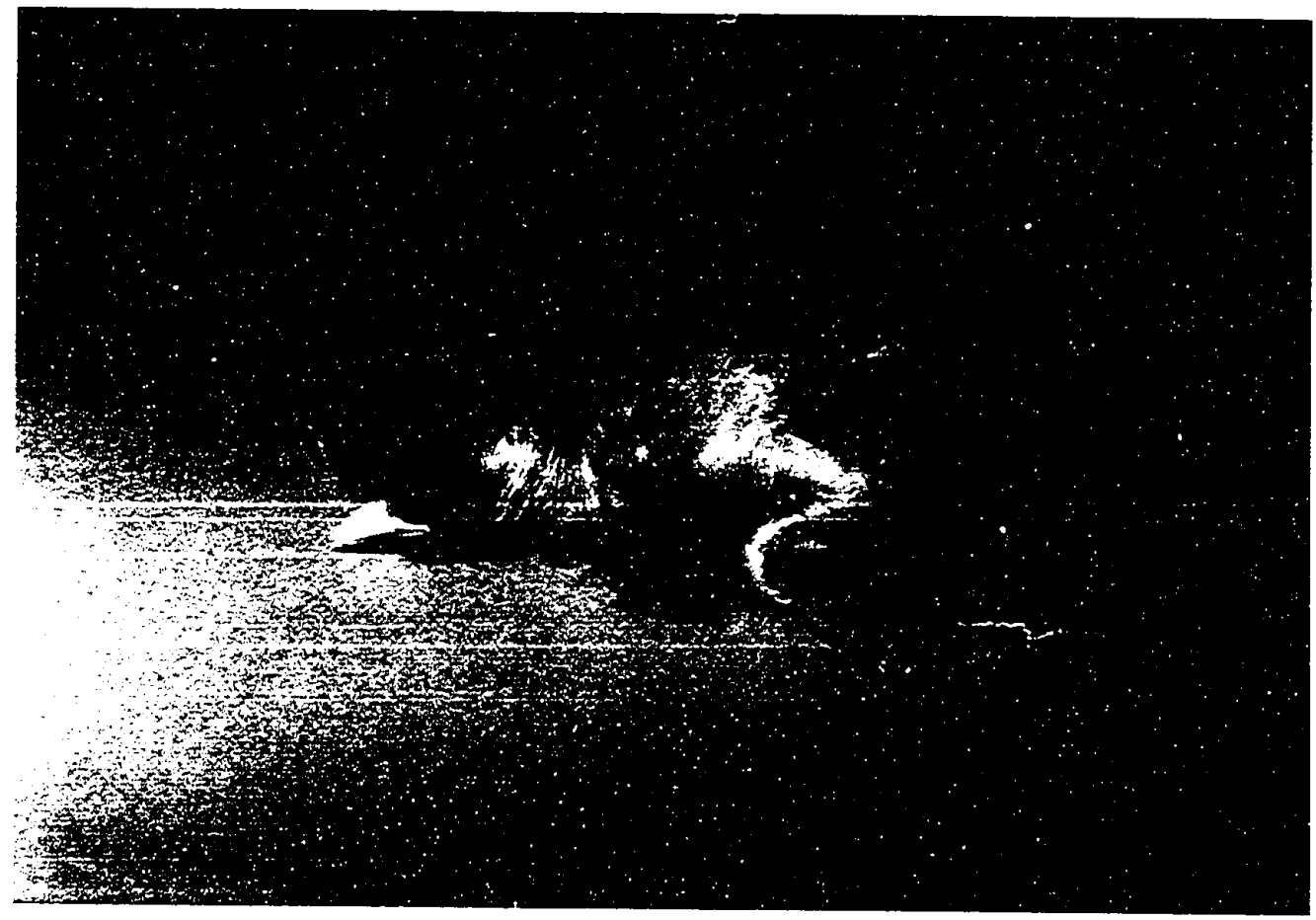

Figure 17. Newly hatched Black Phoebe nestling; the egg tooth is visible near the tip of the upper mandible. 
The skin and tarsi are an orange flesh coior and the mandibles and claws are a light yellow. The viscera are clearly visible through the nearly transparent skin of the abdomen. The bill flanges are a creamy yellow and the gape is a bright yellow-orange The nares are oriented towards the tip of the mandible, the egg tooth is present and approximately $0.5 \mathrm{~mm}$ from the tip of the upper mandible.

The body is lightly covered with a medium gray neossoptiles (natal down piloplume feathers) and the head is more heavily covered with dark gray neossoptiles. The distribution of these neossoptiles over the various pterylae on newly hatched nestling are as follows: (nomenclature is that of Wetherbee 1957) capital tract, bilaterally, 45 neossoptiles up to $8 \mathrm{~mm}$ in length in the coronal region, ocular region 6-8 neossoptiles, the occipital region has several neossoptiles on either side, auricular region from 1-3 neossoptiles emerge from the anterior end of the ear opening and 1-2 neossoptiles from the corner of the jaw, malar region has 3 light gray neossoptiles spinal tract, neossoptiles are paired on either side of the spine and originate in the thoracic region and extend posteriorly to the lower pelvic area, these number 12-13 on either side of the spine, alar tract, humeral region has 6-7 neossoptiles, ulnar region approximately 8-9 neossoptiles in the position of the secondary papillae, one neossoptile in the alular position and the manus has 6-8 short $(1 \mathrm{~mm})$ neossoptiles along its length, femoral tract, 3 light gray neossoptiles anterior to the heel, ventral tract, approximately 14 white neossoptiles in a line placed laterally and running from the lower breast to the caudal region, caudal tract, 3-4 medium gray neossoptiles anterior to the rictrical bulb. In 1 to 2 day old nestlings the primary teleoptiles appear as dark subcutaneous spots on the manus.

Day four of the nestling period.-Eyes of the nestlings are closed, and nestlings no longer rest on their heads with their bills tucked posteriorly. The egg tooth is present. Dark papillae of coronal region of the capital tract discemible, dark gular papillae and dark 
upper ventral papillae also visible as are papillae of primary teleoptiles which are starting to erupt. Lower ventral tract skin roughened, but no papillae obvious. No pigment discernible in the caudal region.

Day six of the nestling period.-Nestling weight is approximately five times hatching weight and $45 \%$ of adult weight. Young birds beat wings, pedal legs and are generally much more active when handled. The eyes are just starting to open and appear as mere slits. The egg tooth is still present and the mandible is starting to elongate. Dark black papillae of the capital tract and gular are small but apparent, as are the dark papillae of the spinal tract, and alar tract including secondary papillae and the elongated primary papillae which form a continuous line. Primary teleoptiles are almost ready to erupt from the epidermis. Rectrical papillae are clearly visible, but not protruding from the skin. Light ventral papillae are visible and given the skin a roughened appearance.

Day seven of the nestling period.-Eyes of the nestlings are barely open. Capital tract papillae are well pronounced and the gular region is well defined bilateral feather tracts, spinal tract papillae are starting to erupt in the thoracic region. Ventral tract light in color abdominally and dark black laterally up on the breast. This feather tract is well defined and almost ready to erupt. Femoral tract papillae black in color, but have not erupted. Alar tract: primary and secondary teleoptiles have ruptured the skin, but are less than $1 \mathrm{~mm}$ in length, coverts are also erupting and the rectrices are about to erupt. The uropygial gland is prominently defined.

Day eight of the nestling period.-Nestling weights are almost seven times hatching weight and $56 \%$ of adult weight. The eyes of the young are starting to open, the nestlings pedal across the scale, gape spontaneously, beat their wing and peep when disturbed, and defecate when handled. Epidermis is flesh in color and the tip of the upper mandible is blackish. Alar tract: primary and secondary teleoptiles have enupted. Primary \# 10 of one 
nestling is $2 \mathrm{~mm}$ in length. Coverts have erupted and the tips of the secondary coverts are cinnamon in color. Capital tract and upper spinal tract feathers have not erupted, but the feathers of the lower spinal tract are just erupting from the skin, as are the feathers of the femoral tract and caudal region (rectrices and coverts) The lower ventral tract feathers have erupted and are approximately $2 \mathrm{~mm}$ in length.

Day nine of the nestling period.-The upper mandible is darkening medially, but is still creamy yellow at the edges and tip. The eyes are open from $1 / 4$ out $1 / 3$ of the way. The egg tooth is still present in all nestlings. Primary \# 10 is now approximately $4 \mathrm{~mm}$ in length, rectrices and upper tail coverts are $2-3 \mathrm{~mm}$ in length. The tips of the secondary feathers and coverts are tipped with cinnamon. All other feather tracts have erupted from the skin.

Day ten of the nestling period.- Nestling weights average ten times hatching weight and are $88 \%$ of adult body weight. The upper mandible is brownish black medially and creamy yellow on the margins. The egg tooth is still present in all nestlings. The front of the tarsi are starting to darken. The nestlings wing length is approximately $30 \%$ of the adult's wing length and their tail length is $8-10 \%$ of the adult's. The feather sheaths of secondaries 8 and 9 have ruptured at the tips, and the secondary coverts are approximately $1 \mathrm{~mm}$ out of their sheaths. Rectrices are about $1 \mathrm{~mm}$ in length and the sheaths of the upper tail coverts have ruptured, as have the feathers of the spinal tract and ventral tract.

Day twelve of the nestling period.-Nestling weights average twelve times hatching weight and $100 \%$ of adult body weight. Eyes are open $1 / 3$ to $1 / 2$ of the way. The nestlings' wing length is approximately $40 \%$ of the adult's wing length and their tail length is $15-18 \%$ of the adult's. Primary $\# 10$ is about $16 \mathrm{~mm}$ in length. The sheaths of the primary coverts are just starting to rupture. Lower ventral tract feathers are approximately $3 \mathrm{~mm}$ out of their sheaths (Figure 18). 


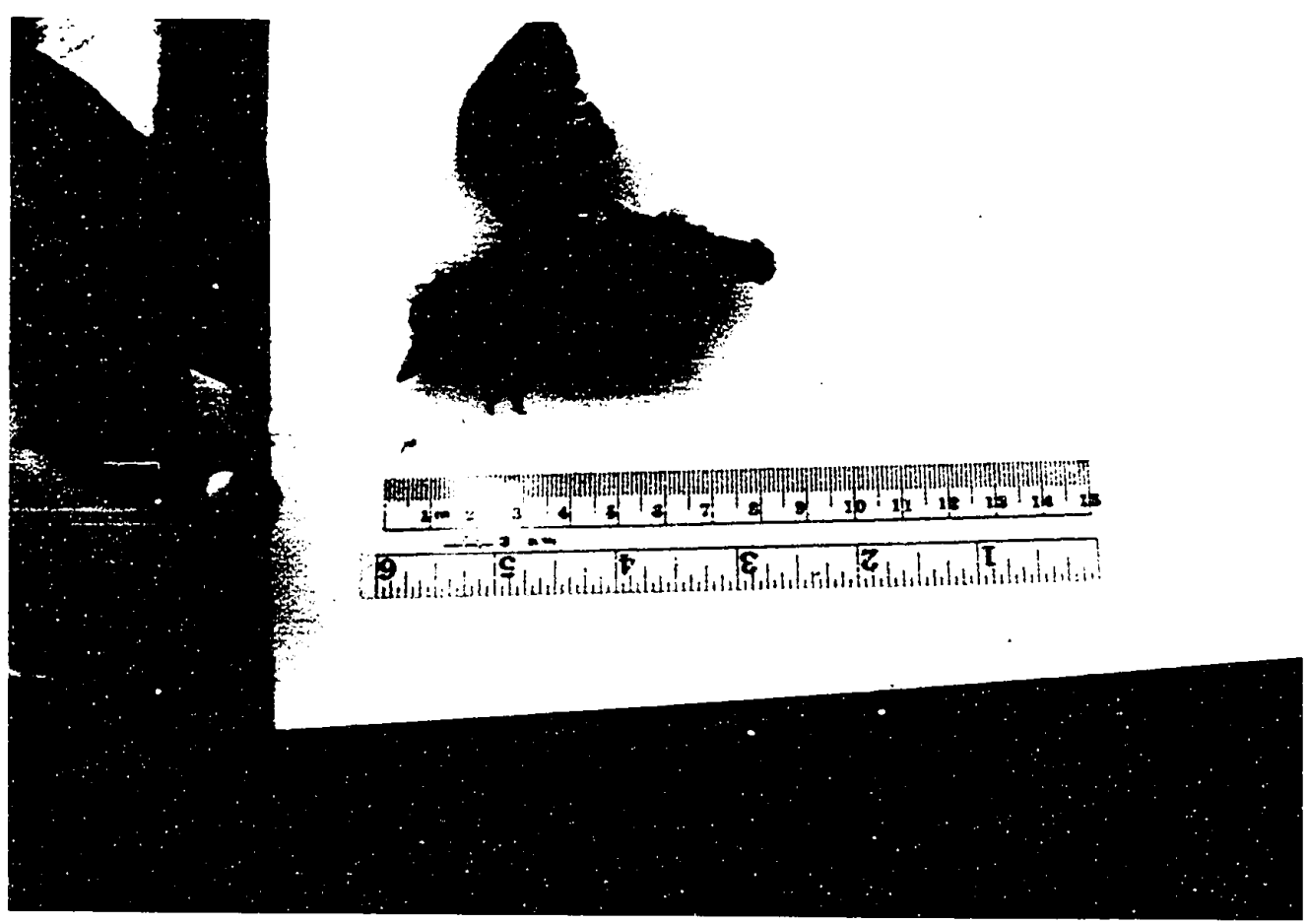

Figure 18. Twelve day old Black Phoebe nestling. Notice that the flight feathers are partially erupted from the feather sheaths. 
Day fourteen of the nestling period.-Nestlings appear alert and their eyes are $2 / 3$ to fully open. The egg tooth is visible on all nestlings. The tarsi appear a reddish black color and the claws are black. The tip of the lower mandible has turned a blackish gray. The rictal bristles have not yet started to emerge. Some neossoptiles remain primarily on the coronal area of the capital tract. The nestlings wing length is approximately $50 \%$ of the adult's wing length and their tail length is $22-25 \%$ of the adult's. Sheaths are ruptured on all feather tracts. Primary $\# 10$ is approximately $37 \mathrm{~mm}$ in length and $10 \mathrm{~mm}$ out of its sheath. Coverts are $1 / 2$ way out of the sheaths.

Day sixteen of the nestling period.-The nestlings are alert and active. Their wing length is approximately $60 \%$ of the adult's wing length and their tail length is $33-35 \%$ of the adult's. Nestlings are well feathered with the contour feathers almost completely out of their sheaths. Primary \#10 is approximately $33 \mathrm{~mm}$ in length and $20 \mathrm{~mm}$ out of its sheath.

Day eighteen of the nestling period.-The nestlings are very alert and if startled will leave the nest quite readily. Mandibles and tarsi are almost completely black. The egg tooth is still discemable on some nestlings. Wing length is now approximately $80 \%$ of adult's wing length and tail length is $50 \%$ of adult length. Primary $\# 10$ is about $34 \mathrm{~mm}$ and $21 \mathrm{~mm}$ out of its sheath (Figure 19).

\section{Fledging}

The day of fledging was observed for some broods in 1989 and 1990. Nestlings in all but one case, left the nest over a period of one to three days. Frequently, the nestlings with the longest wing length fledged first. Nestlings were capable of sustained flight for long distances $(>200 \mathrm{~m})$ on the day of fledging. In one instance, two young birds were found back on the nest on the day after fledging, both young flushed from the nest when I approached the crossover entrance. Broods not visited frequently during the nestling 


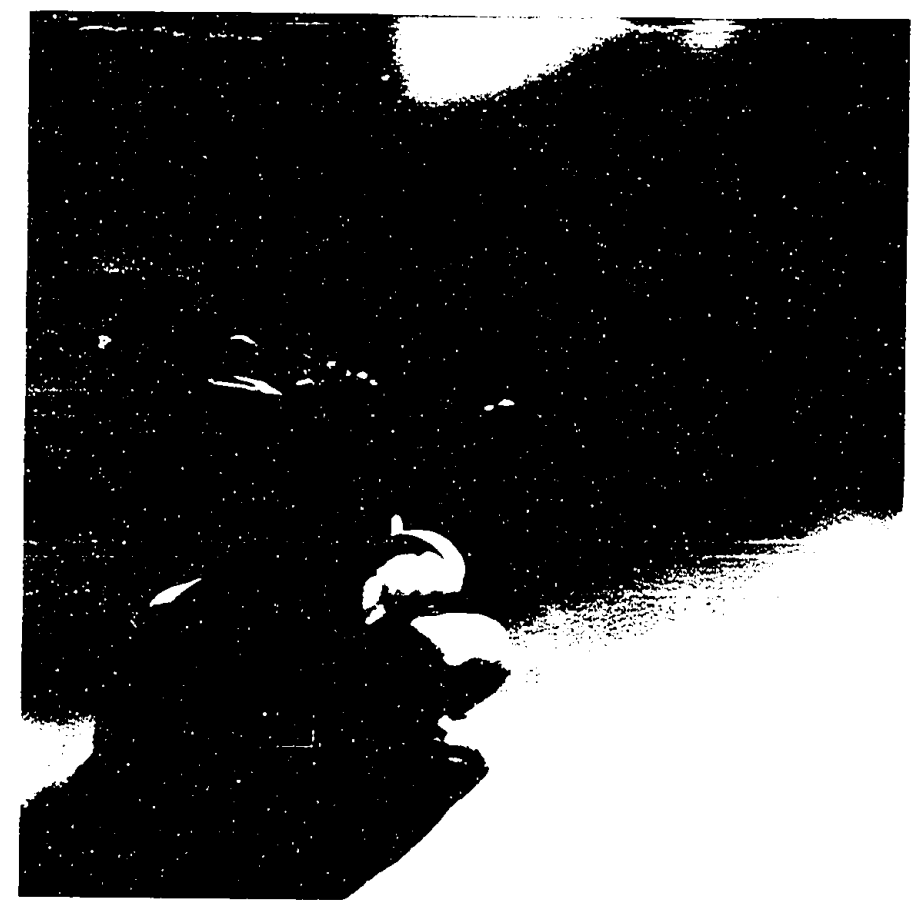

Figure 19. Eighteen day old Black Phoebe nestling. This nestling is capable of sustained flight and is ready to fledge from the nest. 
period were extremely skittish to the approach of humans and in more than one instance the observer induced the young to fledge spontaneously by his approach to the nest. Eightyfour percent of all nestlings fledged between days 18 and 20 (Table 20).

\section{Nesting Success and Mortality}

In $1989,94 \%$ of the 34 eggs laid in first clutches and $77 \%$ of the 26 eggs laid in second clutches hatched (Table 21). One egg was lost due to investigator impact (dropped) and accounted for $3 \%$ of the first clutch egg losses and one egg which failed to develop accounted for the other $3 \%$ of the losses in first clutches. Egg losses in second clutches were higher than those of first clutches and of the six eggs that did not hatch: two failed to develop, one developed but died sometime during the incubation period, one developed in what appeared a normal manner but died when it was unable to break free from the sheli after an extended period, and two died in a nest which was accidently flooded by SJ/SCWPCP personnel.

In $1990,93.3 \%$ of the 30 eggs laid in first clutches and $100 \%$ of the 27 eggs laid in second clutches hatched. Egg losses were confined to one incident of red fox predation which accounted for two eggs (6.7\% of the total in a first clutch losses). The female at this nest was not taken during the incident.

Fledging success (the percentage of nestlings hatched that fledged) in 1989 was $84 \%$ for first clutches and averaged 3.9 fledglings/brood $(n=7)$. Second clutch fledging success was $70 \%$ and an average of 2.8 fledglings/brood $(n=5)$ were produced. Nestling losses in first clutches occured solely due to predation: one clutch of five nestlings (10\% of the total hatched) was lost to an unknown, but believed avian predator. In second clutches disturbance and accidents (7\% of the total number of nestlings hatched) accounted for all nestling losses: five restlings from one brood died from exposure on the night after hatching when the bronding adult was frightened off the nest by a muskrat (Ondarra 
Table 20. Age of nestlings at fledging in days since hatching. The percent of all nestlings fledging is also given below.

\begin{tabular}{cccccccc} 
& \multicolumn{7}{c}{ age (in days since hatching) } \\
\cline { 2 - 8 } Number of nestlings fledging & $\mathbf{1 6}$ & $\mathbf{1 7}$ & $\mathbf{1 8}$ & $\mathbf{1 9}$ & $\mathbf{2 0}$ & $\mathbf{2 1}$ & $\mathbf{2 2}$ \\
\cline { 2 - 8 } & 1 & 2 & 12 & 8 & 8 & 1 & 1 \\
\%o of total fledging & 3 & 6 & 36 & 24 & 24 & 3 & 3 \\
\hline
\end{tabular}


Table 21. Nesting success and mortality for all clutches laid in 1989 and 1990.

\begin{tabular}{lcccc} 
year & 1st clutch & 2nd clutch & 1st clutch & 2nd clutch \\
\hline eggs laid & 1989 & 1989 & 1990 & 1990 \\
eggs hatched & 34 & 26 & 30 & 27 \\
eggs infertile & 32 & 20 & 28 & 27 \\
eggs lost & 1 & 4 & 0 & 0 \\
eggs predated & 1 & 2 & 0 & 0 \\
percent of eggs hatching & $94 \%$ & 0 & 2 & 0 \\
young fledged & 27 & $17 \%$ & $93 \%$ & $100 \%$ \\
fledged per nest & 3.9 & 2.8 & 8 & 23 \\
fledged of eggs laid & $27 / 34(79 \%)$ & $14 / 26(54 \%)$ & $8 / 30(27 \%)$ & $23 / 27(85 \%)$ \\
fledged of eggs hatched & $27 / 32(84 \%)$ & $14 / 20(70 \%)$ & $8 / 28(29 \%)$ & $23 / 27(85 \%)$ \\
young lost before fledging & $5(16 \%)$ & $6(30 \%)$ & $20(70 \%)$ & $4(15 \%)$ \\
\hline
\end{tabular}


zibethicus) which had fallen into the culvert and splashed around underneath the nest, and a single nestling from another nest site was trapped in the mud below the nest during fledging and was unable to escape.

During 1990, fledging success varied dramatically due to extensive red fox predation. First clutches were largely unsuccessful, only $29 \%$ of the 28 nestlings hatching later fledged with an average of 1.1 fledglings/brood $(n=7)$. A red fox pair with a den and six pups 150 meters to the west of nest site 1 (young Black Phoebe wings were found at the den) accounted for $95 \%$ of the losses. The culvert in which the phoebes nested had no water in it during the first half of the breeding season and as a consequence the foxes had easy access to the nests. Human scent near the nest site from the investigator may also have aided the foxes in finding the nests, but this is hard to substantiate. Second clutches faired considerably better than first clutches; $85.2 \%$ of the 27 eggs which hatched later fledged and an average of 3.8 fledglings/brood $(n=6)$ were produced. Two factors were considered responsible: a) substantial rain in early May filled the culvert part way with water eliminating the human scent from under the nest sites ar:d presumably discouraging the foxes from entering the culvert and b) an largely successful effort was made to eliminate the source of predation. Evidence indicated that this work accounted for all of the young and one of the adult foxes.

Overall success (the percentage of the eggs laid during the season which later hatch and fledge from the nest) also varied among years, in 1989 , overall success was $68.3 \%$ and losses were attributed to a number of sources. Predation accounted for the loss $8.3 \%$ of the total number of eggs laid, $6.7 \%$ of the eggs laid failed to develop or developed and did not hatch, $11.7 \%$ of the eggs or young were lost to disturbances or accidents and $1.7 \%$ were lost as a result of investigator impact. During 1990, overall success fell to $54.3 \%$ and all eggs and nestlings were lost due to predation. 


\section{DISCUSSION}

\section{Prenesting Courtship Behavior}

Nest Site Showing.- One of the most commonly observed displays, the nest site showing display was named by Smith (1970) in his study of the Genus Sayornis. Nest Site Showing was also noted by Oberlander (1939); he observed phoebes riuttering around the nest site of the previous year and suggested that the display had importance in establishing the pair bond. Observations from this study support his conclusion.

Chasing.-Chasing also appeared to be an important part of pair bond maintenance throughout the breeding season. Males chased females frequently throughout the day. Most often, the initial greetings between the pair when the female came off her roost after dawn involved a vigorous chase with frequent vocalizations. Chases were localized around the nest site. Both Oberiander (1939) and Irwin (1985) made similar observations and interpretations of chasing behavior.

\section{Nest Site Selection}

Nest Site Characteristics.-Black Phoebes select nest sites based primarily on three factors: a) the site must be close to a source of mud for construction materials, b) most sites are located very near or directly over water and c) virtually all sites have an overhang which protects the nest from the elements (Bendire 1895, Tyler 1913, Grinnell and Storer 1924, Skutch 1960, Ohlendorf 1976, and Irwin 1985). All nests located during the present study also conformed to this profile.

Nest sites can be conveniently divided into two categories: natural sites and manmade sites. Natural sites where nests have been found include: dirt ledges along streams (Bendire 1895, Hoffman 1927), in a sheltered pocket of large rocks projecting over running streams (Tyler 1913, Baily 1921, and Grinnell and Storer 1924), in a tree under a 
broken limb (Robertson 1933). Historically, the lack of suitable natural sites was most likely a major facior in limiting breeding abuncance in this species (Grîñel ânu Siorer 1924). Black Phoebes have readily adopted man-made structures which were suitable nest sites. A partial list includes: under the eaves of buildings (Tyler 1913, Hoffman 1927, Ohlendorf 1976, and Irwin 1985), on bridge stringers (Tyler 1913), in irrigation and drainage culverts (Ohlendorf 1976), in abandoned wells (Bendire 1895, Tyler 1913).

The abundance of man-made structures has greatly increased breding densities over much of the Black Phoebes range. In this study all nests were placed in culverts and were from 50 to $150 \mathrm{~m}$ apart. During 1989 and 1990 eight nesting pairs occupied a $1 \mathrm{~km}$ stretch of culvert. Natural nest sites were scarce or nonexistent in this region.

In the Tran-Pecos region of Texas bridges and culverts are the preferred substrate (Ohlendorf 1976). Only 14\% of 36 nests surveyed in this area occurred on natural structures. The remaining $86 \%$ were placed under bridges and in culverts. The minimum distances between Black Phoebe nests was $160 \mathrm{~m}$. Based on the present study this minimum distance is mostly likely related to the physical placement of these structures and not the territorial requirements of the species.

In a study by Irwin (1985) all nests ( $n=23)$ were located on man-made structures. Of the 21 bridges located within the study area only one was used as a nest site. The other 22 nests observed during the study were located under the eaves of buildings. Eight of the 22 building nests were located relatively close to bridges.

\section{The Nest and its Placement}

Nest description.- Black Phoebes constructed adherent nests made from a mixture of mud peilets and grass stems/leaves. The lining of the nest was a woven pad of grass stems and root fibers approximately one centimeter thick. Nests of similar construction are described by earlier researchers (Bendire 1895, Tyler 1913, Baily 1921, Hoffman 1927, 
Skutch 1960, Ohlendorf 1976, and Irwin 1985). Other lining materials are commonly used

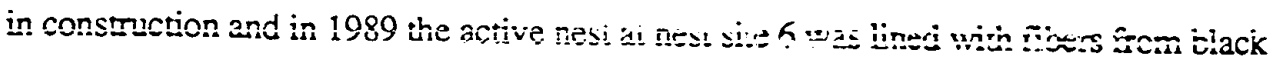
sheeting used to discourage weedy growth in the revegetation plot. One nestling's head became tangled in these fibers and it subsequently died from strangulation. A similar incident involving horsehair was observed by Jewett (1899). Horsehair, and feathers have also been used commonly in the construction of the nest lining (Bendire 1895, Tyler 1913, and Skutch 1960). The use of horsehair as a lining material is probably much less common now than around the turn of the century when horses were a common mode of transportation and much more abundant.

Dimensions of nests monitored in this study (Table 1) are within the range of measurements reported by other investigators. Data on the dimensions of old nests that were added to and reused and newly constructed nests were combined. Bendire (1895) reported measurements of $89 \mathrm{~mm}$ for nest height, $127 \mathrm{~mm}$ for nest width, $70 \mathrm{~mm}$ for nest cup diameter, and 32mm for nest cup depth for a single nest taken in San Yasbel, California on April 28, 1893. Irwin (1985) reported new nest dimensions of $90 \mathrm{~mm}$ for nest height and $130 \mathrm{~mm}$ for nest width across the rim. Old nests as large as $150 \mathrm{~mm}$ in height and $150 \mathrm{~mm}$ across the rim were also observed.

Nest Placement.-Nests tended to be placed towards the center of each crossover and within $50 \mathrm{~mm}$ of it's ceiling. This positioning may tend to minimize the risk of predation in several ways. Placement towards the center provides the maximum concealment from the outside due to the darkened interior. This is enhanced by the placement of nests near the crossover ceiling. The high placement not only positioned the nest in the darkest region of the crossover, but an additional benefit was provided by the abundant spider webs and moth cocoons which broke up the outline of the nest when viewed from outside the crossover. 
In addition, the placement of nests within $50 \mathrm{~mm}$ of the ceiling may restrict access to the nest by larger avian nest predators such as Loggerhead Shrikes and Scrub Jays which, because of their size, are probably unable to land on the nest rim. Support for this argument is provided by an incident of nestling predation in 1989 where five 12 day old nestlings were taken and the nest was left undisturbed. This nest was placed high enough on the crossover wall that a mammalian predator would have had to tear the nest down to gain access to the young. The nest's undisturbed condition thus suggests an avian predator. This particular nest was placed approximately $300 \mathrm{~mm}$ from the crossover ceiling, making it both visible and accessible to an avian predator.

The placement of nests under ceilings or overhangs has been noted frequently (Tyler 1913, Fraser 1930, Robertson 1933, Kinsey 1935, Stoner 1937, Skutch 1960, and Irwin $1985)$ and in addition to providing concealment from potential predators protection from the elements is also afforded. Irwin (1985) also noted that all nests in his study area were placed on the lee side of the building, away from high ( 35 to $55 \mathrm{kph}$ ) prevailing northerly winds. He suggested that the phoebes decided preference for buildings as nest sites instead of bridges may be attributed to the more effective windbreak provided by the former.

\section{Nest Building Behavior}

Construction of New Nests and Reuse of Old Nests. - The earliest date that nest construction was observed at Coyote Creek for a first nesting attempt was March 4 and the latest date March 28 with a median date of March 15. Oberiander (1939) observed the start of nest construction in Berkeley, California on February 28.

Nest construction was accomplished wholly by the female and only in one instance was a male seen attempting to bring material to the nest. The male's few attempts were ineffective and the effort appeared halfhearted. Nest construction by only the female was also noted by Oberlander 1939, Skutch 1960, and Irwin 1985. Jewett (1899) stated that 
both male and female participate in nest construction and that while one bird works on the nest the other stands watch.

Most nesting Black Phoebes choose to refurbish an old nest. In 16 of 20 first nesting attempts and 11 of 13 second nesting attempts phoebes rebuilt the existing nests. This tendency was also documented by Oberlander 1939, Skutch 1960, Verbeek 1975 b and Irwin 1985. Verbeek (1975b) suggested that nest reuse saved time and that pairs building a new nest were precluded from having a second brood that season. All pairs observed constructing new nests during the current study were double brooded and usually reused the same nest. Irwin (1985) reported that four of the seven pairs that built new nests had second broods in that same nest; two of the other nests were destroyed and in the third the nestlings died from starvation. These observations do not support Verbeek's delay hypothesis. Irwin (1985) found nest reuse in 16 of 23 cases, and in one case a nest was reused in six of seven consecutive years.

Nest refurbishment took approximately 7.5 days for first clutches and 5.4 days for second clutches (Table 2). Oberlander (1939) observed nest repair and reuse by a female which took only one or two days. Nest refurbishment periods of from one to five days were reported by Irwin (1985).

New nest construction took an average of 18.8 days for first nesting attempts and 10 days for second nesting attempts. A nest in the advanced state of construction was found by Skutch (1960) and appeared complete four days later. Construction of a first nest was observed by Oberlander (1939) for 12 days until the female was found dead on the nest (air rifle) with mud still in her bill on March 11. At this point the nest appeared almost complete. Irwin (1985) reported that the construction of a new nest took "about five days". 
Actual nest construction was sporadic in nature and was altemated with periods of foraging and other maintenance behaviors. Oberlander (1939) describes construction bouts lasting from six to fifteen minutes interipted by periods of foraging.

\section{Laying}

Dates and Time of Laying.-First egg dates ranged from March 18 to May 6 for first clutches and from April 13 to May 24 for second clutches. High rates of predation in 1990 are responsible for the considerable overlap in egg dates between first and second clutches

(Figures 5 and 6). If data for only 1989 is used, the overlap is eliminated and first egg dates range from March 18 to May 6 for first clutches and from May 8 to May 31 for second clutches. Other investigators in California have reported a wider range of dates. Irwin (1985) reported that laying occurred from 20 March to 24 June in Humboldt County, and Frazer (1931) found a pair of Black Phoebes feeding nestlings on 28 September on the Eel River also in Humboldt County. This late date would place the dates for clutch completion probably in the first or second week of September. Davis (1933) found freshly completed clutches between 1 April and 1 May in Butte County and Tyler (1913) found fresh eggs on June 15 in Fresno County. Tyler suggested that the nesting period extended from 1 March to 1 July and observations from this study support his conclusions.

Eggs were laid within a few hours of civil sunrise with the last egg of a clutch laid the latest (Table 7). The female typically came off the nest or another nearby roost around sunrise and was greeted by her mate. After a brief series of chases and vocalizations both birds started started foraging. The female preened intermittently as she foraged and when ready to lay returned to the the nest. Laying required approximately 15 minutes and the laying behavior is described in Tables 3 and 4. Laying times were not as protracted in Humboldt County and Irwin (1985) reported that all eggs were laid between 0700 and 0830 Pacific daylight Time. Other data on laying times for Black Phoebes were not found, 
but Skutch (1952) reported laying times for a number of species in several families in Costa Rica. Members of the family Tyrannidae surveyed all laid their eggs before mid-day, but varied their laying from just after sunrise to just before noon. Thus the Black Phobe may be seen as a fairly typical representative of its family.

Laying Rate.-At the majority of nests, eggs were laid at a rate of one per day. Several exceptions occurred during a seven day period in May of 1989. In 3 different nests that held second clutches, from 1 to 3 days were skipped between the laying of some eggs. During this period no unusual environmental events were noted and thus an explanation is lacking. Laying rates of one egg per day were also reported by Jewett 1899 , Oberlander 1939, and Irwin 1985. No exceptions to this routine were noted by these investigators and this rate of laying is typical for most passerines.

\section{The Egg: Description, Measurements, and Variation}

General Description and Measurements.-Egg descriptions and measurements are similar to those of Bendire (1895), Bent (1942), and Irwin (1985) (Figure 10 and Tables 8 and 9). Fresh egg mass averaged $10-12 \%$ of female body mass.

Variation in Egg Size.-Multiple regression analyses and two-way ANOVA showed that Black Phoebes laid significantly larger eggs in second clutches than in first clutches in 1989 and 1990 . There also was a slight tendency for egg size to increase with laying sequence (Figures 11, 12, \& 13), but in only one case was this increase in size significant (1990, multiple regression analysis). Based on the weak statistical support for egg size increase with laying sequence, this topic will not be addressed in this discussion.

Second clutch volume showed an increase in total volume of $2.9 \%$ over the volume of first clutches. Hatchling size is correlated positively with egg size in Boat -tailed Grackles (Quiscalus major) (Bancroft 1984), thus the larger eggs in second clutches would tend to produce larger hatchlings. Whether this increase in hatchling size with later clutches 
is a result of increased resource availability is not known in this case. Several studies suggest that increase in size is adaptive. Frequently hatchlings from larger eggs have larger yolk reserves (Parsons 1970). Furthermore, hatchlings from larger eggs survive better during the first few days after hatching than hatchlings from smaller eggs (Parsons 1970, Schifferli 1973).

Consequently, one could suggest that the increase in egg size between clutches is adaptive and is a tactic by which a female may potentially increases her fitness without the added burden of an additional egg. This tactic may be a means whereby an individual can fine tune its reproductive output by increasing egg size, which results in marginally greater costs, rather than laying an additional egg, which has a much greater initial investment and would require feeding another nestling.

An alternative explanation is suggested by Jarvinen and Ylimaunu (1986). They found that in passerines breeding at high latitudes, when average temperatures were low then female body mass was also low. As a result of the reduced body mass these birds laid smaller eggs. During conditions of warm weather the birds increased their body mass and subsequently laid larger eggs. This hypothesis might be tested at lower latitudes with early and late breeders. Body condition and egg size could be monitored. Unfortunately data gathered from this study is not suitable for testing this hypothesis.

Variation in Egg Coloration.-Variation in egg coloration, specifically the occurrence and intensity of spotting, was first noted by Tyler (1913):

"It is interesting to note that when four eggs constitute the set there are generally three that are unmarked and one that is quite heavily spotted with red dots on the larger end, but when there are five eggs in the set then the additional egg nearly always has just a few very fine spots like dust My observations show that nearly always the spotted egg is the last one to be deposited." 
In this study the preserice and absence of spots varied significantly $(p<0.005)$ with egg number and the last egg was spotted more frequently and intensely than the other eggs within a clutch. In 3 of 26 clutches were all eggs were without spots and in 4 of 26 clutches all eggs were spotted to some degree. Eggs within 5 egg clutches were more frequently and intensely spotted than eggs within 4 egg clutches (Tables 13 and 14). Irwin (1985) reported all eggs seen in his study were without spots. This contrasts with the current study in which $38 \%$ of all eggs observed were spotted to some degree. The cause of the spotting is unknown and the only trend observed was an increase in spotting with egg number. Also worth considering are the effects of the increased time that the last egg laid spends in the shell gland. Pigment deposition occurs during the last quarter of the eggshell formation period in the hen (Warren and Conrad 1942). Since there is a tendency for the last egg to be laid 1-2 hours later than the other eggs in the clutch, longer retention in the shell gland could account for the increased pigmentation found on later eggs within a clutch.

\section{Clutch Size}

Variation in Clutch Size. - Clutch size was recorded from a total of 38 complete clutches during the 1988, 1989, and 1990 breeding seasons and averaged 4.55 eggs per clutch (Table 15) and ranged from 3-5 eggs. No significant difference in clutch size was found either between first and second clutches or among years ( $p>.5$ in all cases). Irwin (1985) examined 32 clutches and found an average of 4.2 eggs per clutch with a range of from 3-6 eggs. Ohlendorf (1976) observed 21 Black Phoebe clutches and found an average of 3.57 eggs per clutch in Trans-Pecos Texas. Skutch (1960) indicated that in Costa Rica and the surrounding countries clutch size was 2-3 eggs per clutch. These observations point to a general trend of increasing clutch size with increasing iatiude. This common trend is seen both within and among bird species. Lack (1947b) suggested that 
the increasing day length that accompanies increasing latitudes provided more time for adult birds to gather food and thus supported an increase in the number of young which could be raised. This is one of a number of hypotheses which are loosely supported by the observations above.

\section{Incubation}

General Aspects.-Only female Black Phoebes were observed incubating eggs during the course of this investigation. In Humboldt County, Irwin (1985) observed males incubating eggs at 3 of 16 nests. Jewett (1899) stated that both male and female shared equally in nest construction and incubation. In Costa Rica, Skutch (1960) observed only the female incubating a nest that he observed for several days and Oberlander (1939) observed only the female incubating during his observations. Incubation by male tyrannids is little known and in the least Jewett's (1899) comments are suspect because he suggests that males also aid in nest construction. No evidence of male involvement in nest construction, save one ineffective attempt, was observed during the course of this study and other observers (Oberlander 1939, Skutch 1960 and, Irwin 1985) also indicate that there is a general lack of male involvement in nest construction.

Incubation began with the laying of the last egg of the clutch, although some females were found intermittently on the nest during the laying period. Some birds roosted on the nest during the latter part of the laying period and probably warmed the eggs enough for some development to occur. Nighttime attentiveness before clutch completion is common in passerines and is documented for several North American flycatchers (King 1955, Davis et al.1963, and Morton and Pereyra 1985). Females alternated periods of incubation with shorter periods of foraging and preening. Females generally remained within 50 meters of the nest site during recesses away from the nest. 
Rhythm of Incubation.-Attentive bouts averaged $63-68 \%$ of the observation period and ranged from approximately 1-102 minutes in length (Table 16 and Figure 14). The average attentive period was 12.2 minutes in duration. Inattentive periods accounted for the other $32-37 \%$ of the observation periods and bouts ranged from 1.8-30.5 minutes in length. Inattentive periods averaged 6.3 minutes in length. The number of bouts varied considerably between individuals and ranged from 15-29 bouts during the period of observation between 10:00-16:00. Attentive periods for Black Phoebes in Humboldt County ranged from $4.5-25.5$ minutes and accounted for $68 \%$ of the observation period (Irwin 1985). Attentive bouts averaged 13.8 minutes in length. Inattentive periods ranged from 2-19.5 minutes in duration and averaged 6.5 minutes. Skutch (1960) in Costa Rica observed one female that was incubating for a period of 5 hours. During this time 14 bouts were observed and attentive periods ranged from 8-23 minutes in length and accounted for $73.2 \%$ of the observation period. Attentive periods averaged 15.9 minutes. Inattentive periods ranged from 3-10 minutes and averaged 5.8 minutes in length.

These attentive rates are similar to those found in studies of other North American flycatchers (King 1955, Davis et al. 1963, and Ettinger and King 1980). A study of incubation in the Dusky Flycatcher (Empidonax oberholser) in the Sierra Nevada (Morton and Pereyra 1985) recorded that $75.8 \%$ of the observation period was spent on the nest. Morton and Pereyra (1985) found much more variance in the time spent away from the nest (inattentive) than in the time spent on the nest (attentive). These findings match observations made in the present study. It would appear that the incubating females are much more conservative in their allocation of time spent away from the nest durirg any given bout than time spent on the nest. In the present study $54 \%$ of the inattentive bouts were 5 minutes or less in duration and $94 \%$ of 94 inattentive bouts were less than 10 minutes in length. Limiting time away from the nest during any given bout would limit the 
amount of cooling or, more critically, heating the eggs might be subject too. Heating is not a critical factor with this species because of the protected nature of their nest site. One could imagine natural selection favoring limited inattentive bout lengths sometime earlier in the evolutionary history of the species, when selection of a protected nest site that was facilitated by the construction of specialized adherent mud nest had not yet evolved.

Morton and Pereyra (1985) found that female Dusky Flycatchers varied their inattentive bout frequency and suggested this variance as a means of balancing energetic needs of the adult with the physiological requirements of the clutch. Observations of incubation behavior in this investigation found a two-fold difference in bout frequency among 3 individuals and suggest that perhaps this tactic of varying bout frequency is employed extensively by incubating females.

Length of the Incubation Period.-Black Phoebes incubated their eggs for average of 16.2 days (Table 17) before hatching was completed. Incubation periods ranged from 15.5-17.8 days in length. Oberlander (1939) reported that incubation periods for two 5 egg clutches in Berkeley, California ranged from 15-17 days in length. In Humboldt county incubation periods of Black Phoebes averaged 16.9 days and ranged from 16-18 days in length (Irwin 1985). Eggs incubated during colder weather had the longest incubation periods.

Black Phoebes exhibit longer than predicted incubation periods based a regression of fresh egg mass and actual incubation period of 475 bird species (Drent 1975). Eggs with a mass of approximately 2 gm are predicted to hatch in approximately 13-14 days; actual incubation periods are closer to 16-17 days in length. This extra 2-3 days is a increase of between $14 \%$ and $23 \%$ of the predicted incubation period. Heinroth (1922, cited in Drent 1975) was the first person to compile extensive documentation linking length of the incubation period to length of the nestling period. He found incubations periods positively 
correlated with nestling periods. He suggested that prenatal and postnatal growth be treated as a common developmental phase.

Loss of Weight by Eggs.-All eggs start to lose weight after laying. This change in mass is known to be essentially due to the evaporation of water and is a function of egg mass (Rahn and Ar 1974). Eggs of Black Phoebes weighed in this study lost an average of $17.5 \%$ of their mass during the course of incubation. Extremes values ranged from 13.1$28.5 \%$ (Table 18). Total egg mass loss over the course of incubation averages $16 \%$ for a variety of species thus far examined (Drent 1975). Significantly less water was lost from Black Phoebe eggs during the first half of the incubation period than during the second half of the incubation period $(p<.002)$. This increase in water vapor conductance has been previously documented by Carey et al.(1980) and is particular to some passerine groups. The observations of this study indicate that the characteristics of Black Phobe eggs over the course of incubation are typical of the order to which they are assigned.

\section{Hatching}

Hatching Sequence and Interval.-Eggs tended to hatch in the order in which they were laid. Hatching of the entire clutch took from 24 to 72 hours. In Irwin's (1985) investigation in Humboldt County, California, all eggs hatched within 36 hours. In Berkeley, California, Oberlander (1939) had one clutch hatch over a 36 hour period. Henderson (1924) in her observations of breeding Eastern Phoebes observed hatching over a 72 hour period. Observations by Davis et al. (1963) of breeding Western Flycatchers found hatching occured over a period of 48 hours in most clutches. Taylor and Hanson (1970) observed hatching over a period of 48 hours in one clutch of Vermilion Flycatchers (Pyrocephalus rubinus)in Maricopa County Arizona. These observations suggest that the hatching interval of Black Phoebes observed in this study are fairly typical of tyrannids in general. 
Eggshell Disposal.-Fragments of eggshells were found from 0 to 45 meters from the nest, although most were greater than 5 meters from the nest. Most fragments appeared complete and entire clutches were accounted for, thus I doubt that shell fragments are commonly eaten by females of this species. No observations were made of actual eggshell removal by the parent birds, but based on the role of the female in incubation it is likely that she was responsible. Other observations of eggshell disposal by Black Phoebes are lacking. Davis et al. (1963) observed female Western Flycatchers carry eggshell fragments from 30 to 42 feet from the nest and drop them to the ground.

\section{Nestling Development}

Weight.-Nestling Black Phoebes are classified as altrical by Nice's (1962) postnatal classification scheme. At hatching the young are immobile, blind, ectothermic, and virtually helpless (Figure 17). The majority of energy resources are channeled into growth, as a consequence young phoebes grew rapidly for the first ten days after hatching and had attained $87 \%$ of adult body mass at the end of this period (Table 19 and Figure 15). Mean daily gains in mass during this period varied from $67 \%$ of their previous day's body mass on the 2nd day after hatching to $14 \%$ of their previous day's mass on 10th day after hatching. Adult body mass was surpassed on day 12 of the nestling period and tended to stay above or at adult body mass until fledging at around day eighteen (Table 20 and Figure 19). This eighteen day nestling period is considered extended for a passerine of this body mass. By comparison, Song Sparrows (Melospiza melodia) which place their nests in low growing vegetation and have approximately the same mass as the Black Phoebe have young that fledge 8 to 12 days after hatching, depending on food availability (Nice 1937). This shorter nestling period of the Song Sparrow is in part explained by the higher rates of predation that accompany a relatively exposed nest site. 
The last third of the nestling period in Barn Swallows (Hirundo rustica)was described by Ricklefs (1967) as a period of maturation of the pectorial muscles, heart, liver, and integument (feathers). These processes are characterized by a "drying out" of the involved tissues; that is, their water content declines as maruration proceeds. The development of Barn Swallow nestlings parallels that of Black Phoebes: both species have similar nestling periods, adult body weights, and nest under similar ecological conditions. This extended maturation period also provides additional time for the development of motor coordination necessary for successful fledging. Nest placement over water requires that young birds be very capable flyers when they fledge.

Feather Growth. - Growth of the wings and tail as a function of age are presented in Figure 16. Primary feathers (remexes) did not enupt from the feather papillae until day six of the nestling period. Earlier measurements of the wing represent growth of the manus. Feather eruption at the tail (rectrices) did not occur until day seven of the nestling period. Elongation (growth) of remexes and rectrices was more or less linear over the nestling period. Fledging rarely occured before wing chord length had reached $58 \mathrm{~mm}$. Contour feather papillae of the back started to erupt on day seven of the nestling period. By day nine all contour feathers had erupted from the epidermis. On day 16 most contour feathers were fully out of their sheaths.

\section{Fledging}

General aspects.-Nestlings fledged from their nests over period of 1 to 3 days, with most young in a brood all fledging on the same day. Most nestlings (84\%) were from 18 to 20 days old when they left the nest (Table 20). Black Phoebes in Humboldt County, California, (Irwin 1985) took from 18 to 21 days to fledge with a mean duration of 19.9 days. In Irwin's case, all nestlings in a brood fledged on the same day. In Berkeley, Califorria (Oberlander 1939) young Black Phoebes from one clutch fledged at 21 to 22 
days post-hatching. Jewett's (1899) observations of one brood of Black Phoebes indicates that the young ranged from 17 to 19 days in age when they fledged on May 9, 1896.

\section{Nesting Success and Mortality}

Nest Success and Mortality.-Overall hatching success for all clutches was high at $91.4 \%$ (of the 117 eggs laid) (Tabie 21). Half of all hatching failure (4\%, 5 eggs) was due to predation or interference by man. Reasons for the failure of the other eggs to hatch range from infertility to failure of the hatchling to completely break out of the shell before the membranes had dried. Ohlendorf (1976) in a study of Black and Say's Phoebes in Trans-Pecos Texas reported hatching success rates of $92 \%$ and $73.4 \%$ respectively. Black Phoebes had low : 'fertility rates (1.3\%) compared to those of the Say's Phoebe. Egg loss due to predation and man's interference accounted for $6.7 \%$ and $19.5 \%$ of the total egg production for Black and Say's Phoebes respectively. Ohlendorf (1976) attributed 44.7\% of egg losses before hatching to human destruction of nests under bridges and culverts. Overall hatching failure rates for other temperate zone altrical passerines typically range from 8-18\% (Ricklefs 1969). Sources of hatching failure in Ricklefs (1969) survey of mortality in birds included other factors such as desertion due to weather and interference by other birds. Overall hatching rates for Black Phoebes appear to be high and did not represent the primary avenue of nest failure in this study.

Rates of fledging in this study were lower than those observed by Ohlendorf (1976) for Black and Say's Phoebes in Texas. Overall fledging rates at CCRS were $67 \%$ of the total number of nestlings that hatched. Fledging rates of Black and Say's Phoebes in Texas were $76.8 \%$ and $77 \%$ respectively. Predation by introduced Red fox (Vulpes vulpes) accounted losses of $71 \%$ of the nestlings in 1st broods and $15 \%$ of 2 nd broods in 1990 at CCRS. Lack of rainfall left the culvert within which Black Phoebe nests were placed virtually dry and allowed access of manirialian predators. Predation was not the primary 
factor in nestling losses in Ohlendorf's (1976) investigation. Infestation by argasid tick larva and dermanyssid mites were a major cause of nestling mortality. Irwin (1985) reported the loss of two of three broods of young apparently due to starvation during a two week period of heavy rainfall. Ricklefs (1969) summarized nestling losses of six passerine species and found that predation accounted for $65.8 \%$ of the total losses, desertion and starvation accounted for $6.5 \%$ and $2.1 \%$ respectively and weather accounted for $6.9 \%$ of the losses. Overall nestling success rates for six passerines species was $65.6 \%$ of the number of eggs that hatched. In three of four nesting cycles Black Phoebes had a much greater nestling success rate than would be expected of a passerine that nests in a normally protected location. 


\section{LITERATURE CITED}

American Ornithologists' Union. 1983. Checklist of North American birds. 6th ed. AOU, Washington, D. C.

Baily, F. L. 1927. Handbook of birds of the Western United States. Houghton Mifflin Co., Boston.

Baldwin, P. S., H. C. Oberholser \& L. G. Worley. 1931. Measurements of birds. Sci. Publ. Cleveland Mus. Nat. Hist. 2:1-165.

Bancroft, G. T. 1984. Patterns of variation in size of Boat-tailed Grackle (Quiscalus major) eggs. İbis 126:496-509.

Beal. F. E. L. 1912. Food of our more important flycatchers, Bul. 44, Biological Survey, U.S. Dept. of Agriculture.

Bendire, C. 1895. Life histories of North American birds, from the parrots to the grackles. U. S Natl. Mus. Bull., Spec. Bull. No. 3, Smithsonian Institution, Washington, D. C.

Bent, A. C. 1942. Life histories of North American flycatchers, larks, swallows, and their allies. U. S Natl. Mus. Bull. 179, Smithsonian Institution, Washington, D. C. $\underset{\text { SD }}{\text { Campbell, B. C. \& E. Lack. ed., 1985. A dictionary of birds. Buteo Books, Vermillion, }}$

Carey, C., H. Rahn, \& P. Parisi. 1980. Calories, water, lipid and yolk in avian eggs. Condor 82:335-343.

Cardiff, E. E. 1950. Nesting of the Black Phoebe in the Imperial Valley, California. Condor 52:166.

Cowles, R. B. 1928. Observation on the food habits of a desert Sparrow Hawk. Condor 30:237.

Davis, J., G. F. Fisler \& B. S. Davis. 1963. The breeding biology of the Western Flycatcher. Condor 65:337-382.

Davis, W. B. 1933. The span of the nesting season of birds in Butte County, California, in relation to their food. Condor 35:151-154.

Dawson, W. L. 1923. The Birds of California. South Moulton Co., San Diego.

Drent, R. H. 1975. Incubation, Chapter 6. in Avian Biology, vol 5. pp.333-420 Farner, D. S. \& J. R. King ed. Academic Press, New York \& London.

Ettinger, A. O. \& J. R. King. 1980. Time and energy budgets of the Willow Flycatcher (Empidonax trailii) during the breeding season. Auk 97:533-546. 
Finley W. L. 1907. American birds studied and photographed from life. New York.

Fisher, A. K. 1893. North American Fauna No. 7, The Death Valley expedition. U. S. Dept. of Agr., Washington, D. C.

Fraser, J. T. 1931. Late Nesting of the Black Phoebe. Condor 33:34.

Gander. F. F. 1928. Observations on the feeding habits of some common birds. Condor 30:362-363.

Grinnell, J., \& T. I. Storer. 1924. Animal life in the Yosemite. University of Califomia Press, Berkeley, CA.

Grinnell, J., Dixon, J. \& J. M. Linsdale. 1930. Vertebrate Natural History of a Section of Northem California through the Lassen Peak Region. Univ. Cal. Publ. Zool., vol 35.

Grinnell, J. \& A. H. Miller. 1944. The distribution of the birds of California. Pac. Coast Avif. No. 27. Cocper Omithological Society, Berkeley, CA.

Henderson, H. N., 1924. The phoebe. Bird Lore 26:89-94.

Hoffman, R. 1927. Birds of the Pacific States, Houghton Mifflin Co., Boston.

Holland, H. M. 1923. Black Phoebes and House Finches in joint use of a nest. Condor 25:131-132.

Howell, A. B. 1917. Birds of the islands off the coast of Southem Califomia. Pac. Coast Avif. No. 12. Cooper Ornithological Society, Hollywood, CA.

Howell, A. B. 1924. The Black Phoebe as a fisherman. Condor 26:191.

Hoyt, D. F. 1979. Practical methods of estimating volume and fresh weight of bird eggs. Auk 96:73-77.

Humphrey, P. S. \& K. C. Parkes. 1959. An approach to the study of molts and plumages. Auk 76:1-31.

Irwin, K. 1985. Foraging ecology and reproduction of the Black Phoebe in Humboldt County. Unpublished M.S. thesis, Humboldt State Univ. pp75.

Jarvinen, A. \& J. Ylimaunu. 1986. Intraclutch egg-size variation in birds: physiological responses of individuals to fluctuations in environmental conditions. Auk 103:235237.

Jewett, F. B. 1899. Nesting observations of the Black Phoebe. Condor 1:13.

King, J. R. 1955. Notes on the life history of Traill's Flycatcher (Empidonax traillii) in Southeastern Washington. Auk 72:148-173.

Kinsey, E. C. 1935. Parental instincts in Black Phoebes. Condor 37:277-278. 
Lack, D. 1947b. The significance of clutch size, I-II. Ibis 89:302-352.

Lawson, C. S. 1975. Fish catching by a Black Phoebe. Western Birds 6:107-109.

Linton, C. B. 1908. Notes from San Clemente Island. Condor 10:82-86.

Miller, A. H., H. Friedmann, L. Griscom, \& R. T. Moore. 1957. The birds of Mexico, part 2. Pac. Coast Avif. No. 33., Cooper Omithological Society, Berkeley, CA.

Morton, M. L. and M. E. Pereyra 1985. The regulation of egg temperatures and attentiveness parterns in the Dusky Flycatcher (Epidonax oberholseri). Auk 102:25-37.

Nice. M. M. 1937. Studies in the life history of the Song Sparrow. 1. A population study of the Song Sparrow. Trans. Linn. Soc. N. Y. 4:1-237.

Nice. M. M. 1962. The development of behavior in precocial birds. Trans. Linn. Soc. N. Y. 8:1-211.

Oberlander, G. 1939. The history of a family of Black Phoebes. Condor 41:133-151.

Ohlendorf, H. M. 1976. Comparative breeding ecology of Phoebes in Trans-Pecos Texas. Wilson Bull. 88:255-271.

Palmer, R. S. ed. 1962. Handbook of North American birds, vol 1. Yale Univ. Press. New Haven, CN.

Parsons, J. 1970. Relationship between egg size and post-hatching chick mortality in the Herring Gull (Larus argentatus) Nature 228:1221-1222.

Preston, F. W. 1974. The volume of an egg. Auk 91:132-138.

Quigley, R. 1954. Unusual Black Phoebe nest. Condor 56:222-223.

Rahn, H., \& A. Ar. 1974. The avian egg: incubation time and water loss. Condor $76: 147-152$.

Ridgway, R. 1907. The birds of North \& Middle America, part 4. U. S Natl. Mus. Bull. 50, Smithsonian Institution, Washington, D. C.

Ricklefs, R. E. 1967. Relative growth, body constituents, and energy content of nestling Barn Swallows and Red-winged Blackbirds. Auk 84:560-570.

Ricklefs, R. E. 1969. An analysis of nesting mortality in birds. Smithsonian Contr. Zool. 9:1-48.

Robertson, J. M. 1933. Black Phoebe nesting in a tree. Condor 35:166.

Ross, R. C. 1933. Do Black Phoebes eat honey-bees. Condor 35:232.

Schifferli, L. 1973. The effect on egg weight on the subsequent growth of nesiiniz Creat Tits (Parus major). Ibis 115:549-558. 
Skutch, A. F. 1960. Life histories of Central American Birds, Par 2, Pac. Coast Avif.

No. 34., Cooper Ornithological Society, Berkeley, CA.

Skutch, A. F. 1952. On the hour of laying and hatching of bird's eggs. Ibis 94:49-61.

Smith, W. J. 1969. Displays of Sayornis phoebe (Aves, Tyrannidae). Behaviour 33:283322.

Smith, W. J. 1970a. Displays and message assortment in Sayornis species. Behaviour 37:85-112.

Smith, W. J. 1970b. Song-like displays in Sayornis species. Behaviour 37:64-84.

Smithe, F. B. 1975. Naturalist's Color Guide. Amer. Mus. Nat. Hist. New York.

Sokal, R. R. \& F. J. Rolf. 1981. Biometry. 2nd ed., W. H. Freeman \& Co., New York.

Stoner, E. A. 1938. A Black Phoebe's nest with eggs of three species. Condor 40:42.

Taylor, W. K. \& H. Hanson. 1970. Observations on the breeding biology of the Vermilion Flycatcher in Arizona. Wilson Bulletin 82:315-319.

Traylor, M. A. 1977. A classification of the Tyrant Flycatchers (Tyrannidae). Bull. Mus. Comp. Zool. vol. 148:129-184, Harvard Univ. Cambridge, MA.

Tyler, J. G. 1913. Some birds of the Fresno district, California. Pac. Coast Avif. No. 9., Cooper Ornithological Society, Hollywood, CA. U. S. D. A., 1968. Soils of Santa Clara County. U. S. Printing Office, Washington,
D. C.

Verbeek, N. A. M. 1975a. Comparative feeding behavior of three coexisting tyrannid flycatchers. The Wilson Bulletin 87:231-240.

Verbeek, N. A. M. 1975b. Northern wintering of flycatchers and residency of Black Phoebes in California. The Auk 92:737-749.

Warren, D. C., \& R.M. Conrad. 1942. Time of pigment deposition in brown-shelled hen eggs and in turkey eggs. Poult. Sci. 21:515.

Wetherbee, D. K. 1957. Natal plumages and downy pteryloses of passerine birds of North America. Amer. Mus. Nat. Bull. 113:341-436.

Willett, G. 1912. Birds of the Pacific slope of Southern California. Pac. Coast Avif. No. 7., Cooper Ornithological Society, Hollywood, CA.

Willet, G. 1933. A revised list of the birds of Southwestem California. Pac. Coast Avif. No. 21., Cooper Ornithological Society, Hollywood, CA. 
APPENDIX A

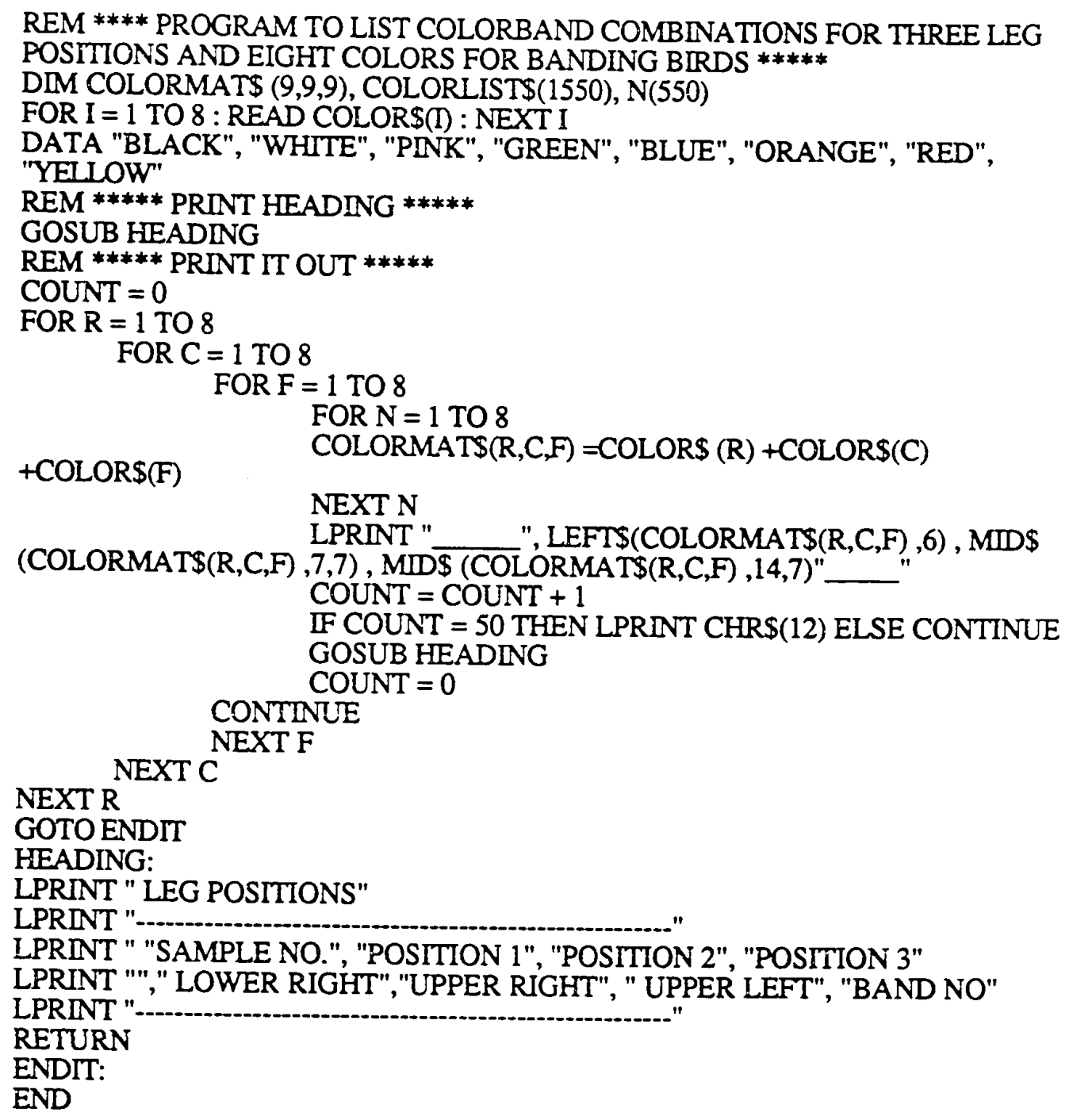

